Portland State University

PDXScholar

Summer 1-1-2012

\title{
A Systems Approach to Ecological Economic Models Developed Progressively in Three Interwoven Articles
}

Takuro Uehara

Portland State University

Follow this and additional works at: https://pdxscholar.library.pdx.edu/open_access_etds

Part of the Growth and Development Commons, Natural Resource Economics Commons, Sustainability Commons, and the Urban Studies and Planning Commons Let us know how access to this document benefits you.

\section{Recommended Citation}

Uehara, Takuro, "A Systems Approach to Ecological Economic Models Developed Progressively in Three Interwoven Articles" (2012). Dissertations and Theses. Paper 553.

https://doi.org/10.15760/etd.553

This Dissertation is brought to you for free and open access. It has been accepted for inclusion in Dissertations and Theses by an authorized administrator of PDXScholar. Please contact us if we can make this document more accessible: pdxscholar@pdx.edu. 
A Systems Approach to Ecological Economic Models Developed Progressively in Three

Interwoven Articles

by

Takuro Uehara

A dissertation submitted in partial fulfillment of the requirements for the degree of

Doctor of Philosophy

in

Systems Science: Economics

Dissertation Committee:

Wayne Wakeland, Chair

David E. Ervin

Olena Kostyshyna

Yoko Nagase

John Rueter

Portland State University

(C)2012 


\begin{abstract}
My dissertation develops and analyzes ecological economic models to study the complex dynamics of an ecological economic system (EES) and investigate various conditions and measures which can sustain a developing economy over the long term in view of resilience and sustainability. Because of the intrinsic complexity of the system, I take a systems approach, using economics as the foundation for the basic structure of an ecological economic model, and system dynamics as the method to build and analyze such a complex ecological economic model. Throughout my dissertation, the model developed by Brander and Taylor (1998) is adopted as a baseline model (henceforth the BT model). The BT model explains population-resource dynamics and is characterized as a general equilibrium version of the Gordon-Schaefer Model, using a variation of the Lotka-Volterra predator-prey model. The findings are presented as three articles. The first article provides a comprehensive analysis of the BT model and its descendants, to elicit directions for further research, including population growth logic, substitutability, innovation, capital accumulation, property rights and institutional designs, and modeling approach. The second article extends the BT model to study the resilience of an EES reflecting three key issues in modeling such systems: 1) appropriate system boundary, 2) non-convexity of ecosystems, and 3) adaptation. The article discusses two types of thresholds: the ecological threshold, a threshold for an ecological system independent of economic systems, and the ecological economic threshold, a threshold for an EES. The latter is often different from the former and is highly dynamic and context dependent.
\end{abstract}


The third article is another extension of the BT model to study the sustainability of an EES by implementing the suggestions made by the first article except for property rights and institutional designs. The main focus is on the impact of endogenous innovation regarding input substitutability on the system sustainability. The main finding is that improvement in the input substitutability, ceteris paribus, may not contribute to sustainable development despite its contribution to expanding the economy. However, it could be possible for susbstitutability improvements to contribute to sustainable development when combined with other specific types of technological progress. 


\section{Acknowledgements}

I acknowledge with sincere gratitude the suggestions and ideas of my committee members: Wayne Wakeland, David E. Ervin, John Reuter, Olena Kostyshyna, and Yoko Nagase.

From the beginning of my Ph.D. study, Professor Wayne Wakeland has guided me properly and very patiently. Further his encouragement was a gem whenever I faced some hardship. Especially model building was challenging and there was a possibility that I could not build a model what I intended. Without his support, I could not have successfully completed my dissertation.

My deep appreciation goes to Yoko Nagase. Without meeting her at Portland State University, I could not have met the topic for my dissertation and published one of the three articles in Ecological Economics. I also highly respect and appreciate her professionalism in research, from which I have learned a lot and have been able to have some confidence in writing a high quality paper in the future.

During my Ph.D. study, Haru, my son, came to me. I cannot thank enough to Haru and Misuzu, my wife for their patience and support.

The final product and any errors that remain are my sole responsibility. 


\section{Table of Contents}

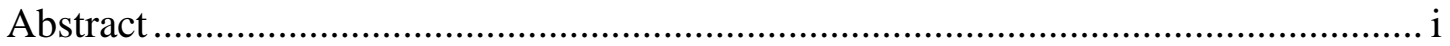

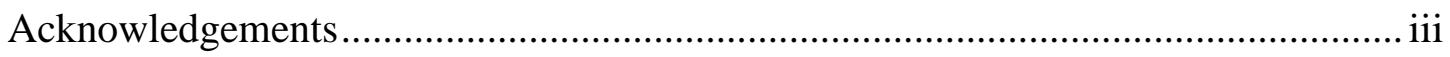

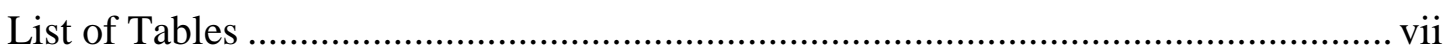

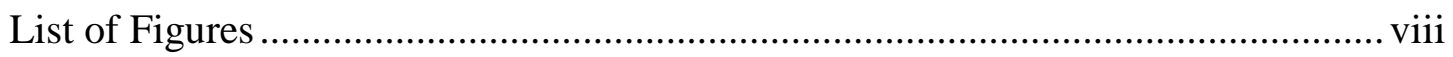

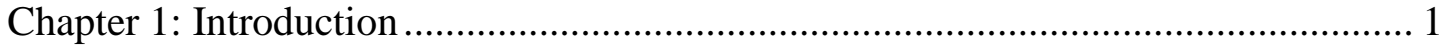

Chapter 2: Evolution of population-resource dynamics models ................................. 8

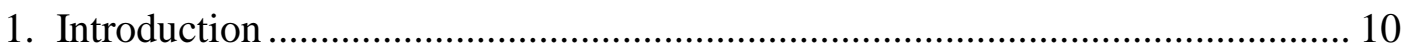

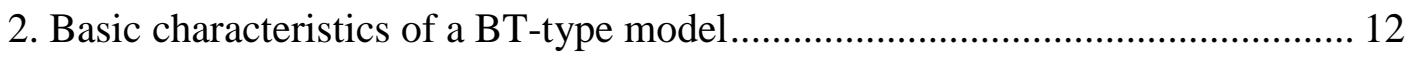

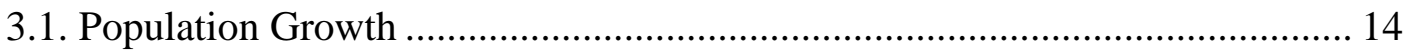

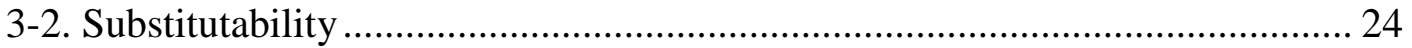

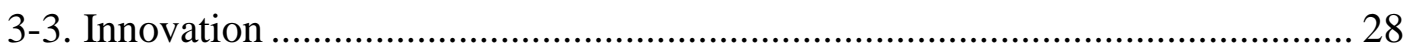

3-4. Capital Accumulation ............................................................................... 32

3-5. Property Rights and Institutional Designs ..................................................... 35

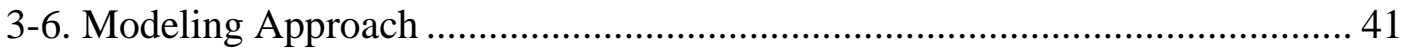

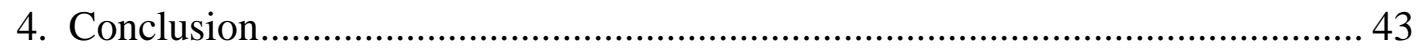

Chapter 3: Ecological Threshold and Ecological Economic Threshold: Implications from an ecological economic model with adaptation .................................................... 46

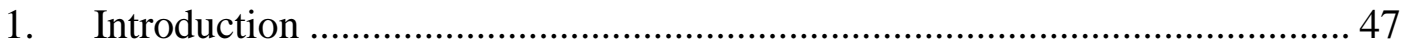


2. Background.

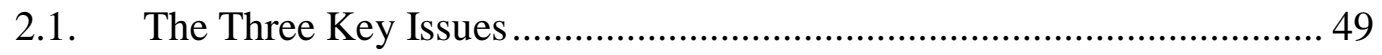

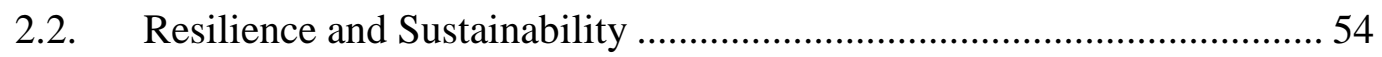

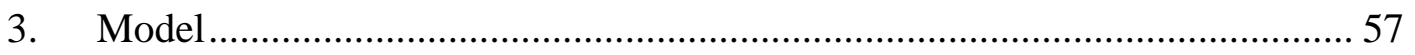

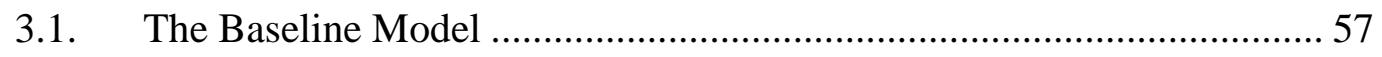

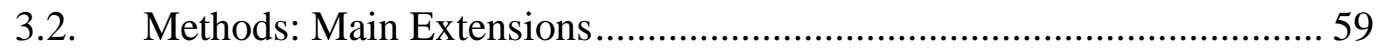

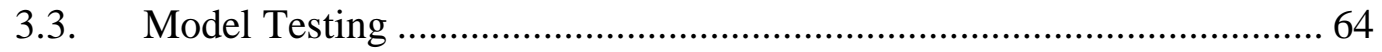

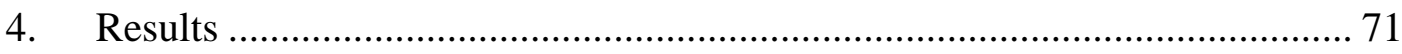

4.1. The Impact of an External Shock: The Model without Adaptation ......... 71

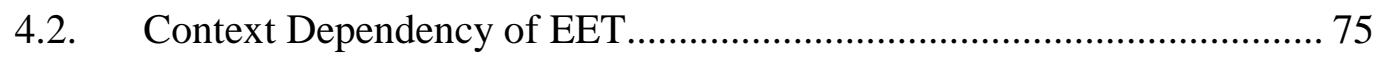

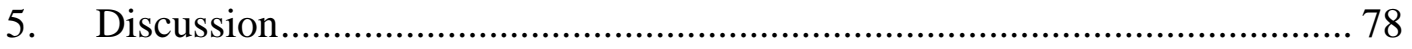

5.1. Ecological Economic Threshold ………………................................... 78

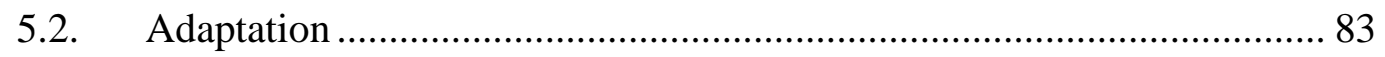

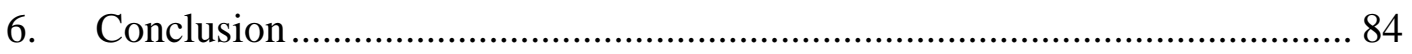

Chapter 4: System Dynamics Implementation of a Model of Population and Resource

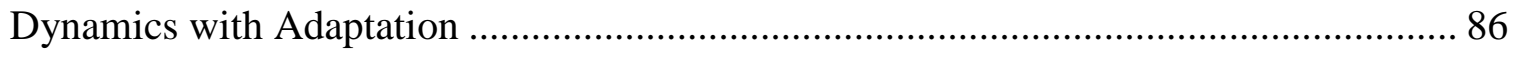

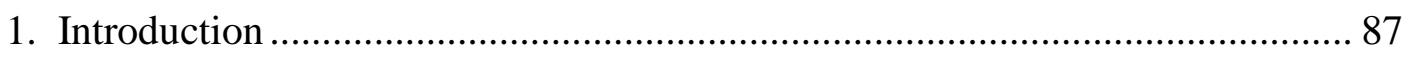

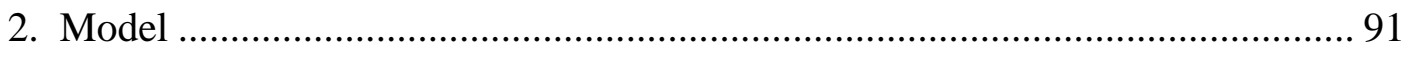

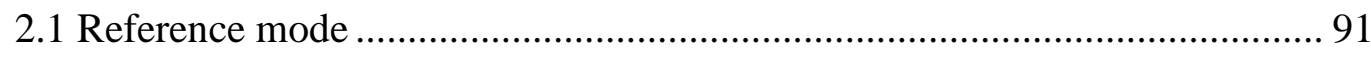


3. Results

3.2 Impacts of $S_{\max }$ and $\eta$ on the System

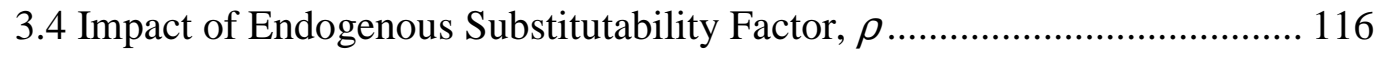

3.5 Impact of Technological Progress on Utility-per-Capita ......................... 122

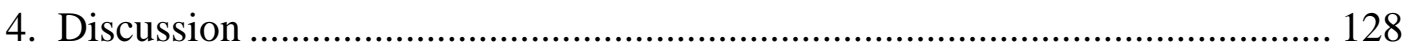

5. Conclusion.......................................................................................... 130

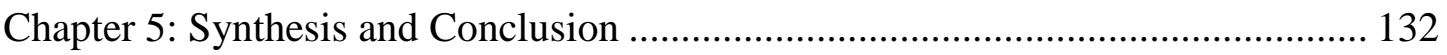

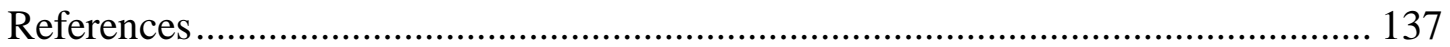

Appendix A: Stock and Flow Diagrams ............................................................... 155

Appendix B: Values of exogenous variables for the baseline model ..................... 158

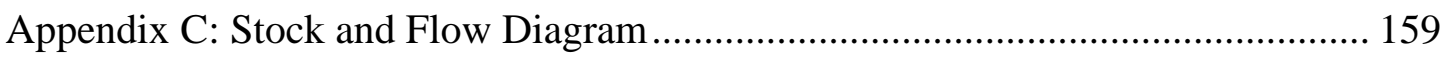




\section{List of Tables}

\section{Chapter 3}

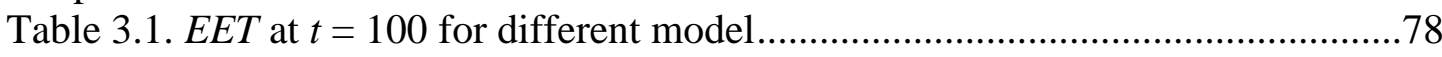

\section{Chapter 4}

Table 4.1. Model Boundary ... 


\section{List of Figures}

Chapter 2

Figure 2.1. Period-by-period material and cash flow and agents' behaviour in a BT-

type model.

Figure 2.2. Static equilibrium outcomes and their feed-in mechanisms for the population and resource dynamics. (Equations are based on the original BT model; Asterisks indicate that these expressions are equilibrium values.). 14

Chapter 3

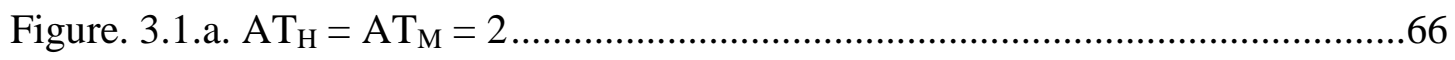

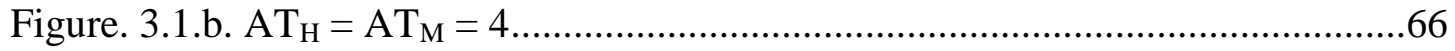

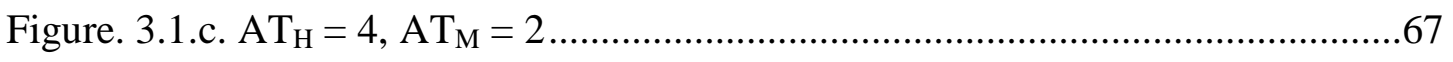

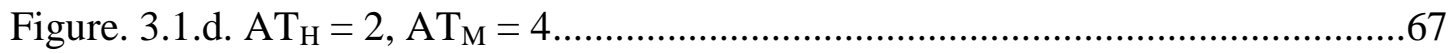

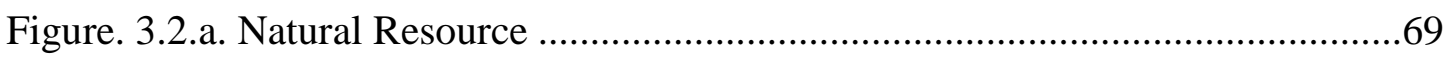

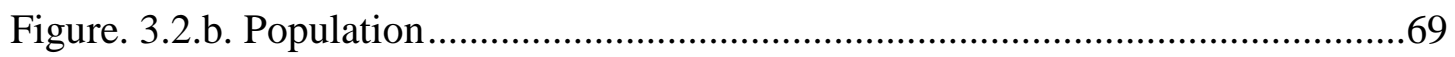

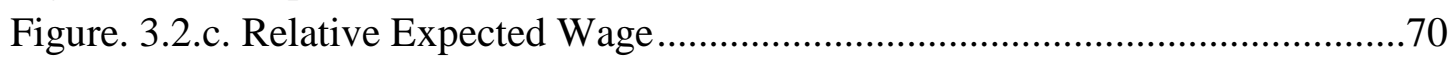

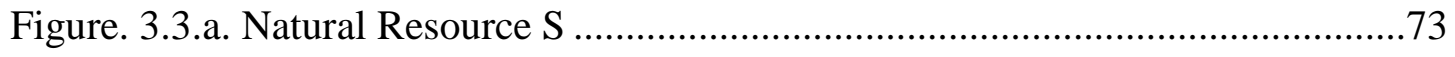

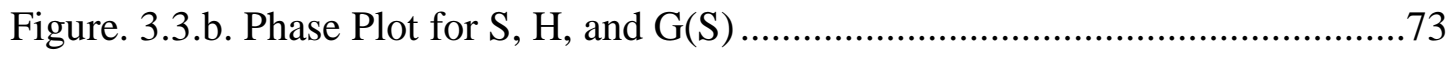

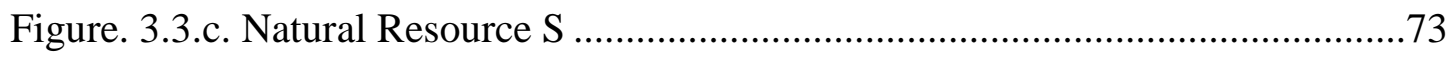

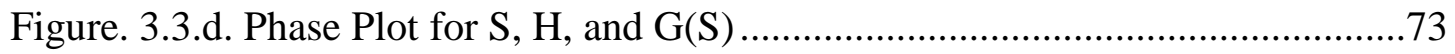

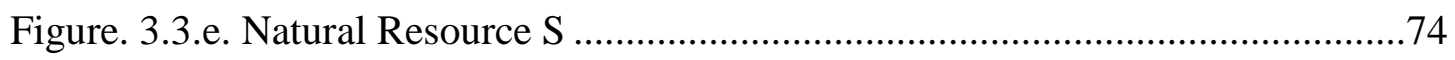

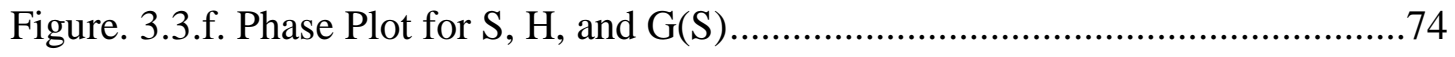

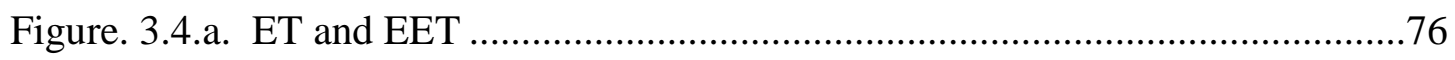

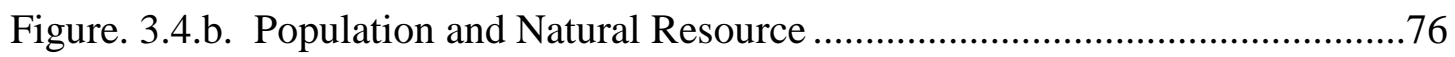

Figure. 3.5. Change in Natural Resource $S$ after an external shock at $t=100$...........77

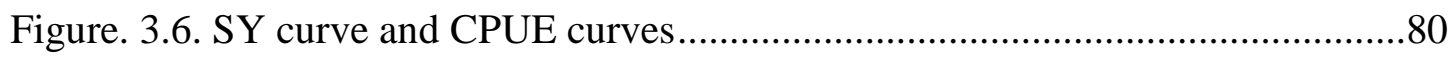

Figure. 3.7. SY curve and CPUE curves with Government Intervention ...................81

\section{Chapter 4}

Figure 4.1. Easter Island dynamics from archaeological study by Bahn and Flenley

Figure 4.2. Population and Cultivated Land in Japan during Edo Era (1603-1868).

Source: Wikipedia and Kito (1996).... .93

Figure 4.3. Causal Loop Diagrams for the Extended Model. Red texts and thick arrows indicate newly added items. 103

Figure 4.4. Extended Model Population and Resources .108 viii 


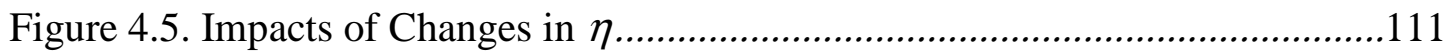

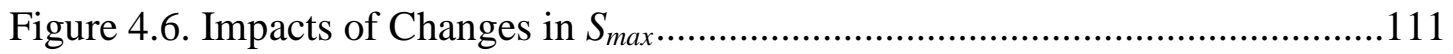

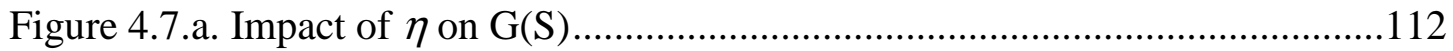

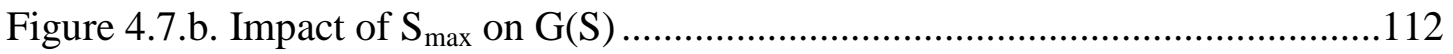

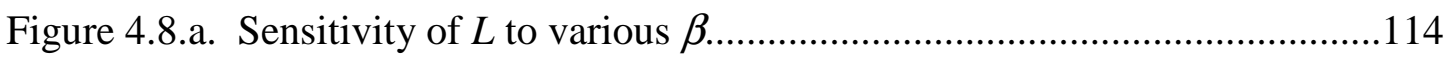

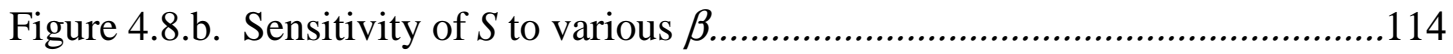

Figure 4.9. Test results to verify the logic that calculates $\rho$ endogenously ...............117

Figure 4.10. Impact of endogenous $\rho$ compared to fixed $\rho$ for six key model

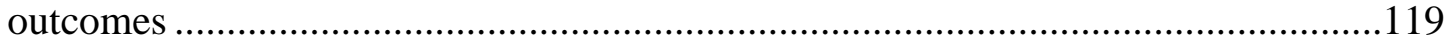

Figure 4.11. Sensitivity analyses to the choice of $b_{2}, d_{2}$, and $b_{2} \times d_{2}$ on UPC between simulations with constant and endogenous $\rho$..............................................122

Figure 4.12.a. Impacts of Endogenous $\rho$ in combination with other technological

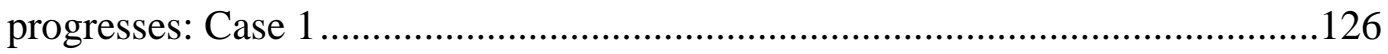

Figure 4.12.b. Impacts of Endogenous $\rho$ in combination with other technological progresses: Case 2 
[The Limits to Growth and Beyond the Limits] do not conform to either national accounting systems or to standard economic definitions, nor does any explanation occur for the wealth of analytic neologisms.

- William D. Nordhaus (1992, p.8)

The study of possible feedback loops between poverty, population growth, and the character and performance of both human institutions and natural capital is not yet on the research agenda of modern growth economists.

- Partha Dasgupta (2008, p.2)

Real problems in complex systems do not respect academic boundaries.

- Herman Daly and Joshua Farley (2010, xvii)

\section{Chapter 1: Introduction}

The purpose of my dissertation is to develop theoretical ecological economic models using the system dynamics method and drawing from economic theories to investigate the complex interactions among population, natural resources, and economic growth in order to find demographic, ecological, and economic conditions that can sustain an economy over a long term. This is an important issue for all economies, and especially for developing economies. 
Although ecological economic systems (henceforth EESs) are 'undeniably' complex (Limburg et al., 2002), traditional economics has generally taken a strategy of simplification to be able to employ analytic approaches. However, simplification has many drawbacks. There are many examples of this. First, simpler functions such as the Cobb-Douglas type function (e.g., Solow, 1974a; Anderies, 2003), while easy to handle analytically, limit the analysis of substitutability between man-made capital and natural resources that is essential for sustainable development under natural resource constraints. Second, the system boundary is set narrowly for the sake of simplicity. In analyzing the role of substitutability in an economy, the law of motion of resources is often ignored (e.g., Bretschger, 1998). However, feedbacks between ecological systems and economic systems play an important role (Costanza et al., 1993). Whenever an element is treated as exogenous, the feedback loops are dropped and the element does not respond to changes in the state of the system. Third, standard economic theories mostly focus on equilibrium conditions. "Transition dynamics" has mostly been neglected (Sargent, 1993), except for the recent development of learning (expectation) theory in modern macroeconomics (e.g., Evans and Honkapohja, 2009; Evans and Honkapohja, 2011; Bullard, 2006). Out-ofequilibrium states and equilibrium-seeking adaptive systems have not been investigated well in economics, but such transition dynamics are important for ecological economic models (Costanza et al., 1993).

System dynamics is an approach to analyze such complex systems (Forrester, 1961; Sterman, 2000). System dynamics strives to model and evaluate complex systems 
as they are, without over simplifications that may leave out the analysis of essential aspects of the systems. However, system dynamics models have been criticized by some economists for their inconsistency with economic theories. As a prime example, a system dynamics approach to ecological economic modeling found in The Limits to Growth by Meadows et al. (1972) has been severely criticized by economists (e.g., Nordhaus et al., 1992).

My dissertation is an attempt to bridge economics and system dynamics in order to provide deeper insights into the dynamics of EESs. While system dynamics has often neglected economic theories because of their unrealistic tendencies (in the views of systems dynamicists), economics seems to ignore system dynamics (except for the notable reaction against The Limits to Growth) because of its inconsistencies with economic theories. On the one hand, it is true that economic theories provide a solid foundation for modeling economic systems. On the other hand, system dynamics provides tools and a way of thinking for studying complex systems. Therefore I propose to employ standard economic theories as a base for ecological economic models and to employ the system dynamics approach to build, validate, and learn from the models. Since the research employs the system dynamics approach as a primary method, the analysis of model results will look different from the way they are typically presented in economic journals.

Technically, system dynamics is a computer-aided approach to solve a system of coupled, nonlinear, first-order differential equations. What characterizes system 
dynamics is its emphasis on 1) feedback thinking, 2) loop dominance, 3) nonlinearity, and 4) taking an endogenous point of view. The endogenous point of view is the sine qua non of systems approaches (Richardson, 2011). System dynamics also uses several unique techniques for mapping a model, including causal loop diagrams, system boundary diagrams, and stock and flow diagrams, in order to visualize a complex system.

The model developed by Brander and Taylor (1998) (henceforth the BT model) is adopted as a baseline ecological economic model throughout my dissertation. The BT model explains a pattern of economic and population growth, resource degradation, and subsequent economic decline. In a structural sense, the BT model is characterized as a general equilibrium version of the Gordon-Schaefer Model, using a variation of the Lotka-Volterra predator-prey model. Since its initial appearance in American Economic Review, the BT model has generated many descendants (Anderies, 2003; Basener and Ross, 2005; Basener et al., 2008; D'Alessandro, 2007; Dalton and Coats, 2000; Dalton et al., 2005; de la Croix and Dottori, 2008; Erickson and Gowdy, 2000; Good and Reuveny, 2006; Maxwell and Reuveny, 2000; Nagase and Mirza, 2006; Pezzey and Anderies, 2003; Prskawetz et al., 2003; Reuveny and Decker, 2000; Taylor, 2009). In addition to its high quality, the BT model is attractive, because of its simplicity and potential extendability. Hence the BT model should serve as a good starting point for investigating the role of such critical factors as substitutability, resource management regimes, population growth, and adaptation in an economy under limited available natural resources in evaluating the sustainability and resilience of an EES. 
My dissertation consists of three articles. The first article is a comprehensive analysis of the BT model and its descendants to elicit directions for future research. This article has been published in Ecological Economics (Nagase and Uehara, 2011). Dr. Nagase and I are both primary authors for the paper. The paper provides a comprehensive analysis of the BT-type models from the following six perspectives: population growth, substitutability, innovation, capital accumulation, property rights and institutional designs, and modeling approach.

The second article builds and analyzes an extended BT model that reflects three important yet not fully explored aspects of ecological economic models: appropriate system boundary, non-convexity of ecosystems, and adaptation. The main focus of the paper is on resilience, particularly on the two types of threshold: the ecological threshold (hereafter $E T$ ), a threshold for an ecological system independent of economic systems, which is also called the minimum viable population or critical depensation (Daly and Farley, 2010) and the ecological economic threshold (hereafter EET), a threshold for an ecological economic system. The main findings are: 1) ecological threshold and ecological economic threshold may not be identical, 2) ecological economic threshold may be highly context dependent and dynamic, which suggests the precautionary principle, 3) market response to an external shock may be insufficient to maintain resiliency, 4) it may be possible to restore an EES even after passing ecological economic threshold by intervention, 5)various transitional paths could be possible to restore the system, and 6) adaptation may affect resilience in a non-negligible way, which suggests 
the importance of better information and education. The article is single authored. An earlier version of the article has been accepted and were presented at the International Society for Ecological Economics conference 2012 to be held in Brazil, June 2012.

The third article focuses on sustainability rather than resilience. It further extends the BT model reflecting suggestions by Nagase and Uehara (2011). Since reflecting all the six attributes is highly ambitious, the article left the role of property rights and institutional designs for future research. The main contribution of the article is to investigate the impact of endogenous innovation regarding input substitutability which is, to the best of my knowledge, the first such attempt. The results show that the endogenous substitutability could contribute to an expansion of an economy (i.e., increases in production of goods and population) but not be favorable in terms of sustainability due to barely changing utility per capita and the greater use of natural resources. However, there could exist some sustainable paths that can realize higher utility and the lower use of the natural resource stock, when endogenous substitution is combined with other types of technological progress, which suggests the importance of induced technological change (ITC). In addition to the findings about the sustainability conditions, the article also discusses the possible problems with the use of an exogenous consumer preference and the differential system impact of innovation on the intrinsic regeneration rate of a natural resource compared to the impact of innovation on the carrying capacity of the resource. I am the lead author, with Drs. Nagase and Wakeland as co-authors. Three earlier versions were: 1) presented at the International System 
Dynamics Conference 2010 held in South Korea, 2) presented at the International Society for Ecological Economics conference 2012 held in Brazil, June 2012, and 3) presented at the International System Dynamics Conference 2012 held in Switzerland, July 2012.

Although the models are intended to contribute to understanding of developing economies under resource constraints, the models are evaluated based not on the fitness of the model to historical data of specific developed countries, but rather on the theoretical soundness of their model structures. Since developing economies may go through unprecedented experiences because their situations could be quite different from the currently developed economies (e.g., the availability of many technologies and the increased scarcity of natural resources), it may not be wise to place an emphasis on the past experience of developed economies which have existed for a mere 250 years (Dasgupta, 2008). The purpose of this dissertation is not to propose a model that strives to serve as a panacea that could be applied to any ecological economic systems (cf., Ostrom, 2007; Anderies et al., 2007). Instead, this dissertation shows the importance of a systems approach employing system dynamics and economics to tackle complex EESs, and also adds to the existing repertoire of models designed to improve understanding of the complex behavior of EESs for sustainable development. 


\title{
Chapter 2: Evolution of population-resource dynamics models
}

\begin{abstract}
This paper provides a comprehensive analysis of Brander and Taylor's (1998) model and its descendants from the following perspectives: population growth, substitutability, innovation, capital accumulation, property rights and institutional designs, and modeling approach. This survey aims to contribute to a better understanding of population and resource dynamics models in general and facilitate further application of the model framework to relevant circumstances. Although often treated as exogenous in optimal growth models, making population growth an endogenous function allows us to analyze broader effects of economic activities on population. The issues of substitutability, innovation and capital accumulation are intertwined; allowing a model to address the effect of an endogenous technological change on substitutability between natural and man-made capital facilitates our analyses of sustainability issues. To address internalizing inter-generational externalities in resource use, incorporating property right changes and institutional designs to this type of model is a useful exercise, but careful attention is needed for the consistency between such an arrangement and the mathematical representation of the depicted economy. Finally, although the common criticism regarding convenient mathematical assumptions applies to the existing BT-type models,
\end{abstract}


the use of computer simulation can relax such assumptions, to better represent the intended relationships between the relevant variables. 


\section{Introduction}

An economy has a potential to outgrow its supporting ecosystems, leading to a collapse.

In economics, there are two types of literature on resources and growth. The first type consists of models that assume that advances in technology are fast enough to overcome the increasing scarcity of renewable resources (e.g., Solow 1999), or even nonrenewable resources (e.g., Stamford da Silva, 2008; Cheviakov and Hartwick, 2009). The other type is characterized by models that accept the fluctuation of economic growth driven by resource dynamics. Brander and Taylor's (1998) so-called BT model, originally designed to replicate the population and resource dynamics of Easter Island (henceforth E.I.), belongs to this category. Since its initial appearance, the BT model has generated many descendants (Dalton and Coats, 2000; Erickson and Gowdy, 2000; Maxwell and Reuveny, 2000; Reuveny and Decker, 2000; Anderies, 2003; Pezzey and Anderies, 2003; Prskawetz et al., 2003; Basener and Ross, 2005; Dalton et al., 2005; Nagase and Mirza, 2006; Good and Reuveny, 2006; D’Alessandro, 2007; Basener et al., 2008; de la Croix and Dottori, 2008; Taylor, 2009).

This study examines existing BT-type models through the following set of attributes: (1) population growth, (2) substitutability, (3) innovation, (4) capital accumulation, (5) property rights and institutional designs, and (6) modelling approach. By integrating the existing models through a common set of attributes, this study aims to 
provide a better understanding of population and resource dynamics models in general, and the BT-type models in particular, that are suited to study the sustainability of certain types of economies, as revealed by the following sections.

Our comparative analysis of the models yields the following conclusions. An endogenous, rather than exogenous, population growth function allows a model to incorporate the effect of economic activities on population, through variables that reflect individuals' economic decisions. The issues of substitutability, innovation and capital accumulation are intertwined; a model that sheds light on the effect of an endogenous technological change on substitutability between natural and man-made capital or goods facilitates our investigation of sustainability issues. Allowing a model to internalize intergenerational externalities in resource use by incorporating property right changes and/or institutional designs is a useful exercise, but careful attention is needed for the consistency between such an arrangement and the mathematical representation of the depicted economy. Finally, the common criticism regarding the use of convenient mathematical assumptions applies to the existing BT-type models, but computer simulation allows for a wider array of functions that can better represent the intended relationships between the relevant variables.

The rest of the paper is organized as follows. Section 2 provides a brief introduction to the BT model. Section 3 compares and integrates the BT-type models through the above-mentioned six attributes. Section 4 concludes our analysis. 


\section{Basic characteristics of a BT-type model}

Figure 2.1 depicts the period-by-period material and cash flow and agents' behaviour in a typical BT-type model. A typical BT-type model has the following characteristics. It depicts a small, closed economy. It has a renewable resource $(S)$ to be used to produce two types of good, a harvested good $(H)$ and a manufactured good $(M)$. The resource dynamics is hence given by the resource growth and harvesting activities. An additional input for each sector is labour $\left(L_{H}, L_{M}\right)$, or population $\left(L \equiv L_{H}+L_{M}\right)$, and population growth is endogenously driven by a fertility function. The economy is decentralized in the sense that the relative price of the goods and the wage are determined by market forces. Although people as consumers individually maximize utility in each period, the original BT model has one sector-level production function for each sector. In the original BT model, the aggregate production function for each sector is linear in labour, given the existing resource and population stock sizes. Therefore, a fullydecentralized (and possibly primitive) interpretation of production activities is possible, namely, each worker independently has her one-person production activity and receives the "wage" $(w)$ that equals her marginal revenue product of one unit of labour, given the market prices of the two goods. Finally, in most of the BT-type models, individuals behave in a myopic manner; these agents do not maximize utility across multiple time periods and instead focus on the given period. Therefore, most of the BT-type models consist of a combination of agents' static optimization in each time period, taking the 
sizes of the resource stock and population as given, and transitional processes from one period to the next given by a set of dynamic equations for these stock variables. Figure 2.2 shows this mechanism using the static equilibrium values of the original BT model. A major appeal of the BT-type models is its ability to demonstrate potential volatility of an economic system. Also, its simplicity leaves room for incorporating variables that can address key issues of sustainability.

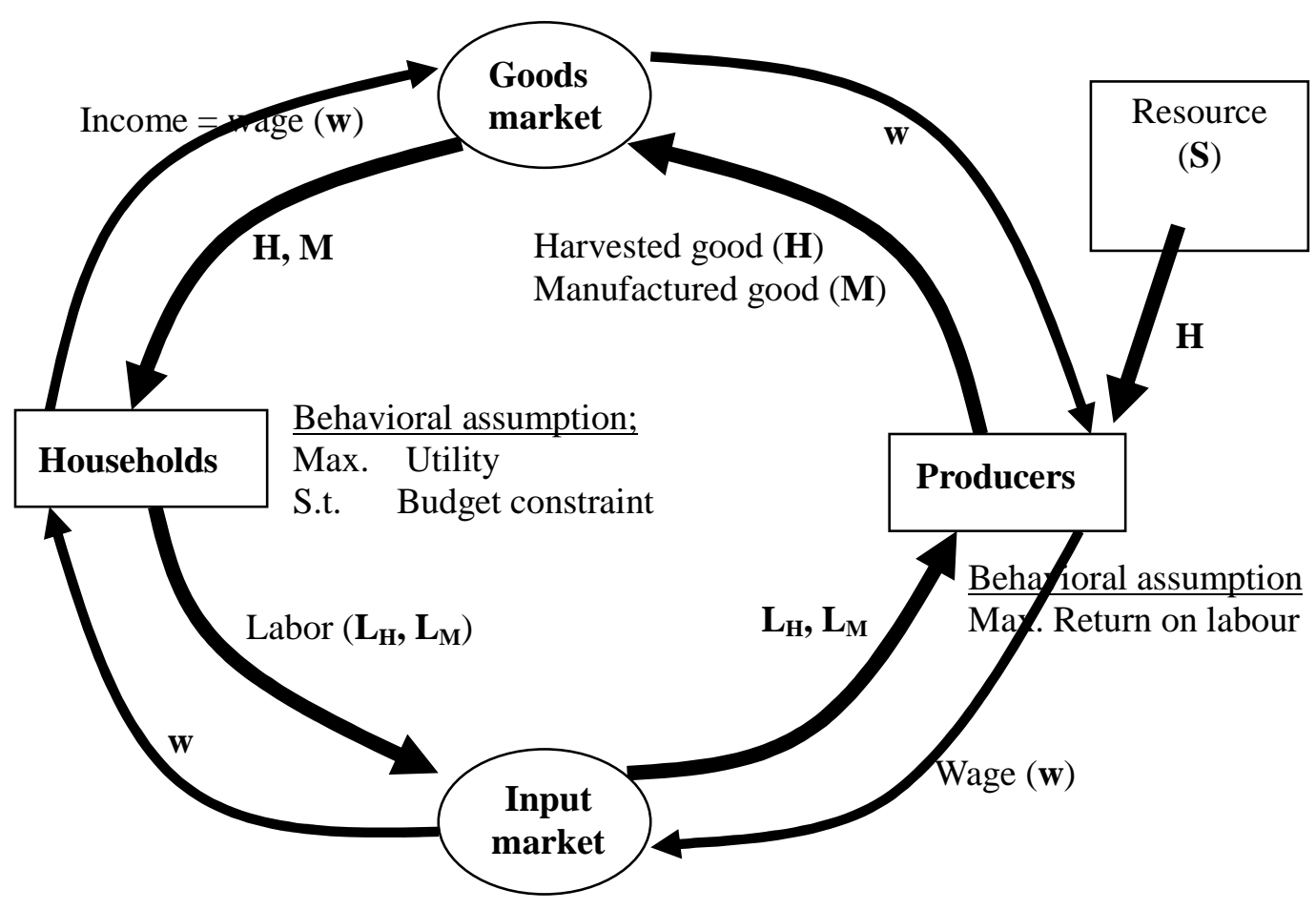

Figure 2.1. Period-by-period material and cash flow and agents' behavior in a BT-type model. 


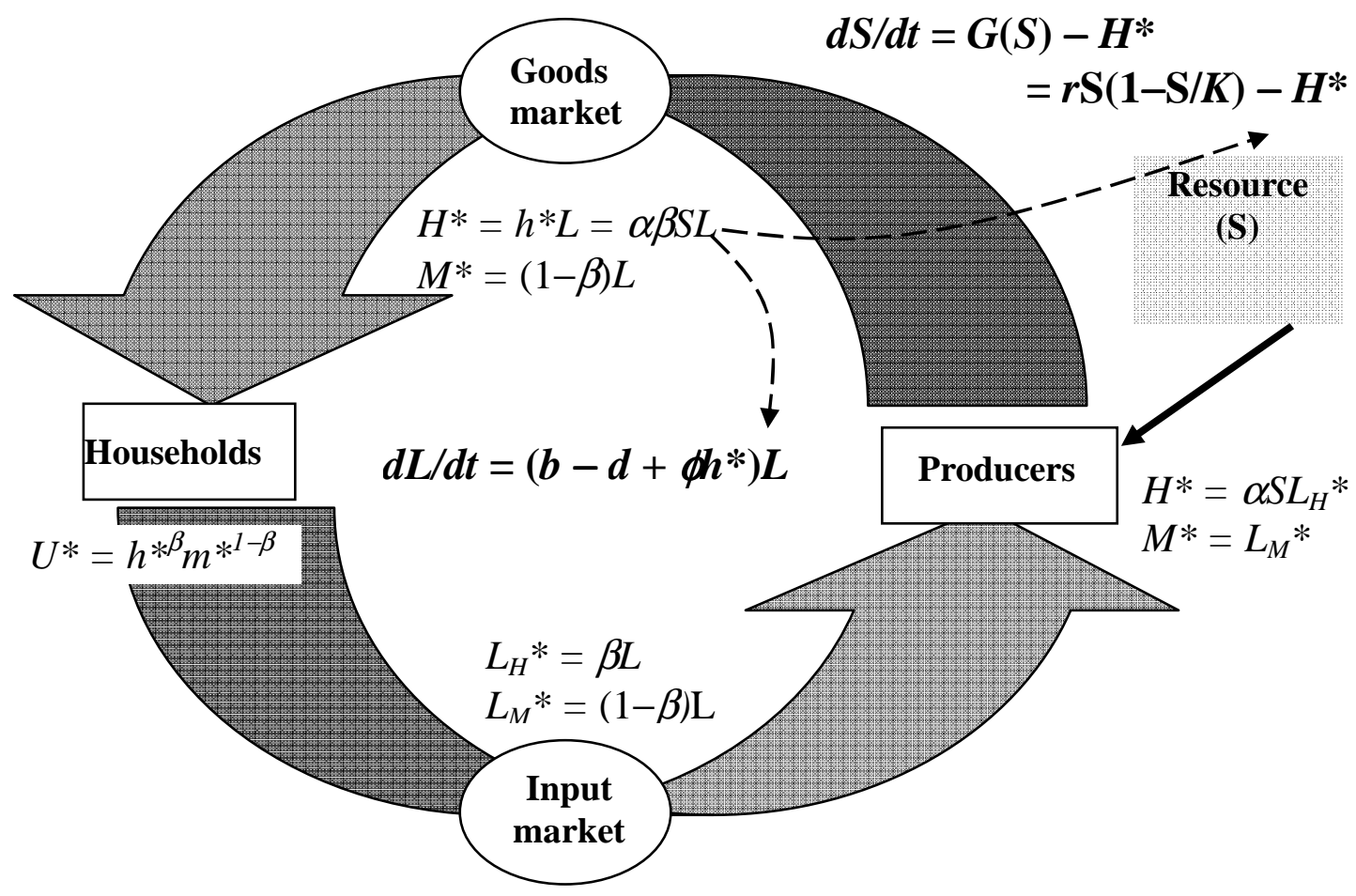

Figure 2.2. Static equilibrium outcomes and their feed-in mechanisms for the population and resource dynamics. (Equations are based on the original BT model; Asterisks indicate that these expressions are equilibrium values.)

\subsection{Population Growth}

Although population growth has been treated as exogenous in many studies of economic growth and natural resources (e.g., Dasgupta and Heal, 1974; Elíasson and Turnovsky, 2004; Economides and Philippopoulos, 2008), endogenous population dynamics is indispensable for models whose purpose is to address sustainability of an economic system. Empirical case studies support that there is a feedback mechanism 
between population and natural resource (e.g., Diamond, 2004). In general, population dynamics models use ordinary differential equations in the form of:

$$
\frac{d L / L}{d t} \equiv f \text { (weather, food, predators, etc.), }
$$

where $L$ denotes the population size. Population change per time period is typically defined as a summation of fertility at the individual level.

Since a feedback mechanism between population and natural resource is essential, it is better to discuss population dynamics along with resource dynamics. The most popular framework for modelling this type of predator-prey interactions has the following structure (Turchin, 2003):

$d S / d t=$ "prey growth in the absence of predators" - "total killing rate by predators"

where $S$ denotes the natural resource stock and

$d L / d t=$ "predator growth (or decline) in the absence of prey" + "conversion of eaten prey into new predators."

The basic idea is that the right-hand side of each equation consists of two parts. The first part of each equation indicates the independence of one stock variable from the other, while the second part shows the interdependence between the two stock variables.

The original BT model uses Volterra's (1931) framework in which a natural resource grows logistically in the absence of the harvest (as cited in Turchin, 2003): 


$$
\frac{d S}{d t}=r S\left(1-\frac{S}{K}\right)-H
$$

where $K$ denotes the carrying capacity for this resource, $r$ denotes the intrinsic growth rate, and $H$ denotes the predator $L$ 's harvest level (Figure 2.2 ). ${ }^{1}$ The population growth function in the BT model is given by:

$$
\frac{d L}{d t}=\left(b-d+\phi \frac{H}{L}\right) L,
$$

where the amount of $H$ in each static equilibrium depends on $S$ (Figure 2.2). The BT model expresses Malthusian population dynamics in which population growth consists of two parts: the net birth rate $(b-d)$ that is independent of the level of percapita food consumption $(H / L)$ and the fertility rate $\phi$ that affects the population growth only with nonzero level of $H / L$. Since $b-d$ is assumed to be negative, in the absence of harvest from the nature the population will be extinct.

This population growth function has two notable traits. First, the population growth rate is linear in $H / L$, which implies that the more they eat the more they produce offspring. This feature may contradict situations in some developed countries where there

${ }^{1}$ One of the standard frameworks of population-resource dynamics in biology is the Lotka-Volterra (LV) model, a bilinear system that is the simplest possible version of this type of interaction. The original L$\mathrm{V}$ model, however, is not very realistic, and there have been many descendants with other functional forms. (Turchin, 2003). 
is a negative relationship between income level and population growth. ${ }^{2}$ Second, the function assumes that consumption of the manufactured good (that could be regarded as a composite of, e.g., medicine, fishing equipments, boats, and agricultural equipments) does not affect population growth. Brander and Taylor (1998) do not include such manufactured goods, because, as Reuveny and Decker (2000) point out, in equilibrium the per-capita manufactured good is always a constant: $M^{*} / L=(1-\beta)$, where $1-\beta$ is a parameter representing consumer's preferences for good $M$ (Figure 2.2). However, as we address later the effect of the consumption of manufactured goods on population growth matters when substitutability issues and the effects of capital accumulation are taken into account.

Descendants of the BT model fall into two groups in terms of population dynamics. The models in the first group use the population growth functions of the original BT model, either as it is or with slight modification. The models in the second group employ population growth functions that are very different from the one used in the original BT model.

Regarding the models in the first group, Dalton and Coats (2000), Pezzey and Anderies (2003), Dalton et al. (2005), Good and Reuveny (2006), and Taylor (2009) use the same equation of motion as that of the original BT model, whereas several others use

${ }^{2}$ Galor and Weil (2000) develop a unified growth model that captures the transition from a Malthusian to a Post-Malthusian regime. 
variations. Erickson and Gowdy (2000) focus on the effect of manufactured capital (A) accumulated from the harvested good. Compared with the archaeological evidence of E.I., the population in the original BT model peaks about 200 years too early. To explain this gap and improve the fitness of the model (i.e., to obtain the estimate of population dynamics that is more consistent with the archaeological evidence), the authors introduce the third equation of motion for $A$ :

$$
\frac{d A}{d t}=H-\delta A
$$

where parameter $\delta$ represents the capital depreciation rate. The accumulated capital contributes to the fertility rate, with the lag of 100 years (denoted as $A_{100}$ ):

$$
\frac{d L}{d t}=L\left(b-d+\phi \frac{H}{L}+\phi \alpha \beta A_{100}\right),
$$

where $\alpha$ and $\beta$ are parameters representing the productivity of the $H$ sector and consumer's preferences for $H$, respectively (Figure 2.2).

This approach invites us to contemplate its assumptions and formulation. First, this approach reflects the fact that individuals' well-being, including health and fertility, improves with the consumption of a capital good. The chosen lag period improves the fitness of the model for this specific case; as a general rule, theoretical reasoning and/or empirical evidence should guide such a choice. An alternative approach may be to let the effect of the capital good be felt immediately, with a coefficient that represents the marginal effect. Second, an interpretation of the supposed mechanism of capital 
formulation would be helpful to better understand the portrayed economy. In the above model, people consume the harvested good, while at the same time accumulating the same amount of the good as capital. That is, the harvested good in each period is used for both immediate consumption and capital accumulation. Whether capital should be accumulated from the harvested good or the manufactured good is another issue to consider. In another BT-type model by Anderies (2003), investments are made on the portion of the manufactured good that is set aside separately from immediate consumption purposes to be accumulated for capital formation.

D'Alessandro (2007) provides a more general framework to account for the heterogeneity of environmental development paths. His model includes two types of natural resources: a renewable resource (forest) and an inexhaustible one (land). This model can explain the situation in which people may continue to exist as they exhaust the renewable resource stock, as it may have been the case with E.I. This is expressed as follows:

$$
\frac{d L}{d t}=\left[\gamma \frac{C}{L}+\phi \frac{H}{L}-(b-d)\right] L,
$$

where $C$ denotes "corn" obtained from land, the harvested good $H$ is obtained from forest, and $\gamma$ and $\phi$ are the caloric units (or fertility rates) of consumption of $C$ and $H$, respectively. Since land is assumed to be inexhaustible, people can survive even after 
depleting the forest. ${ }^{3}$ An issue to consider here is the assumption of the perfect substitutability between the two types of goods, whose validity would depend on the characteristics of the specific cases.

Reuveny and Decker (2000) incorporate population management into the population dynamics. They replace the linear fertility coefficient $\phi$ in the original BT model with a function:

$$
F=\phi\left(\frac{H}{L}\right)^{x}
$$

that can be concave $(0<x<1)$, linear $(x=1$, the original BT case), or convex $(x>1)$. The characteristics of this fertility function depend on the value of $x$, a policy instrument. Although the authors' purpose for introducing $x$ to the model is to examine the effect of population management, their population function can also address the criticism that, in the original BT model, fluctuation of the population size can be arbitrarily large when harvest is abundant (Basener and Ross, 2005). By employing $0<x<1$, growth can be tamed to a reasonable level. Also, nonlinearity of a fertility function in consumption of goods would be consistent with empirical evidence (the "Demographic Transition").

\footnotetext{
${ }^{3}$ In this model, good $C$ replaces good $M . C$ has a production function of labour input only, as the production function of $M$ in the original BT model. $C$ also contributes to the utility function in the same manner as $M$ does in the original BT model. Therefore, another way to interpret this model is that the manufactured good contributes to fertility.
} 
Maxwell and Reuveny (2000), followed by Prskawetz et al. (2003), relate natural resource scarcity to emergence of conflicts. They assume that when per-capita resource level $S / L$ is less than a given threshold level $\bar{V}$, conflicts emerge and increase the death rate, expressed as follows:

$$
\frac{d L}{d t}=\left((b-\eta d)+\phi \frac{H}{L}\right) L
$$

where $\eta$ represents the effect of conflicts. $\eta$ is greater than 1 under conflicts and is equal to 1 otherwise. While the authors assume discontinuous changes in the dynamics once conflicts set in, Prskawetz et al. (2003) propose continuous changes by assuming that the death rate is a function of a threshold for conflict and natural resource scarcity, defined as follows:

$$
\frac{d L}{d t}=\left[b-\eta\left(\bar{v}, \frac{S}{L}\right) d+\phi \frac{H}{L}\right] L ; \eta\left(\bar{v}, \frac{S}{L}\right)=1+\frac{\eta_{\max } \bar{v}^{p}}{\bar{v}^{p}+\left(\frac{S}{L}\right)^{p}} .
$$

Here, $\eta$ is a logistic function of $S / L$. $\eta_{\max }$ represents the maximum impact that a conflict may exert on the death rate. When the per-capita resource becomes very low, the death rate is at its maximum, i.e., $\eta=1+\eta_{\max }$. Together with two more conflict-driven parameters that affect labour allocation and resource growth, both studies show that conflicts can serve as a stabilizing feedback mechanism as long as it becomes active early enough. 
In contrast, models in the second group, proposed by Basener and Ross (2005) and Basener et al. (2008), abandon the framework used in the original BT model and adopt the logistic predation originally proposed by Leslie (1948), expressed as follows (Basener and Ross, 2005):

$$
\frac{d L}{d t}=\left[a\left(1-\frac{L}{S}\right)\right] L
$$

where $a$ and $r$ are the intrinsic growth rates of population and natural resource, respectively. ${ }^{4}$ Although without the fertility component that represents the conversion of eaten prey into new predators, these models show better fitness to the archaeological data. Another advantage of this population function is that they can avoid the BT model's aforementioned problem of arbitrarily large population growth; with the logistic function, the population growth rate is capped by the nature's carrying capacity. Meanwhile, this population growth framework also has a disadvantage. The per-capita consumption (and hence production) level of the harvested good remains constant, i.e., scarcity does not affect individuals' economic decisions, contradicting neoclassical economic theory. ${ }^{5}$

${ }^{4}$ Basener et al. (2008) propose the discrete version of the model.

${ }^{5}$ Another study by de la Croix and Dottori (2008) takes a different approach. Instead of the BT-type predator-prey system, they incorporate competition between two tribes. It is an overlapping generations model in which each tribe chooses its fertility rate to maximize its tribal utility. Their approach is considerably different from those of the other studies, and we do not fully explore it here. 
Although the resource side of equations of motion lacks variations across the models (most BT-type models use the same logistic growth function minus harvest, as the equation of motion), we examine one variation given by D'Alessandro (2007) and Taylor (2009) who employ a critical depensation growth function:

$$
\frac{d S}{d t}=r S\left(1-\frac{S}{K}\right)\left(\frac{S}{K}-1\right)-H .
$$

$\underline{K}$ represents the "tipping point" of the resource stock level below which the regeneration rate becomes negative (Taylor, 2009). This arrangement allows their models to address the irreversibility problem. A tipping point becomes a determinant of the stability of the interior steady states in D'Alessandro's (2007) model, and Taylor (2009) shows that it is one of the three preconditions for the system to reach an environmental crisis, including the collapse of the system. ${ }^{6}$ Ecological studies support depensation growth functions, and these authors' results warrant further investigation of the use of this type of function.

In conclusion, there are two types of the population dynamics among the BT-type models, and each has different features. As Basener et al. (2008) suggest, unlike fundamental laws of physics there is no right single differential equation for the population dynamics. Hence we should choose one based on the purposes and the

${ }^{6}$ Taylor (2009) defines an environmental crisis as "a dramatic, unexpected, and irreversible worsening of the environment leading to significant welfare losses." 
corresponding assumptions of the model. An advantage of the framework used in the original model is that it incorporates neoclassical economics considerations into the population growth in the sense that the harvested good is obtained from agent's optimization. There are pros and cons to the population growth functions explored in this section, and we further propose two directions for extending the original BT model to enhance its theoretical basis and empirical relevance in application. First, incorporating the manufactured good into the population growth function allows the model to capture the effect of broader economic activities on the population dynamics. Second, population growth as a function of the nature's resource capacity allows the population growth rate to be aligned with, or constrained by, the surrounding nature's carrying capacity.

\section{3-2. Substitutability}

Opinions on economic models that presume various degrees of substitutability between man-made and natural inputs are based on both theoretical and empirical arguments. Theoretically, for a constant elasticity of substitution (CES) function strong sustainability requires that the elasticity of substitution (henceforth denoted by $\sigma$ ) between man-made good (or input) and environmental amenities (or natural resources) must be less than one (Gerlagh and van der Zwaan, 2002; Lawn, 2003). ${ }^{7}$ Using a nested

\footnotetext{
${ }^{7}$ We focus on what is known as Hicksian or full $\sigma$ (Markandya and Pedroso-Galinato, 2007).
} 
CES production function and multinational data, a recent study by Markandya and Pedroso-Galinato (2007) provides two sets of estimates of $\sigma$ : one set of values based on past studies (1971-1998), and another set freshly estimated by the authors, using more recent data. The first set consists of low values of $\sigma$ between capital and energy (0.87), labour and energy (0.42), and labour-capital composite and energy (0.42 and 0.5). The second set consists of higher values, e.g., between capital-human resource-energy composite and land (1.00), and capital-human resource-labour composite and energy (1.00). The only low figure from the second set is between capital and energy (0.37). Compared with the estimated value of 2.0 by Nordhaus and Tobin (1972), the estimates given by this more recent study suggest that the values of $\sigma$ are lower than previously thought. Since we expect that the values of $\sigma$ change as economies evolve, changes in estimated values as described above are not surprising, although a common view is that as economies develop the relationship between energy and capital tends to evolve from being complements to substitutes (Ayres, 1998). As for substitutability in consumption, although low degrees of substitutability have been observed in various surveys (Gelso and Peterson, 2005), we are not aware that empirical literature (in real, rather than hypothetical, settings) on this issue is pointing to any particular direction.

Most of the BT-type models so far have not addressed substitutability issues. As for production functions, some of the BT-type models continue to employ variations of the original BT model's linear production functions in labour $(L)$ for both good $H$ and $M$ : $H=\alpha S L_{H}$ and $M=L_{M}$, where $\alpha$ is an exogenously given productivity parameter and $L_{H}$ 
and $L_{M}\left(L_{H}+L_{M}=L\right)$ are the labour force allocated to the two sectors (Figure 2.2). Meanwhile, other BT-type models employ variations of Cobb-Douglas (C-D) functions. This latter approach allows the authors to introduce inputs in addition to labour. Among these models, Anderies' (2003) model is the most general in the sense that both $H$ and $M$ are functions of labour and manufactured capital $(A):^{8}$

$$
H=E_{H} S^{\alpha_{S}} L_{H}{ }^{\alpha_{H}} A_{H}{ }^{1-\alpha_{H}}
$$

and

$$
M=E_{M} L_{M}^{\alpha_{M}} A_{M}^{1-\alpha_{M}},
$$

where $E_{H}$ and $E_{M}$ are efficiency factors (to be explained more in section 3-3), $\alpha_{S}, \alpha_{M}$, and $\alpha_{H}$ are between 0 and 1 , and $A_{H}+A_{M}=A$. As $L$ and $S, A$ is a stock variable and is given during each period. While introducing man-made capital is critical to address substitutability between natural and man-made inputs, C-D functions limit $\sigma$ between inputs to be one. Nagase and Mirza (2006) employ a CES function $M=\left[\theta H_{M}{ }^{\rho}+\right.$ $\left.(1-\theta) L_{M}{ }^{\rho}\right]^{1 / \rho}$ where $H_{M}$ denotes the amount of $H$ used as an input. Their study provides sensitivity analyses with respect to various (exogenously given) values of $\sigma$.

${ }^{8}$ Dalton et al. (2005) modify the production function for $M$ to be a C-D function of $L$ and land, a nondepletable but fixed amount of resource. De la Croix and Dottori (2008), due to their focus on the analysis of conflict and bargaining between clans, omit good $M$ from the model and adopt for $H$ a C-D production function of $S$ and $L$. 
A different approach by Prskawetz et al. (2003) adopts a production function $H(S$, $L)=e S L_{H}\left(f L_{H}+S\right)^{-1}$, where $e$ and $f$ are positive parameters (while keeping the linear production function for $M$ ). As a C-D or CES does, this function exhibits diminishing marginal returns and has a constant $\sigma(=0.5)$. Meanwhile, this function has a unique feature: for a given level of an input, the output is asymptotically bounded from above as the other input level goes to infinity. ${ }^{9}$

As for substitutability in consumption, most BT-type models maintain the C-D utility function adopted by the original model (Figure 2.2). In contrast, Nagase and Mirza (2006) employ a CES function for the utility function as well as the above-mentioned production function. Their simulation results show that reduced substitutability in both production and utility functions makes the population and resource dynamics more volatile. They also observe the fluctuation of agents' utility levels to address the issue of changes in agents' well-being over time.

Most of the existing BT-type models have population growth functions with endogenously determined per-capita consumption of the harvested good; therefore, by adopting utility functions that allow for varying degrees of substitutability these models can portray the effect of substitutability in consumption on harvesting activities, and hence on the population and resource dynamics. In addition, adoption of production

${ }^{9}$ Prskawetz et al. (2003) classify this function as a Monod-type, although a classical Monod-type kinetics function does not have the predator stock $(L)$ as part of the numerator. 
functions with man-made capital and endogenous innovation will further allow these models to examine how consumers' preferences regarding substitutability affect the relative price of the two goods and drive the innovation path--these topics are addressed in the next two subsections.

While the empirical investigation of $\sigma$ still awaits further studies, analysing the existing BT-type models in terms of substitutability yields some points to consider. First, extending the existing models to allow for analyses of the effect of varying degrees of substitutability both in production and consumption on population and resource dynamics would serve one of the primary purposes of the BT-type models: studying sustainability. Second, allowing $\sigma$ to evolve over time endogenously has both theoretical and empirical bases--this is to be addressed in 3.3. Finally, while not explored by the authors, the production function of Prskawetz et al. (2003) provides another channel to address substitutability issues. As described above, this production function caps the output level, being consistent with the notion of strong sustainability. Since the amount of harvest is bounded by the existing stock size during any given time period and ultimately by the nature's carrying capacity, in addressing substitutability issues this function could be better suited for the manufactured good rather than the harvested good. Combined with the introduction of man-made capital as an input, this function allows us to examine the trade-off between man-made and natural capital under the strong sustainability criterion.

\section{3-3. Innovation}


Non-exogenous technological change can be distinguished into endogenous technological change (ETC) and induced technological change (ITC). A technological change caused by economic activities represented by endogenous variables in the model is an ETC, while a policy-induced additional change to ETC can be considered an ITC (Edenhofer et al., 2006). ${ }^{10}$ The economics literature on ETC and ITC is flourishing; for the purpose of this paper it suffices to say that there are strong supports for ETC and ITC in both theoretical and empirical literature. Economic theory dictates that economic agents respond to prices that reflect relative resource scarcity, and empirical studies on resource price and innovation support this implication (e.g., Popp, 2002; Khatri et al., 1998; Thirtle et al., 1998).$^{11}$ Another critical issue surrounding ETC and ITC is the effect of learning curves. Studies show that in addition to the price of resources, existing knowledge base affects the innovation path (Gritsevskyi and Nakićenović, 2000; Köhler et al., 2007).

The original BT model has no innovation processes; it and some of the BT-type models provide comparative statics analyses of the steady state, with respect to parameters such as $\alpha$ (harvest productivity), $r$ (intrinsic growth rate), and $K$ (carrying

${ }^{10}$ Alternatively, the term ITC can be used to represent both ETC and ITC (Grubb et al., 2002).

${ }^{11}$ Popp (2002) uses U.S. patent data. Khatri et al. (1998) and Thirtle et al. (1998) provide case studies on innovation and agriculture in the UK and South Africa, respectively. 
capacity). With the original BT model, the steady-state resource stock size $S^{*}$ decreases with an improvement in the harvesting technology (an increase in $\alpha$ ). The steady-state population size $L^{*}$ increases with an innovation in biotechnology (an increase in $r$ or $K$ ), while the effect of an increase in $\alpha$ on $L^{*}$ depends on the steady-state resource growth level. Anderies (2003), as described earlier, adopts C-D production functions for $H$ and $M$ with efficiency factors $E_{H}$ and $E_{M}$. This model also has parameter $\eta$, an indicator of negative impacts of agriculture on the natural resource base. The author provides the boundary combinations of the values of $E_{H}$ and $E_{M}$ for the existence of a steady state and a comparative static analysis on changes in $\eta$. His analysis shows that, with the given set of parameter values, higher productivity in both sectors (larger $E_{H}$ and $E_{M}$ ) increases the likelihood of population overshooting and collapse, and that reduced externalities (smaller $\eta$ ) do not prevent this scenario without systemic changes in the feedback loop between resource use and population. D'Alessandro (2007) examines the effect of an innovation introduced as a shock that increases the value of $\alpha$. With the given set of parameter values, the author shows that a productivity shock reduces the resilience of the internal steady state and increases the risk of the collapse of $S$. As described in 3-1, thanks to the non-depletable resource (land), even with the collapse of the renewable resource $S$ this model yields a steady state with a positive population size. The author also examines the effect of technology shocks that yield increases in land productivity. Such 
changes can increase the steady-state population size but also reduces the resilience of the internal steady state.

Two of the BT-type models adopt time-dependent exogenous technological change and ITC. Reuveny and Decker (2000) employ time-dependent logarithmic and exponential growth functions for $K, r$, and $\alpha$. Their simulation results show two intuitively sound results: innovation in harvesting technology, ceteris paribus, can cause population crash due to resource depletion, and higher resource growth rates, ceteris paribus, can sustain larger population sizes. One outcome that awaits an interpretation is that exponential growth of carrying capacity can trigger a feast-famine cycle. Contrary to all other studies, Dalton et al. (2005) incorporate ITC into their model. In this model, changes in $L$ (embodiment of the existing knowledge and experience with technologies) affect the sizes of $\alpha$ and $r$, defined by the following difference equations: $\alpha_{t}=\alpha_{t-1}[1+$ $\left.\xi_{\alpha} \lambda(d L / L)\right]$ and $r_{t}=r_{t-1}\left[1+\xi_{r} \lambda(d L / L)\right]$ for $d L>0$ and $\alpha_{t}=\alpha_{t-1}$ and $r_{t}=r_{t-1}$ otherwise. $^{12}$ They find that, compared with the original BT model, making $\alpha$ and $r$ endogenous following these rules worsen the feast-famine cycle. The negative effects (exacerbated feast-famine cycle with lower $S^{*}$ and/or $L^{*}$ ) of increases in $\alpha$ or positive effects (more stable system with higher $S^{*}$ and/or $L^{*}$ ) of increases in $r$, ceteris paribus, are qualitatively

${ }^{12}$ Parameter $\lambda(>0)$ represents the marginal effect of population changes. Parameters $\xi_{\alpha}$ and $\xi_{r}$ represent the status of institutional arrangement of property rights, to be explained in $\mathbf{3 . 5}$. 
similar to those of above-mentioned studies. One puzzling aspect of their simulation result is that increases in $r$ alongside increases in $\alpha$ affect the system negatively.

From these studies, we notice the general effects of certain types of technological changes, namely, stimulating harvesting technologies have negative effects whereas biotechnologies have positive effects (meaning of negative and positive as described in the previous paragraph). Meanwhile, the analyses conducted so far are mostly of innovation as one-time or time-dependent exogenous changes, not allowing us to study the effect of continuous innovation driven by scarcity and market prices on the stability of the system and its agents' well-being. One model by Dalton et al. (2005) employs ITC, and each innovation process is a function of the population $L$ that represents the knowledge base of the economy. Such an innovation function could include other variables that allow the technology to evolve in response to changing relative scarcity of productive resources, including man-made or natural capital.

To conclude, since a major purpose of analysis using the BT-type models is to understand the interactions among population, resource use, and the stability of the economy, letting this type of model depict the transitional adjustment process by incorporating both scarcity-driven ETC and policy-driven ITC that address additional needs for the depicted economy to reallocate resources is a beneficial direction for extending these models.

\section{3-4. Capital Accumulation}


Despite the remarks we have made so far on introducing capital accumulation into the models, the main obstacle for most of the existing BT-type models in motivating the agents to accumulate and maintain capital stocks is the agents' time preferences. Accumulation and maintenance of any form of capital (man-made or natural) takes place when agents in the modelled economy care about their future. Whereas in most of the BT-type models agents are myopic, except one by Good and Reuveny (2006) in which consumer's choice is modelled as a dynamic, multi-period optimization process. The resulting agent's optimal choice in this model takes account of the shadow prices of the two stock variables (population $L$ and natural capital $S$ ). Such a model could potentially incorporate saving activities and man-made capital accumulation as typically done in Ramsey growth models.

Two models that include man-made capital are given by Erickson and Gowdy (2000) and Anderies (2003). In Erickson and Gowdy's (2000) model, accumulated manmade capital $A$ affects the fertility function (see 3-1 for the description of the capital accumulation rule) but has no direct effects on other functions. As described in 3-2, in Anderies' (2003) model production of both $H$ and $M$ are functions of $A$. The capital accumulation rule in this model is given by the difference between the investment and capital depreciation: $d A / d t=s w \cdot L / P_{M}-\delta A$, where $s$ denotes the marginal propensity to save and $\delta$ the depreciation rate, both exogenously given. Total savings of the economy 
in each period $(s w \cdot L)$ are used to purchase the manufactured good to form the man-made capital, as described in 3-1.

The motivations behind the introduction of man-made capital are, in Erickson and Gowdy's (2000) case to hypothesize weak sustainability that seems to be indicated by the archaeological evidence of E.I., and in Anderies' (2003) case to analyse the effect of investment on demographic transition and the effect of innovation on the dynamics of the system through capital accumulation. To focus on these objectives, in both models agents' optimization processes are kept as static, and the question remains as to how to interpret the motivation behind the formation of capital in the portrayed economies. This question is to be more fully explored in $\mathbf{3 - 5}$ where we address the compatibility issue between agents' static views in the BT-type models and introducing into the models institutional designs or evolution of property rights.

The existing models shed light on possible directions to extend the models for the purpose of studying sustainability issues with the introduction of man-made capital. In addition to incorporating man-made capital into production functions, another dimension to consider is the consumption side. Having $S$ and $A$ in a model allows us to explore a variety of issues. For example, one can incorporate substitutability between the environmental amenity from the natural resource stock and the service flow from the man-made capital stock as social infrastructure. The effect of changes in the amount of such services, as a result of accumulation or depletion of these stocks, on individuals' well-being can be studied by observing changes in the utility levels. One could also 
introduce a threshold level of the natural resource stock size that maintains the minimum life-support system for individuals, or that keeps individual's consumption levels of goods and services above certain levels, with varying degrees of substitutability between the two stocks.

\section{3-5. Property Rights and Institutional Designs}

Two questions that help us address the treatment of property rights in the BT-type models are: what type of property rights historically existed in E.I., and what type of property rights are represented by the mathematical specifications of the models. For the purpose of replicating the population and resource dynamics of E.I., consistency between the two questions is critical. Meanwhile, if one's interest is to analyse property-right issues using the BT-type models as a tool, it is important, first, to understand what a chosen model framework represents and then extend the model accordingly. Dalton et al. (2005) point to the evidence that Polynesian-style communal ownership ruled by a chief or tribunal council, with tightly controlled access to the resource and strong focus on immediate consumption of resources, existed in E.I., and the design and operation of the BT-type models can be interpreted as such. ${ }^{.13}$

${ }^{13}$ We distinguish common or communal ownership, under which resources are subject to regulation and access to the resources is restricted, from open-access in which resources are up for grabs by all takers 
When an economy is "compact", collective or common ownership can be effective (Demsetz, 2002; Libecap, 2009), whereas some of the authors of the BT-type models regard the potential of resource depletion that is inherent in these models as a market failure due to inter-generational externalities in resource use. ${ }^{14}$ These authors introduce into their models measures that can reduce the risk of resource depletion and population overshooting, namely, institutional designs such as user charges (Pezzey and Anderies, 2003) and limitation on harvesting activities (Dalton and Coats, 2000; Pezzey and Anderies, 2003). These authors posit stronger (more private) resource ownership as the motivation behind the emergence of such instruments. Dalton and Coats (2000), for example, explain that when a resource is expected to become relatively scarce in the future, under stronger property rights people are more likely to assign a smaller labour force for harvesting today than they would under weaker property rights. Meanwhile, the mathematical specifications of these models represent the unchanging behavioural assumptions for agents across varying degrees of resource ownership. Therefore, an alternative interpretation for the emergence of these instruments is possible, and it is that

(Merrill, 2002). It is our understanding that, in order to focus on the property right issues surrounding the renewable resource, authors of the BT-type models presume implicitly that goods are traded as private goods, and that labour is traded as a privately owned input. When man-made capital is present in the production function, it is also presumed to be privately owned (Anderies, 2003, p.240).

${ }^{14}$ A "compact" economy is one in which economic interactions are biologically, geographically, and/or socially close so that cultural customs and feelings for others are influential (Demsetz, 2002). 
they are institutional designs introduced by a chief or community leaders, while maintaining the existing common resource ownership. ${ }^{15}$ Such an interpretation is consistent with the theoretical and empirical literature that suggests that privatization is not the only solution to resource overconsumption under common ownership and that historical examples suggest that long-lasting, self-governed management of common property resources is possible (Ostrom, 2002 and 1990).

In contrast to such institutional designs, Dalton et al. (2005) and Good and Reuveny (2006) choose innovation in harvesting technology and discount rates, respectively, as the areas affected by varying degrees of property rights. Dalton et al. (2005) examine the effect of strong or weak property rights on the direction of innovation, by incorporating two types of technological change: resource-conserving

${ }^{15}$ Functional specification for an agent's optimization problem can be considered different under different property right regimes, reflecting agents' varying degrees of resource ownership and their alternative states of preferences (e.g., Caputo and Lueck, 2003). With private property rights, the production activity in this sector may be better defined at the individual agent's level as a function of her property rather than the sector-level stock size S. Dalton and Coats (2000), for example, introduce parameter $\chi$ that represents the varying degrees of property rights. This parameter appears in the reducedform equilibrium labour allocation for the harvest sector $L_{H} * \chi$ does not appear in agents' optimization process, suggesting that the behaviour of agents in this economy remains unchanged across the alternative states of property rights. Therefore, we could alternatively interpret these parameter changes as a representation of a chief's resource conservation policy under the existing property right regime. 
technology and resource-depleting technology, represented by parameters $\xi_{\alpha}$ and $\xi_{r}$ as presented in 3-3. In this model, stronger property rights promote resource conserving technology, whereas weaker property rights encourage resource-depleting technology. ${ }^{16}$ Good and Reuveny (2006) examine the effect of various states of property rights on the level of harvesting through changes in consumers' discount rates for their multi-period utility maximization problem. In this model, with stronger (weaker) property rights people have low (high) discount rates.

The analytical results of these BT-type models are qualitatively consistent with the implications of comparative statics of the original BT model; changes in parameters (due to institutional designs or otherwise) that discourage harvesting activities tame boom-and-bust cycles of population and resource dynamics. These results are compatible with the motivations behind the introduction of property right changes into the models by these authors.

Existing literature provides two prime candidates that explain the mechanism of evolution of property rights: interest-group theories and social-norm theories (Merrill, 2002). The former suggests that in in-egalitarian societies changes in property rights are imposed in a top-down manner by those who are more capable than others in an attempt

${ }^{16}$ As described in 3-3, the technology parameters $\xi_{\alpha}$ and $\xi_{r}$ in Dalton et al. (2005) appear in the equations of motion for the innovation process but not in agents' optimization process; hence the same alternative interpretation as described in the previous footnote is applicable here as well. 
to capture economic rent, whereas the latter suggests that in egalitarian, close-knit societies changes in property rights emerge in a bottom-up manner as a social norm or pressure, by societal members who shares strong common interests (e.g., Barzel, 2000; Kaiser and Roumasset, 2007). ${ }^{17}$ As indicated by Pezzey and Anderies' (2003) interpretation of institutional designs as "social norms, pressures, or taboos", or Dalton et al. (2005) and Good and Reuveny's (2006) representation of the effect of property rights on preferences and innovation paths, these models are consistent with social-norm theories, although in the BT-type models that incorporate property right issues, changes in property rights are exogenous. ${ }^{18}$ Comparatively, as mentioned earlier these models could alternatively be interpreted as being consistent with Ostrom's $(1990,2002)$ finding that an introduction of institutional designs does not have to be interpreted as being driven by more private ownership but instead by "locally evolved institutions and norms", with the existing common ownership.

Meanwhile, there remains an issue of compatibility between most of the BT-type models being static optimization models and the long-term perspectives that motivate

${ }^{17}$ Barzel (2000) analyses the trade-off for a dictator between alternative property right regimes, and Kaiser and Roumasset's (2007) case study of Hawaii is an example of the shift between the bottom-up and top-down evolution of property rights.

${ }^{18}$ While property rights are given exogenously in many studies, some studies incorporate property rights regimes as endogenous variables (e.g., Birdyshaw and Ellis, 2007; Bhattacharya and Lueck, 2009). 
institutional designs or evolution of property rights (and, as discussed in $\mathbf{3 . 4}$, capital accumulation). Although motivated by stronger property rights, with only static optimization provided in the models the aforementioned institutional designs are not based on long-term rationality. Evolution of institutional designs or property rights themselves requires long-term perspectives among individuals. In response to the question of how do norms for sustainable resource use evolve, Ostrom (2002) states that sustainable resource use is likely when long-term stewardship rights are given to compact groups of people who value fairness, trustworthiness, cooperation and reciprocation and who communicate with each other. With such groups of people in society, an introduction of institutional designs or property right regime changes that facilitate sustainable resource use tend to stem from concerns for future. Consequently, there seem to be two reasonable alternatives for the BT-type models to address these issues: (1) switch to multi-period optimization models (e.g., Good and Reuveny, 2006) to introduce the forward-looking views of individuals in general, or (2) while maintaining most individuals' myopic views, assume that someone (e.g., a social planner or a chief) has longer-term perspectives, and regard institutional designs and possibly property right regime changes as representative of such perspectives.

To conclude, both institutional designs and evolution of property rights are useful approaches, and which one (or possibly both) should be incorporated into a model depends on the circumstances to be analysed. For the purpose of using a BT-type model to analyse a compact economy, institutional designs that sustain common-resource 
ownership, along with the mathematical specification and the optimization process of the model that exemplify the chosen approach, are an option.

\section{3-6. Modeling Approach}

Dynamic modeling often faces the trade-off between mathematical representation of intended characteristics of economic activities and mathematical assumptions for the sake

of convenience. In this section, we revisit the issues of substitutability and innovation and extend our analysis to consider alternative approaches to dynamic modeling based on various objectives of using these models.

Certain functions are popular for the easiness with which to obtain analytic solutions, but these functions may not necessarily represent the intended relationships between the relevant variables. As described earlier, most of the BT-type models so far employ linear or C-D production functions and C-D utility functions. These functions are easy to solve for equilibrium outcomes but restrict these models' scope to address substitutability issues $(c f$. 3-2). One way to address this problem is to use a CES function and conduct sensitivity analyses with respect to the elasticity of substitution $\sigma$.

However, there still remains the issue of $\sigma$ being exogenously given and constant across time. What is critical about substitutability is not its static value but the rate of change in this parameter over time (Beltratti, 1997). Introducing innovation into a model can help address the impact of technological progress on substitutability. For 
example, changes in relative scarcity of harvested versus man-made inputs, represented by the relative price of the two inputs, can drive the direction of innovation and affect the value of $\sigma$.

Convenient mathematical assumptions also arise when a model aims to provide a steady-state equilibrium. Neoclassical optimal growth models tend to employ linearly homogeneous functions so that steady-state growth rates can be expressed in per-capita terms. ${ }^{19}$ While this is a generally accepted approach, whether it is desirable to require a steady state in a model of population and resource dynamics depends on the objective of the analysis. In reality an economy may never reach a steady state due to a continuous process of changes and disruptive forces that cause instability (Scrieciu, 2007; Barker, 2008). Most of the BT-type models can be classified as a combination of a static general equilibrium model and a simulation model whose transitional process is given by a set of differential equations. ${ }^{20}$ By design a model of this type requires a static equilibrium for

${ }^{19}$ Edenhofer et al. (2006) provide a general classification for models with innovation and resource issues: (1) optimal growth models (inter-temporal maximization of social welfare), (2) energy system models (cost minimization for the energy sector), (3) simulation models that start with a set of initial values for an economy and calculate the values for the following periods using a set of differential equations, and (4) general equilibrium market models that employ demand and supply analyses in multiple, interdependent sectors.

${ }^{20}$ Good and Reuveny (2006) present an optimal growth model. Basener and Ross (2005) and Basener et al. (2008) provide models that are defined outside the framework of neoclassical economic theory. 
each period; however, such a model does not necessarily need to simplify functions to obtain an analytic solution; instead of solving by hand, computational tools are available to yield numeric solutions for simulation analyses. ${ }^{21}$

\section{Conclusion}

This survey article provides a review of models that demonstrate the interdependency between population dynamics and natural resource dynamics. In particular, we focus on the BT framework and its descendants that are originally designed for a small, closed economy. These models are characterized by the feedback mechanisms between agents' individual, period-by-period optimization of how to allocate their labour endowment and consumption activities and the transitional processes from one period to next given by a set of laws of motion for the population and resource stocks. As a result, the consequences of individuals' static decisions are reflected in the population and resource dynamics. We believe that this branch of literature is of great interest for the study of sustainability issues. This literature prompts us to question our future prosperity, through our reflection on the demise of past civilizations, and also through the understanding of the modeling of population and resource dynamics in general. A little

${ }^{21}$ Another possible direction is to employ a non-equilibrium approach in which we specify behavioural and interaction rules for agents and let the power of a computer reveal the dynamics of the model through repeated simulations (Economist, 2009). 
over a decade has passed since the initial appearance of the BT model, and with various extensions that have contributed to expand the literature in multiple directions as we demonstrated, it seems to be the right time to provide a summary of the literature.

This survey aims to integrate a group of models through a set of attributes that are commonly present across these models, namely, population growth functions, substitutability between man-made and natural goods or inputs, innovation, capital accumulation, property rights and institutional designs, and modelling approach through requirements on the types of solutions and corresponding functional choices. Through our analyses in this manner we aim to elicit how each attribute can be incorporated in various ways to address specific issues of one's interest. We hope that such a survey will facilitate a better understanding of this type of model and further application of the model framework to relevant modern circumstances. We regard the BT model as the skeleton of a general model of population and resource dynamics. As demonstrated by its descendants, the simplicity of the original model leaves room for incorporating variables that allow us to address various issues that are relevant in contemporary economies. ${ }^{22}$

Through our analyses we identify unexplored areas and suggest alternative approaches and interpretations as possible directions of extending the model framework. We are not proposing that a model should encompass every possible feature, but we hope

${ }^{22}$ Brander and Taylor (1998) and Maxwell and Reuveny (2000) provide examples of potential application. 
that highlighting these features in relation to the existing models will stimulate further development of the literature. 


\title{
Chapter 3: Ecological Threshold and Ecological Economic Threshold: Implications from an ecological economic model with adaptation
}

\begin{abstract}
This paper investigates ecological threshold and ecological economic threshold by developing an ecological economic model: an extension of a population-resource dynamics model developed by Brander and Taylor (1998). The model reflects three critical issues concerning an ecological economic system: system boundary, nonconvexity, and adaptation. The main findings are: ecological economic threshold may come first; ecological economic threshold may be highly context dependent and dynamic, which suggests the precautionary principle; market response to an external shock may be insufficient to maintain resiliency; we could restore the system even after passing ecological economic threshold by intervention; various transitional paths could be possible to restore the system; and adaptation may affect resilience in a non-negligible way, which suggests the importance of better information and education. Because of the complexity of the model, the system dynamics approach was used to develop and analyze the model.
\end{abstract}




\section{Introduction}

This paper develops a model of an ecological economic system ${ }^{23}$ in order to enhance understanding of thresholds and resilience.

Since ecological economic systems are 'undeniably' complex (Limburg et al., 2002) because of intertwined relationships between ecological and economic systems, whose characteristics are described with terms such as non-convexity, non-linearity, feedback loops, adaptation, out-of-equilibrium, and thresholds, it is hard to predict how these systems behave and to implement optimal management (Folke et al., 2002). This paper focuses on thresholds, which are a key concept for the resilience of the systems. Currently, despite their critical importance, there is limited understanding of resilience and thresholds related to ecological economic systems (Carpenter et al., 2005).

This paper defines two types of threshold: the ecological threshold (hereafter ET), threshold for an ecological system independent of economic systems, which is also called the minimum viable population or critical depensation (Daly and Farley, 2010), and the ecological economic threshold (hereafter EET), a threshold for an ecological economic system. While it is well known that $E T$ is not a threshold for an ecological economic

${ }^{23}$ In resilience literature (e.g., Folke et al., 2002; Carpenter et al., 2005), a social-ecological system (SES) may be more common but I will use an ecological economic system for my narrower focus on economic systems rather than broader social systems. 
system but a threshold in the absence of human activities, EET has not been well investigated. $^{24}$ In this paper, I will provide a dynamic model to obtain a better understanding of EET, how EET depends on the context, the relationship between ET and EET, how markets respond to disturbances to ecological systems, and what measures could be used to maintain or increase the resilience of an ecological economic system. ${ }^{25}$

The model developed in this paper reflects three key issues that are essential for studying ecological economic systems in general. They are 1) appropriate system boundary, 2) non-convexity of ecosystems, and 3) adaptation. They are particularly important for developing economies, as I discuss in the following section.

The model is an extension of a population-resource dynamics model developed by Brander and Taylor and published in the American Economic Review in 1998 (henceforth the BT model). The BT model is characterized as a general equilibrium version of the Gordon-Schaefer model, using a variation of the Lotka-Volterra predatorprey model. To reflect the three key factors, adaptive mechanisms for price expectations and a variant of the logistic function proposed by Taylor (2009) for the dynamics of a natural resource that reflects a threshold are incorporated into the BT model.

${ }^{24}$ Kahn and O’Neil (1999) and Muneepeerakul and Qubbaj (2012) point out the similar point developing a model but their models do not model economic systems and adaptation.

${ }^{25}$ In addition to the use of a model, Carpenter et al. (2005) suggest three other approaches to investigate resilience. They are stakeholder assessments, historical profiling, and case study comparison. 
Because of the complexity of the model, I adopt a system dynamics approach, which uses computer simulations to analyze complex systems (e.g., Sterman, 2000). As Nagase and Uehara (2011) discuss, there are two ways of the use of modeling: use a model for replication and use a model as a tool. The purpose of the use of the BT model for this paper is the latter. This paper uses the BT model as a tool to investigate various possible scenarios. While the eventual target of the model is its application to today's developing economies, the model fitness to historical data of a certain economy is not the main focus because developing economies are facing unprecedented phenomena. For example, Lech et al. (2011) describe the current phenomenon as "complex and dynamic" in which environmental conditions, developments in science and technology, social systems and economic systems are changing more rapidly. A UN report (UNESCAP, 2010) called the unprecedented phenomenon "a new economy" in which natural resource constraints are largely defining the future outlook, and a new economic paradigm is needed.

\section{Background}

\subsection{The Three Key Issues}

Economic models have been developed in order to study the sustainability of an economic system, and most of them are extensions of either a neoclassical growth model (e.g., Dasgupta and Heal, 1974; Solow, 1974a; Stiglitz, 1974) or endogenous growth 
theory (e.g., Bretschger, 2005; Bretschger and Smulders, 2006; Pittel, 2002). Whichever growth theory is adopted, these economic models share a preference for simplification. Such simplifications are sensible provided that, as Robert Solow (1956) puts it, "the final results are not very sensitive" (p.65) to such simplifications. Since an ecological economic system is complex, the model of the system should contain an appropriate level of complexity, with appropriate simplifications. Here I will discuss the importance of the aforementioned three issues that represent complexity necessary for an ecological economic model to be able to provide useful policy insights for developing economies.

1. System Boundary. Since an ecological economic system is undeniably complex (Limburg et al., 2002), it is critical to set an appropriate boundary of the system. Specifically, population, economic growth, and natural resources should all be treated as endogenous variables within the boundary of the system (Dasgupta, 2008). When a variable is treated as exogenous, the feedback loops amongst the variables are lost. Consideration of these feedback loops has not been the primary focus of modern growth economists. New growth theory depicts economic growth and natural resources endogenously, but with a fixed (or zero) population growth on the one hand. On the other hand, unified growth theory treats economic growth and population as endogenous, but natural resources are not incorporated into the models. These assumptions may be sensible for studying an economic system where natural resource constraints and population dynamics do not play significant roles. However, when it comes to developing economies, these are among the most critical issues. Treating ecological 
systems and economic systems separately is "a poor choice of boundary" (Costanza et al., 1993). The lack of their strong interactions in a model results in severe misperceptions and even policy failures (Costanza, 1987). Folke et al. (2002) call the two assumptions adopted in policy making practices the fundamental errors underpinning past policies for natural resource issues: an assumption that ecosystem responses to human use are linear, predictable and controllable; an assumption that human and natural systems can be treated independently. Dasgupta and Mäler (2003) assert that to drop natural resources from a model is not sensible when studying development possibilities today. This argument is supported empirically as well. For example, a report by the United Nations (UNESCAP, 2010) shows that natural resource constraints actually have an impact on the growth of developing economies. In sum, to set an appropriate system boundary, it is necessary to incorporate endogenously population, natural resources, and economic growth.

2. Non-convexity of ecosystems. Concerning natural resources, in contrast to the abundance of studies on the dynamics of non-renewable resources and economic growth, much room remains for studies on the modeling of renewable resources in conjunction with economic growth. A key is to reflect "ecosystem non-convexity" (Dasgupta and Mäler, 2003) or a "non-marginal system" (Limburg et al., 2002) that enables us to address more fully the complexity of the dynamics of renewable resources. Nonconvexity of ecosystems often indicates the existence of multiple equilibria, thresholds, and positive feedback loops (Dasgupta and Mäler, 2003). One example of such non- 
convexity is that a renewable resource has a threshold (or critical depensation level or minimum viable population (Daly and Farley, 2010)). To incorporate non-convex ecosystems into an economic model is particularly important for two reasons (Dasgupta and Mäler, 2003). First, developing economies, especially poor economies, often have to operate very close to the threshold. Once an ecological economic system passes the threshold for overusing natural resources, positive feedback drives the system to a different state of equilibrium (often to a bad state). Second, poor economies often depend heavily on natural resources and do not have the substitutes available to rich countries. There are also empirical supports that some economies have already passed their thresholds (e.g., Rockstrom et al., 2009). In sum, although identifying the locations of these thresholds is often difficult (Daly and Farley, 2010), their impact is not negligible so we must strive to better understand their roles if our aim is to study the implications of policy interventions.

3. Adaptation (learning). Most economic models employ the presumption of instantaneously achieved equilibrium states, neglecting adaptation or learning processes that allow a system to be in an out-of-equilibrium state. When the state of the system is expected to change gradually, ignoring adaptation may not make any notable differences. However, this may not be the case where the state of a system changes rapidly or a sudden external shock occurs. In such situations, agents may have imperfect information and cannot make the rational decisions assumed in instantaneous equilibrium models. Under such circumstances, incorporating adaptation processes into a model could 
contribute to a better depiction of the dynamics of the system. An economy dependent significantly on non-convex ecosystems may have such an attribute. As Leach et al. (2010) maintain, today's world is highly complex and dynamic in the sense that system state is changing dynamically at a rapid pace. In the context of sustainability and resilience, the importance of adaptation and out-of-equilibrium has been often pointed out (e.g., Folke et al., 2002; Leach et al., 2010; Levin et al., 1998; Solow, 1974b). Meanwhile, modeling out-of-equilibrium has not been developed well. Modeling adaptation or learning is a prevailing subject in modern macroeconomics (e.g., Arifovic and Maschek, 2006; Evans and Honkapohja, 2011), but such modeling approaches to adaptation have not been applied to natural resource issues, save a few exceptions (e.g., Hommes and Rosser, 2001 and Forini et al., 2003). ${ }^{26}$ Adaptation is likely to be a nonnegligible theme in developing economies where the available information is often more limited. In sum, because of the important roles it plays for sustainability and resilience, adaptation that allows for out-of-equilibrium states can provide further insights that instantaneous equilibrium models could not provide.

${ }^{26}$ Adaptation here is a narrower concept and is different from "adaptive management" recently often used in sustainability issues in the sense that the former focuses on how to form an expectation of some variables in the future such as prices. This use of the term is similar to the one used in adaptation or learning in macroeconomics. 


\subsection{Resilience and Sustainability}

Resilience and sustainability are two major criteria to evaluate an ecological economic system. In economics, sustainability or intergenerational equity has been a major focus. The first major contributions are made by Dasgupta and Heal (1974), Solow (1974a), and Stiglitz (1974). Solow (1974a) suggests an operational notion of sustainability which has been often used by later economists. Adopting the notion of John Rawls, Solow forms the problem of sustainability as the maximization of constant consumption per capita which satisfies the max-min principle. There have been various definitions of sustainability proposed since then. The Hartwick rule (Hartwick, 1977) is a practical rule which satisfies the constant per capita consumption criteria. Instead of consumption, Pezzey (1989) proposes non-declining utility. Later, Pezzey with Toman propose an opportunity-based judgment instead of utility-based judgment, that is, nondeclining wealth or aggregate capital (Pezzey and Toman, 2005).

Those concepts could be appropriate when an ecological economic system behaves well (i.e., its dynamics are predictable and controllable). However, when ecological and economic systems are highly interdependent, as Dasgupta and Mäler (2003) argue, the system may have positive feedback processes, thresholds, and multiple equilibria. In this case, the system could cross a threshold and result in a sudden change in the behavior of the system, which could lead to a collapse. Most concepts of sustainability may not reflect this possibility. In reality, however, the possibility of 
thresholds followed by sudden changes in system behavior, are a realistic issue, especially in developing economies. The concept of resilience introduced to my model takes into account such a possibility. ${ }^{27}$

Resilience is a concept rooted in ecology (e.g., Holling, 1986; Pimm, 1984) but it has been also recently been applied to ecological economic systems. ${ }^{28}$ For ecological economic systems, Holling and Walker (2003) provide the following explanation of resilience:

"Resilience," as applied to ecosystems or to integrated systems of people and natural resources, has three defining characteristics:

- The amount of change the system can undergo and still retain the same controls on function and structure (still be in the same state, within the same domain of attraction)

- The degree to which the system is capable of self-organization

- The ability to build and increase the capacity for learning and adaptation

${ }^{27}$ It should be noted that while sustainability is a normative concept, resilience is a descriptive concept.

${ }^{28}$ For example, Environment and Development Economics (1998, (3), 221-262) published a policy forum on the resilience of ecological economic systems. 
The main attribute of the resilience is the first statement. The second and the third definition complement the first. In this paper, I follow an operational definition of resilience proposed by Derissen et al. (2011), specified as follows:

The ecological-economic system in state $\left(x\left(t_{\Delta}\right), w\left(t_{\Delta}\right)\right)$ is called resilient to disturbance by an actual shock $\Delta$ at time $t_{\Delta}$ if and only if the disturbed system is in the same domain of attraction in which the system has been at the time of disturbance:

$$
\left(x\left(t_{\Delta}\right), w\left(t_{\Delta}\right)\right) \in A_{i} \rightarrow\left(x\left(t_{\Delta}+d t\right), w\left(t_{\Delta}+d t\right)\right) \in A_{i}
$$

where $A_{i}, x\left(t_{\Delta}\right)$, and $w\left(t_{\Delta}\right)$, are respectively $i$ th domain of attraction, and two different types of natural stock at time $t_{\Delta \cdot}^{29}$

Because my model incorporates the non-convexity of natural resource, I will focus on the resilience of the system rather than its sustainability. ${ }^{30}$

${ }^{29}$ In my model, there is only one type of natural resource stock, $S$.

${ }^{30}$ Resilience is often seen as a necessary condition for sustainability (e.g., Mäler, 2008; Arrow et al., 1995). However, Derissen et al. (2011) show that their relationship (i.e., necessary and/or sufficient) depends on the situation. 


\section{Model}

\subsection{The Baseline Model}

The BT model stylizes causal relationship between a population growth, resource growth, and their effects on the state of the economy, and it has been applied to the economy of Easter Island to demonstrate its historical boom and bust. The BT model is characterized as a general equilibrium version of the Gordon-Schaefer Model, using a variation of the Lotka-Volterra predator-prey model. Resource $(S)$ dynamics and Population $(L)$ dynamics are given by (dropping the time argument for convenience)

$$
\frac{d S}{d t}=G(S)-H=r S\left(1-\frac{S}{S_{\max }}\right)-H
$$

where $G(S), r, S_{\max }$, and $H$ are a logistic growth function of $S$ (or sustainable-yield), the intrinsic growth rate, the carrying capacity, and the harvest of $S$, respectively, and

$$
\frac{d L}{d t}=L\left(b-d+\phi \frac{H}{L}\right)
$$

where $b-d$ and $\phi$ are respectively the net base rate of population increase and a positive fertility parameter. The population dynamics is Malthusian in the sense that higher per-capita-consumption of the resource good leads to higher population growth. The economy consists of two sectors, the harvested good $(H)$ and the manufactured good $(M)$.

At any point in time, the production functions for goods $H$ and $M$ are given by 


$$
H^{P}=\alpha S L_{H}
$$

$M^{P}=L_{M}$

where $\alpha, L_{H}$ and $L_{M}$ are respectively a productivity coefficient, labor allocated to producing $H$ and labor allocated to producing $M\left(L_{H}+L_{M}=L\right)$.

A representative consumer who is endowed with one unit of labor maximizes utility:

$$
u=h^{\beta} m^{1-\beta}
$$

subject to the budget constraint

$$
P_{H} h+P_{M} m=w,
$$

where $h, m, \beta, P_{H}$, and $P_{M}$ are respectively individual consumption of $H$ and $M$, preference for consumption of $H$, and price for $H$ and $M$.

Solving the representative consumer's and producers' maximizing problems, we can get the reduced forms of the laws of motion:

$$
\begin{aligned}
& \frac{d S}{d t}=r S\left(1-\frac{S}{S_{\text {max }}}\right)-\alpha \beta L S \\
& \frac{d L}{d t}=L(b-d+\phi \alpha \beta S)
\end{aligned}
$$

Three characteristics of the model are worth highlighting. First, the harvest $H$ is determined endogenously as the result of an economic activity explained by a general equilibrium model. Second, agents in this model face a period-by-period optimization problem, without taking into account any consequences of the future resource availability 
and population size. It would be a reasonable assumption for a situation where the resource stock is in open access and the agents are atomistic (Taylor, 2009). Third, at each moment of time, the economy reaches a temporary general equilibrium instantaneously given fixed amounts of natural resource stock and population at that point in time. Since the natural resource stock and population will change over time, so do the equilibrium prices and quantities.

\subsection{Methods: Main Extensions}

The model expands the BT model to reflect the three key issues: appropriate system boundary, non-convexity of natural resources, and adaptation. Since the BT model reflects an appropriate system boundary (i.e., population dynamics, natural resource, and economic growth are modeled as an endogenous variable), non-convexity of natural resources and adaptation are additionally incorporated. To build the model, a system dynamics approach is adopted. Because the extended model includes many components and some of them are technical, I focus here on explaining how non-convexity and adaptation are incorporated in the model. For the purpose of replication of the results in this paper, a full list of equations for the model in Vensim format will be provided upon 
request. $^{31}$ The full model using the stock and flow diagram can be found in the Appendix A.

\subsubsection{The Non-Convexity of Natural Resources}

While the natural growth function in the BT model does not include a threshold, I include a threshold to reflect the non-convexity of a natural resource growth. The formulation follows Taylor (2009) who uses the form to incorporate crisis into the BT model.

$$
G(S)=r(S-T)\left(1-\frac{S}{S_{\max }}\right)
$$

$T$ represents the $E T$. Once the resource stock size $S$ is smaller than $T$, even zero harvesting cannot recover $S$. The interpretation of $T$ depends on the situation. For example, if $S$ is a forest, crossing $T$ could mean soil erosion due to lower $S$ intensifies a decline in $S$. It should be noted that the rate of growth at $S=0$ is strictly negative, meaning that "since a negative stock is not possible, these dynamics will imply a sudden

${ }^{31}$ Parameters used by Brander and Taylor (1998) are adopted except for variables newly added such as the threshold $T$ and adjustment times. To reflect the current unprecedented rapid changes in developing economies (e.g., Leach et al., 2010), the rates of change are assumed to be per year instead of per decade as specified by Brander and Taylor. 
stop to stock depletion as the $S=0$ barrier is crossed. This has the flavor of a car hitting a brick wall at $S=0$ and decelerating to zero instantaneously" (Taylor, 2009, p.1250).

\subsubsection{Adaptation}

Adaptation or learning is applied to producers' learning prices for good $H$ and $M$ to make production decisions.

There are many variations of learning that can be used to model bounded rationality. For example, there is a growing literature in macroeconomics (e.g., Arifovic and Maschek, 2006; Evans and Honkapohja, 2011). Learning in macroeconomics refers to models of expectation formation in which agents revise their forecast rules over time as new data becomes available (Evans and Honkapohja, 2008). To be consistent with the cognitive consistency principle, agents are assumed to be about as smart as (good) econometricians (Evans and Honkapohja, 2011). ${ }^{32}$

Instead of assuming agents to be econometricians, I adopt simple adaptive expectations (Nerlove, 1958; Sterman, 2000). For the purpose of this model, however, such an assumption is problematic. The imperfect knowledge of agents is due to the complexity of an ecological economic system in which we even do not know the

${ }^{32}$ The most commonly used estimation method may be the recursive least squares (RLS) (Evans and Honkapohja, 2008). Another approach is the sample autocorrelation (SAC) learning which is, for example, applied to the learning of prices for a fishery market (Hommes and Rosser, 2001). 
probability of, for example, passing the threshold of the global climate. Hence learning without assuming the knowledge of probability could be more appropriate for the present model. ${ }^{33,34}$ Because of its simple learning structure, it is relatively easy to interpret outcome. Agents' knowledge and skills are assumed to be more bounded and they gradually update their beliefs using a simple rule instead of a sophisticated econometric learning as they find the gap between their beliefs and the actual value of the variable.

Adaptive expectations are applied to producers' price expectations in the $H$ and $M$ industry as;

$$
p_{i, t}^{e}=p_{i, t-1}^{e}+\frac{1}{A T_{i}}\left(p_{i, t-1}-p_{i, t-1}^{e}\right) \quad A T_{i} \geq 1, i=H, M
$$

where $p_{i, t}^{e}$ is the producers' expected price of $i$ for $t$ at $t-1, p_{i, t-1}$ is the market price of $i$ at $t-1$ and $A T_{i}$ is the adjustment time or the speed of adjustment for $i$.

In addition, market prices are assumed to be non-market clearing, to make the adaptive characteristics of an ecological economic system more realistic. The dynamics

${ }^{33}$ This formation is in line with the Post Keynesian uncertainty which asserts that probability distributions are not the basis for comprehending real world behavior under uncertainty (Davidson, 1991).

${ }^{34}$ There are four sources of imperfect knowledge; risk, ambiguity, uncertainty, and ignorance (Common and Stagl, 2005) that are sorted based on the availability of the information about probabilities and outcomes. 
of market price follows the simplest tatonnement process or "market groping" (Day, 1994), defined as follows:

$$
p_{i, t}=p_{i, t-1}+\frac{1}{A T}\left[\frac{D_{i}\left(p_{i, t-1}\right)}{S_{i}\left(p_{i, t-1}\right)}\right], i=H, M
$$

where $D_{i}\left(p_{i, t-1}\right), S_{i}\left(p_{i, t-1}\right)$, and AT are quantity demanded at $t-1$, quantity supplied at $t-1$ for $i$, and a fixed adjustment time for both $H$ and $M$.

My model allows market transactions while the market is seeking a marketclearing price, although market transactions are generally not allowed in the tatonnement process until the market-clearing price is found (Takayama, 1974). In other words, nonperishable goods are assumed for $H$ and $M$ in the present model.

Once price expectations are formed, expected wages for $H$ and $M$ are formed as well. Since total revenues are paid exclusively to labor in both $H$ and $M$ industry, assuming zero rent, expected wages are computed as:

$$
w_{i, t}^{e}=\frac{p_{i, t}^{e} \times Q_{i, t-1}}{L_{i, t-1}}, i=H, M
$$

where $w_{i, t}^{e}, Q_{i, t-1}, L_{i, t-1}$ are respectively expected wage for industry $i$ for $t$, quantity sold in industry $\mathrm{i}$, and labor in industry $i$ at $t-1$. While adaptive expectations are applied to the price expectation, the quantity sold and labor applied are at the current state. This is a simplification and can be interpreted as a naïve expectation (i.e., expected value $=$ current 
value). Since wages should be equal in equilibrium, labor allocation between $H$ and $M$ industry continues until wages are equalized.

In sum, the model has a self-referential feature (Branch, 2004; Davidson, 1991); the [next] system state depends on expectations, which depend in turn on the [current] system state.

\section{3. $\quad$ Model Testing}

\subsubsection{Learnability of equilibrium}

Since the model adopts a general equilibrium structure as a base, the markets should be moving towards equilibrium. When the natural resource $S$ and population $L$ are changing, the system is always seeking market clearing prices under new $S$ and $L$ and is therefore often out of equilibrium. To examine the validity of the model, the dynamics of the model are tested with $S$ and $L$ kept constant (i.e., $d S / d t=d L / d t=0$ ) to see whether the model can find an equilibrium. ${ }^{35}$

${ }^{35}$ Learnability here simply means that expected prices converge to actual market prices. Learnability in macroeconomics provides more sophisticated discussions and definitions. For example, there are several concepts of learnability or convergence to equilibrium such as Rational Expectations Equilibrium (REE), Restricted Perceptions Equilibrium (RPE), and Consistent Expectations Equilibrium (CEE). A good summary on these equilibria is made by Branch (2004). 
The dynamics were tested by raising the market price for $H, P_{H}$, by 10 at $t=10$ as a shock. To see the effect of different adjustment times (AT) for price expectations of $H$ and $M$, four combinations of them were tested: (1) both adjustments were relatively quick $\left(\mathrm{AT}_{\mathrm{H}}=\mathrm{AT}_{\mathrm{M}}=2\right) ;(2)$ both adjustments were relatively slow $\left.\left(\mathrm{AT}_{\mathrm{H}}=\mathrm{AT}_{\mathrm{M}}=4\right) ; 3\right)$ adjustment for $P_{H}$ was relatively slow $\left(\mathrm{AT}_{\mathrm{H}}=4\right.$ and $\left.\mathrm{AT}_{\mathrm{M}}=2\right)$; and 4$)$ adjustment for price $M$ was relatively slow $\left(\mathrm{AT}_{\mathrm{H}}=2\right.$ and $\left.\mathrm{AT}_{\mathrm{M}}=4\right)$.

Because of a general equilibrium setting, a shock on the $H$ market affects the $M$ market as well. When $P_{H}$ changes, the change affects $w_{H, t}^{e}$ which leads the relative wage, $w_{H, t}^{e} / w_{M, t}^{e}$ to differ, causing labor reallocation between the $H$ industry and the $M$ industry. Different labor allocation to the $M$ industry affects the production of $M$ as well.

Figure 3.1.a through 3.1.d show the results. In all four cases, fluctuations of the price expectations for both commodities are moderated compared with their actual market prices. This is because suppliers do not reflect the price change totally (i.e., naïve expectations); instead, they update their expectations only partially. Although there are some differences in behavior for different combinations of ATs, they are not so obvious given $d S / d t=d L / d t=0$. But these differences may be non-negligible when $S$ and $L$ are endogenous as shown in the next section. 


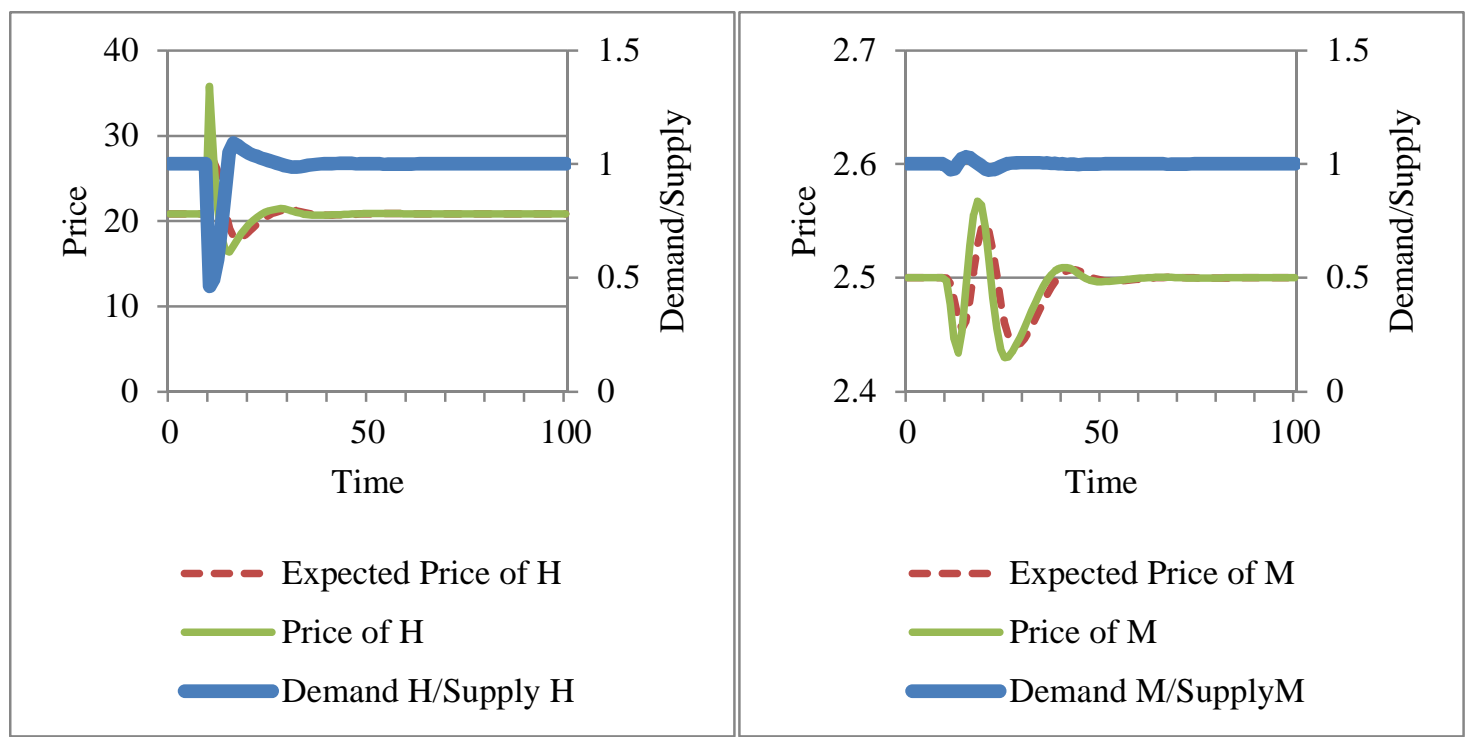

Figure. 3.1.a. $\mathrm{AT}_{\mathrm{H}}=\mathrm{AT}_{\mathrm{M}}=2$

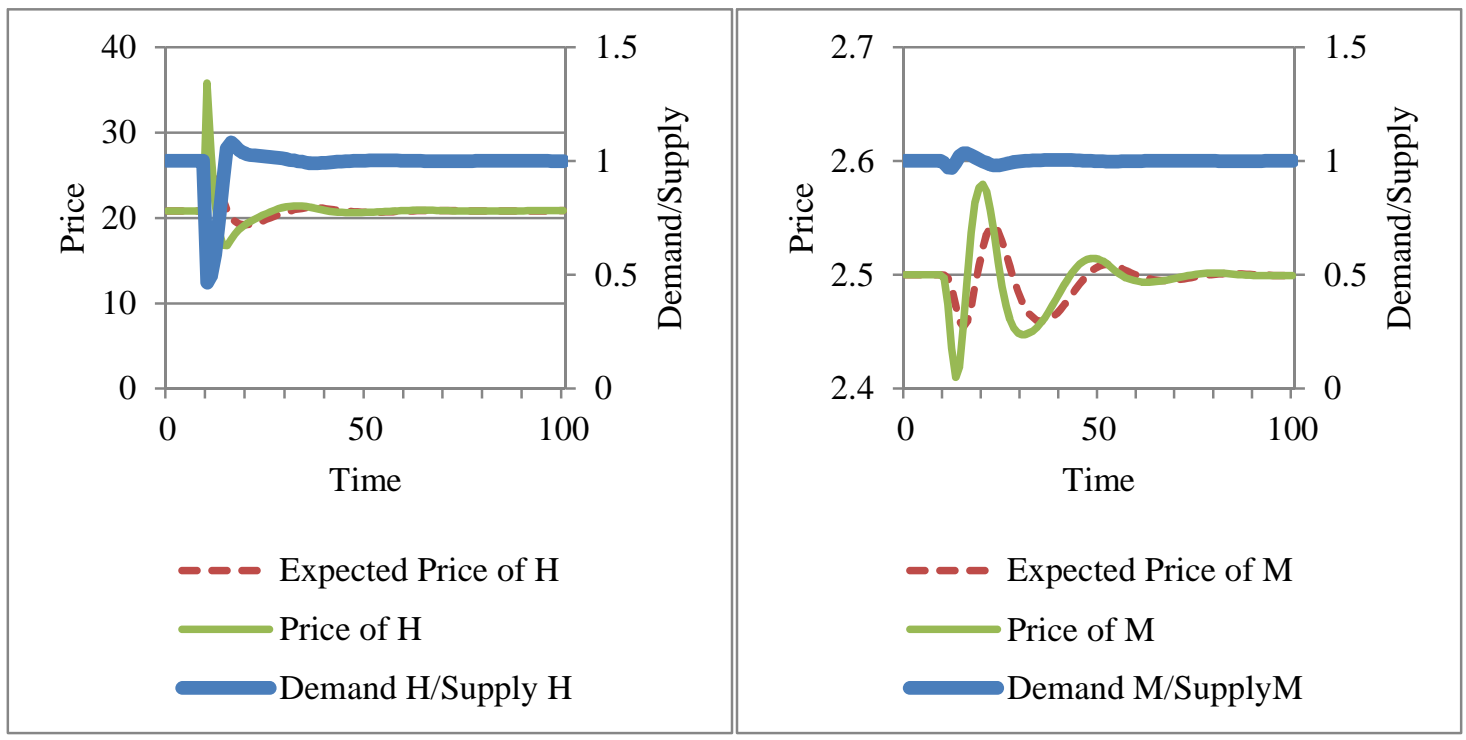

Figure. 3.1.b. $\mathrm{AT}_{\mathrm{H}}=\mathrm{AT}_{\mathrm{M}}=4$ 


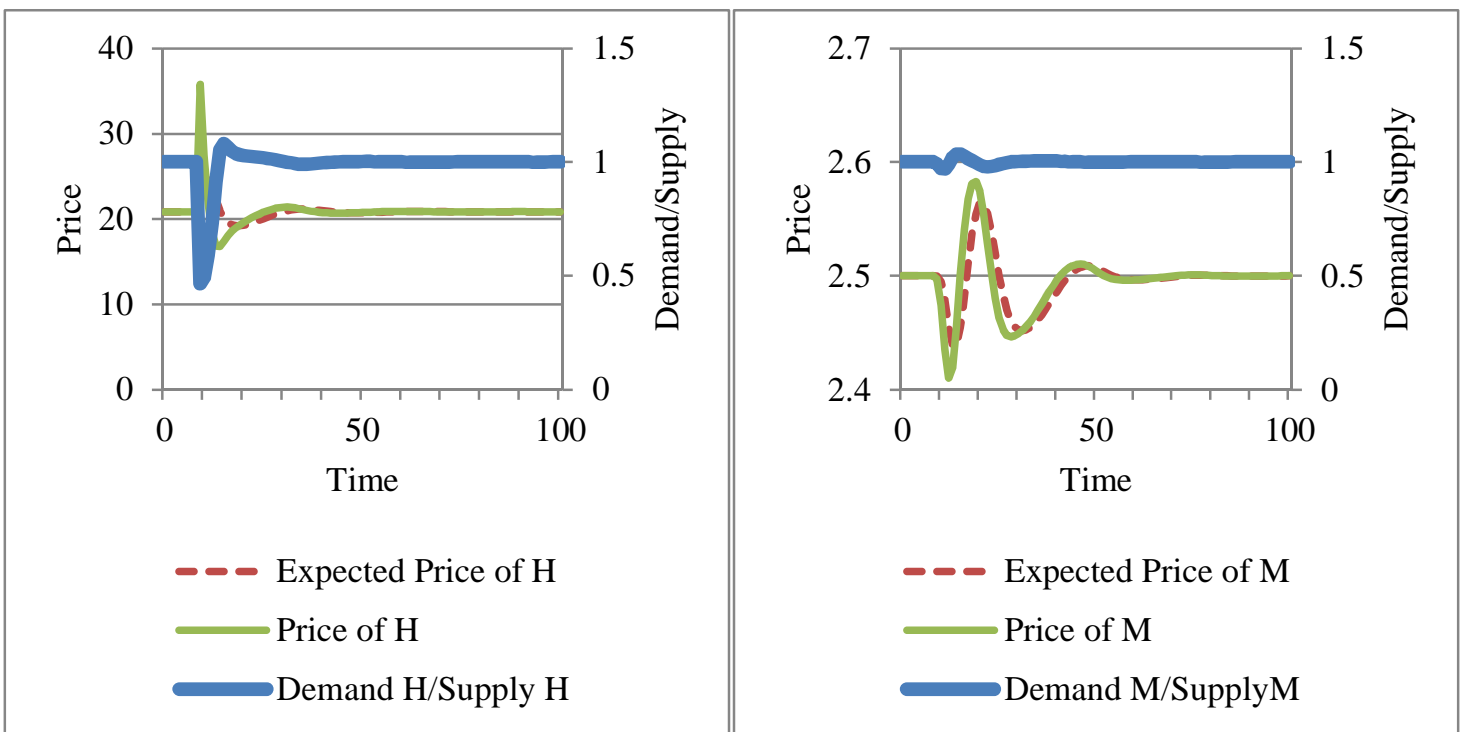

Figure. 3.1.c. $\mathrm{AT}_{\mathrm{H}}=4, \mathrm{AT}_{\mathrm{M}}=2$

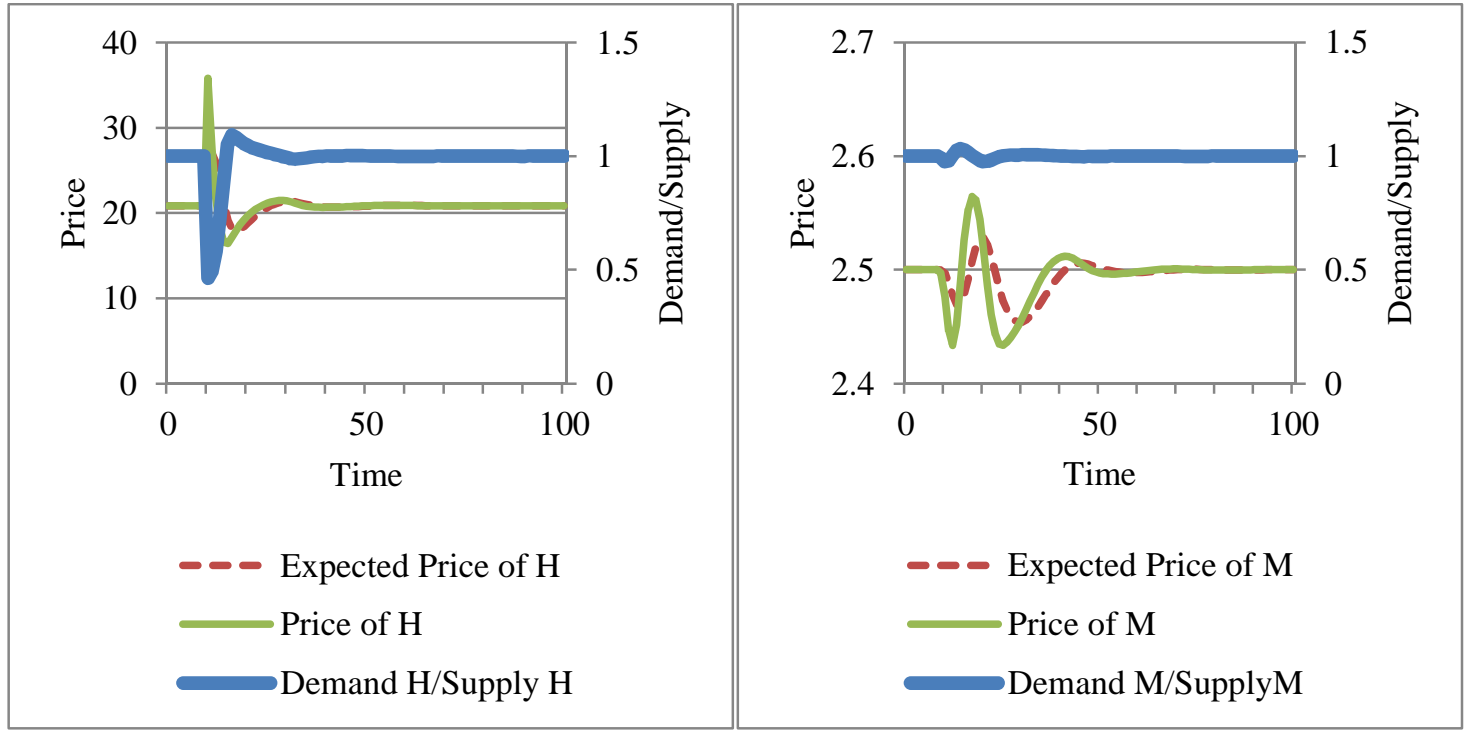

Figure. 3.1.d. $\mathrm{AT}_{\mathrm{H}}=2, \mathrm{AT}_{\mathrm{M}}=4$ 


\subsubsection{Comparison of the Original BT with the Extended Model}

To see the impact of different ATs on population and a natural resource, five simulations are reported and compared. These five variations are: without adaptation (i.e., zero adjustment time), and the four different combinations of ATs. Sensitivity analysis using different combinations of ATs helps us to see the variability of results for different ATs.

There are three points worth highlighting. First, with the same ATs, the trough of the natural resource and the peak of population arrive slower than observed in the model without adaptation. This is because the model for the adaptation process involves delays. Second, the results do not change very much when both ATs are changed by the same degree. This is because in the baseline simulations variables change gradually, and expectations remain close to actual prices. Third, when different ATs are applied to each industry, however, the dynamics of the natural resource and the population change significantly. A longer AT indicates that agents will respond to a change slowly. When agents in both industries update their expected prices at the same speed (i.e., cases for $\mathrm{AT}_{\mathrm{H}}=\mathrm{AT}_{\mathrm{M}}=2$ and $\left.\mathrm{AT}_{\mathrm{H}}=\mathrm{AT}_{\mathrm{M}}=4\right)$, the relative expected wage, $w_{H, t}^{e} / w_{M, t}^{e}$, does not change very much, as shown in Fig. 3.2.c. However, when their adjustment speeds are different, their expected prices and the resultant expected wages will change at different rates, which has a more significant impact on the natural resource and on Population. 


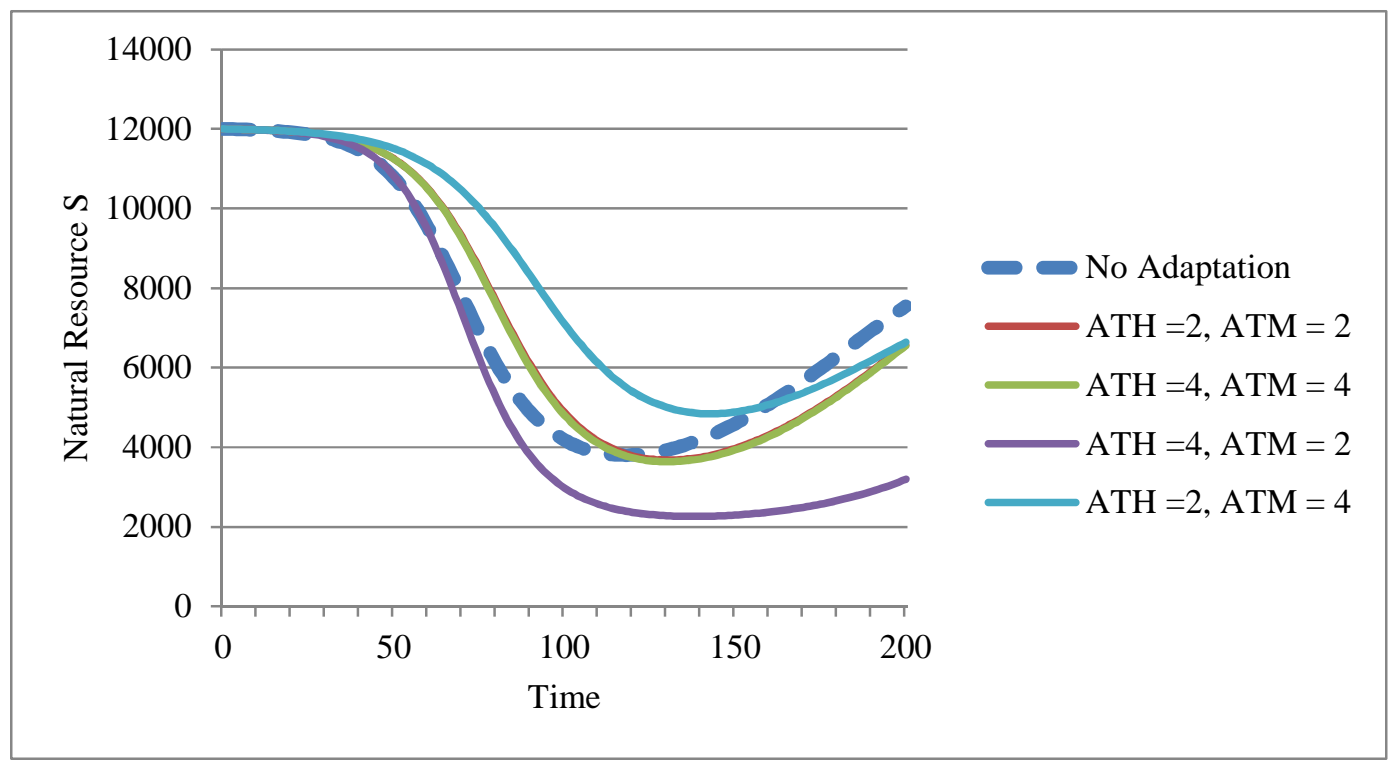

Figure 3.2.a. Natural Resource

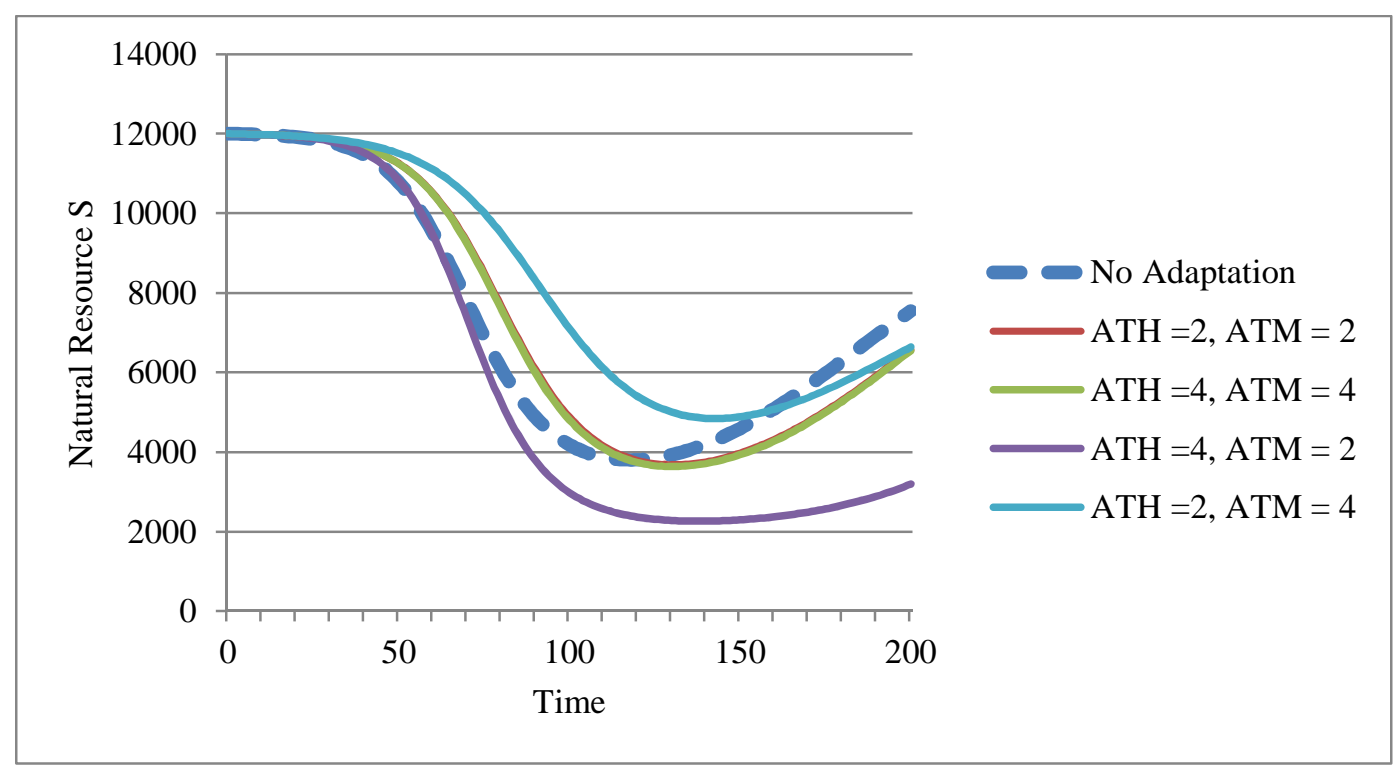

Figure 3.2.b. Population 


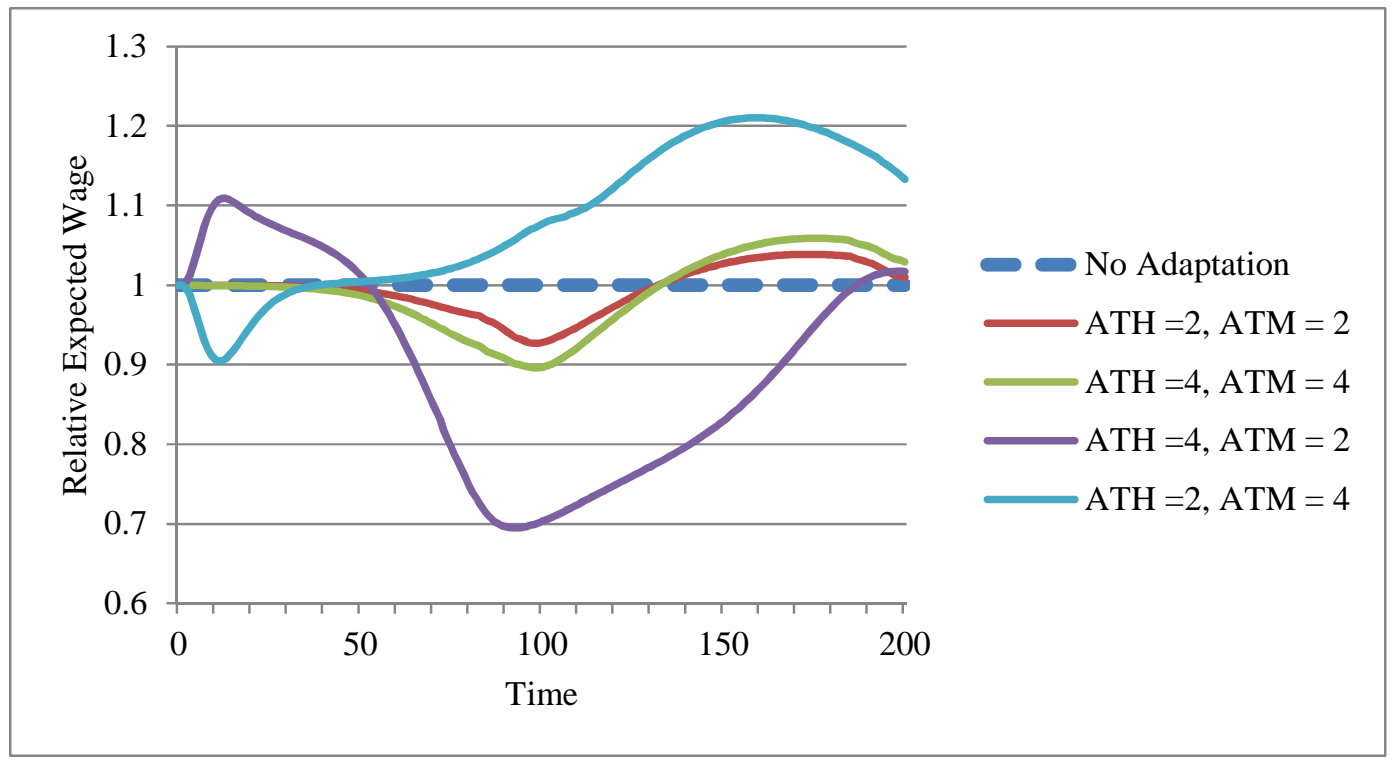

Figure 3.2.c. Relative Expected Wage

In the simulation results of the case (3), both $P_{H}$ and $P_{M}$ decline initially. When the market prices are going down, the $H$ industry with a longer AT will stick more to previous higher prices and will not lower the expected price and expected wage, relative to the expected price and expected wage by the $M$ industry with a shorter AT, resulting in a higher relative wage. With the higher relative wage, more labor is allocated to the $H$ industry and more natural resources are exploited, as shown in Figure 3.2.a. Since the consumption of $H$ influences population growth rate, population reaches a higher peak, as shown in Figure 3.2.b. Interestingly even though adaptation processes take time, model behavior when adaptation is included does not necessarily mean that the overall system response is "slower" when compared to the instantaneous equilibrium model without 
adaptation. This is possible because of the nonlinear impact of reinforcing feedback loops.

This result reinforces the importance of setting an appropriate system boundarya boundary that allows researchers to study more fully the interdependencies between population and natural resources.

\section{Results}

In this section, I show how the models with and without adaptation respond to an external shock. Here the external shock is a hypothetical shock that suddenly reduces the stock of the natural resource $S$. This could be due to a natural disaster such as an earthquake and/or tsunami.

\subsection{The Impact of an External Shock: The Model without Adaptation}

Figure 3.3.a. through 3.3.f. show the results obtained from the model without adaptation under three different cases: no external shock (Case 1), a smaller external shock (Case 2), and a larger external shock (Case 3). Figures on the left side show the dynamics of $S$. Figures on the right side show a phase plot for the sustainable-yield, $G(S)$, (red line) and the harvest $H$ (blue line). Ecological threshold, $E T$, is set as $S=$

2,000. To show the eventual convergence of $S$, figure 3.3.b. and 3.3.d. show the results with longer simulation periods $(t=1000)$. Case 1 shows that $H$ converges to the 
sustainable yield in the long run (Fig.3.3.b). In Case 2, although $S$ declines suddenly (Fig.3.3.c), it restores to the level where $H$ equals to $G(S)$ (Fig.3.3.d). Hence the system is resilient against this smaller external shock at $t=100$. Case 3 shows an interesting result. Because of a larger external shock, the system crosses $E T$ and $S$ goes zero in the end. What should be noted here is that the external shock does not reduce $S$ below the $E T$ instantaneously. It is because of the EET by the shock that cause $S$ to go extinct in the end. This indicates, without economic activities, $S$ should recover after the shock, which is shown in the dashed line in Fig.3.3.e. After the external shock, $S=2,337>2,000$. $S$ ends up crossing $E T$ because of the interaction between the ecological and economic systems. As shown in Fig.3.3.f., since $H$ is larger than $G(S), S$ keeps declining after the shock. This tells us that to maintain system resilience, we should pay more attention to the ecological economic threshold, EET, rather than the ecological threshold, ET. Even if the external shock alone does not reduce $S$ below ET, $S$ becomes zero if the external shock reduces $S$ below $E E T$. 


\section{Case 1: No External Shock}

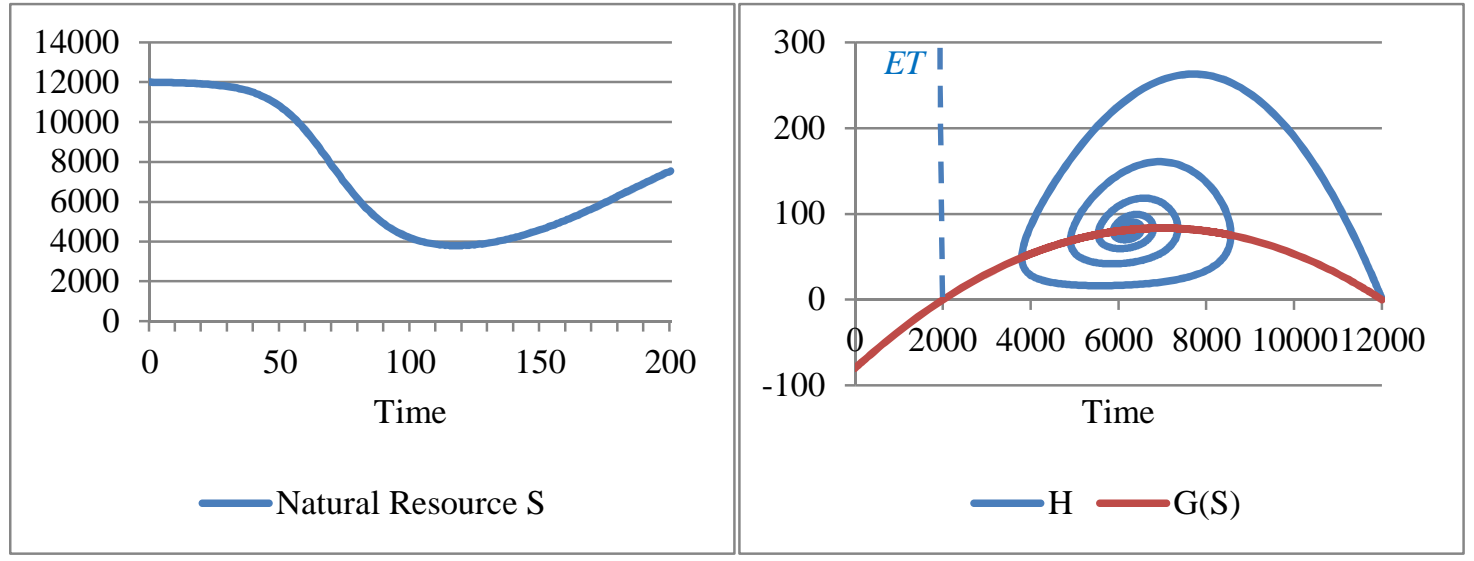

Figure 3.3.a Natural Resource $S$

Figure 3.3.b Phase Plot for $S, H$, and $G(S)$

Case 2: A Smaller External Shock ( $S$ declines by 1,000 at time $\mathrm{t}=100$ )

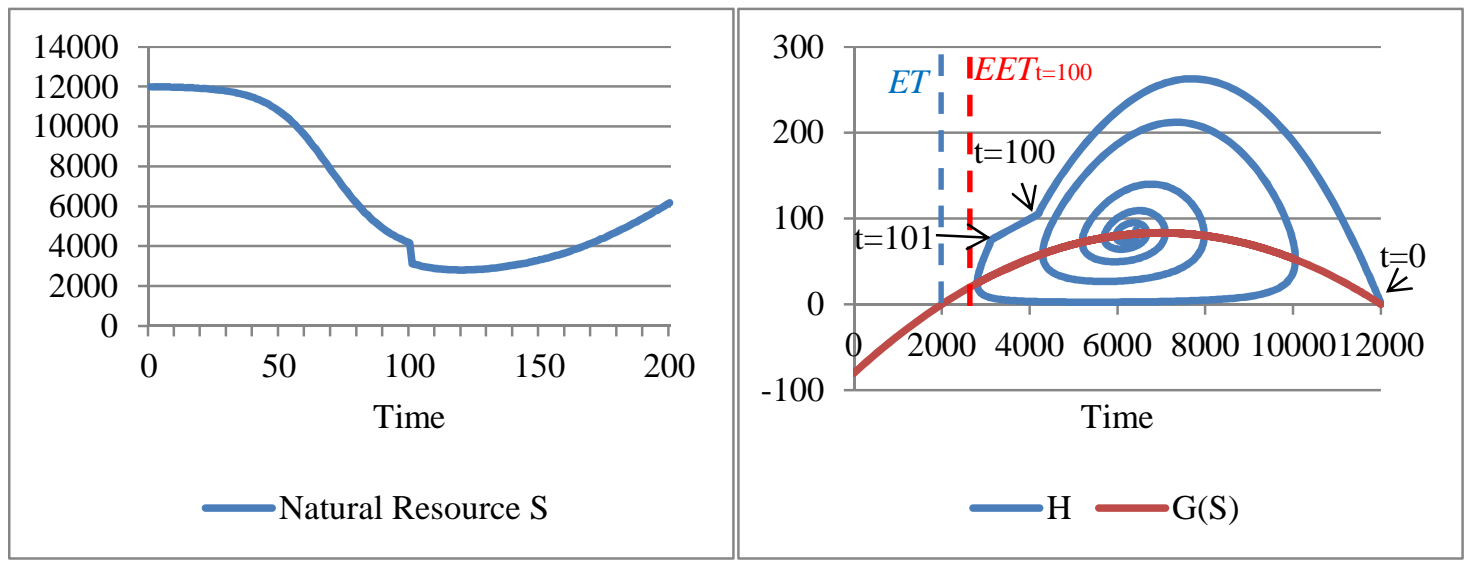

Figure 3.3.c Natural Resource $S$

Figure 3.3.d Phase Plot for $S, H$, and $\mathrm{G}(S)$

$* \operatorname{EET}_{\mathrm{t}=100}=2,639$ 
Case 3: A Larger External Shock ( $S$ declines by 1,800 at time $\mathrm{t}=100$ )

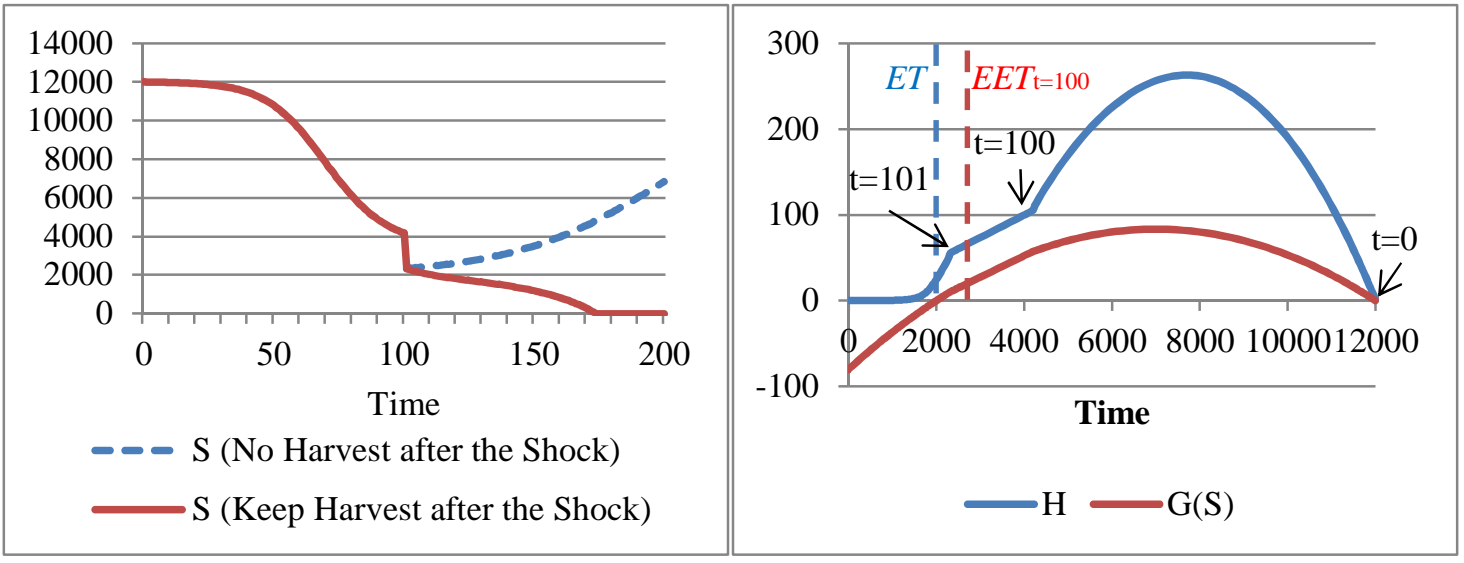

Figure 3.3.e Natural Resource $S$

Figure 3.3.f Phase Plot for $S, H$, and $G(S)$

$* \mathrm{EET}_{\mathrm{t}=100}=2,639$

The model adopts a general equilibrium structure as a base, hence it allows us to investigate how the economic systems respond to an external shock. The reduced-form solution of the original BT model provides useful insights into the system outcome. The temporary equilibrium $P_{H}$ is $1 / \alpha S$; the temporary equilibrium quantity is $\alpha \beta L S$. Therefore, with an external shock that reduces $S, P_{H}$ will go up and the harvest will go down. However, the response via price signals may not be enough to avoid a collapse, or passing EET, as shown in Fig.3.3.e and 3.3.f. To avoid passing EET, the following condition has to be satisfied:

$$
\frac{d S}{d t}=r(S-T)\left(1-\frac{S}{S_{\max }}\right)-\alpha S L_{H} \geq 0 .
$$

Hence the $E E T$ is reached when 


$$
S=\frac{\zeta+\sqrt{\zeta^{2}+4 T S_{\max }}}{2} \quad \text { where } \zeta=S_{\max }+T-\frac{\alpha L_{H} S_{\max }}{r}
$$

Given fixed $S_{\max }, T, \alpha, \beta$, and $r$, we can derive a threshold number of $L_{H}$. However, as shown in Fig. 3.3.f, dS/dt is positive after the shock, which warns that the price signals may not lower $L_{H}$ enough to satisfy the above inequality. In sum, although price signals may help increase resilience in an ecological economic system by reducing the harvest, they may be insufficient. One of the reasons for this inadequacy of the price signals is that they do not reflect information about resilience or the ET (Levin, et al., 1998). ${ }^{36}$

\subsection{Context Dependency of EET}

Since EET is the result of interaction between ecological and economic systems, EET changes as the state of the system changes. Whether the system passes EET with an external shock depends on the context.

Figure 3.4.a compares $E T$ with $E E T$. While $E T$ is fixed at $S=T, E E T$ changes as $S$ and $L_{H}$ change (EET is the result of complex interactions between ecological and

${ }^{36}$ While it is well recognized the difficulty of observing ET (Carpenter et al., 2005), Mäler (2008) proposes one approach to price resilience. The basic idea is to evaluate the distance between the current state of the system and the threshold (Mäler, 2008). This valuation, however, does not reflect the EET. 
economic systems). ${ }^{37}$ By considering both Figures 3.4.a and 3.4.b, a high correlation between $E E T$ and population can be observed: when population increases, EET rises as well, which means that the system becomes less resilient.

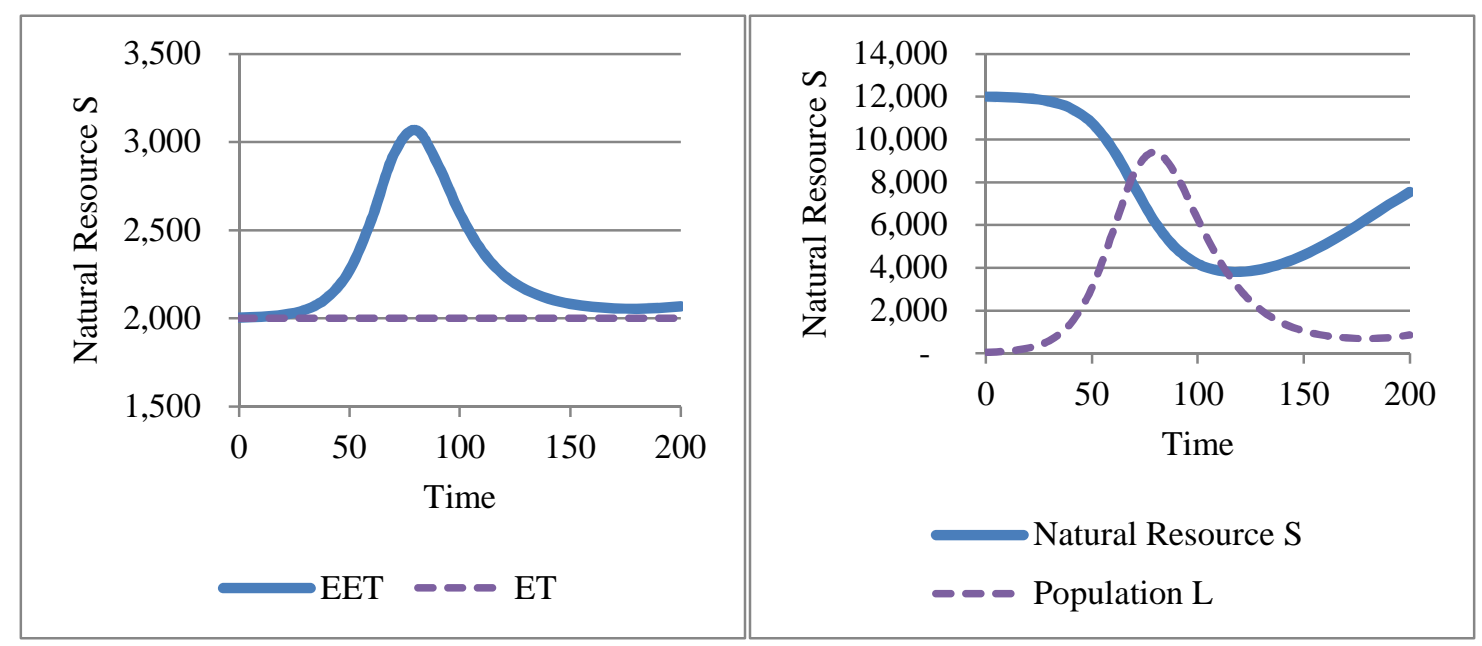

Figure 3.4.a. ET and EET

Figure 3.4.b. Population and Natural Resource

The context dependency of EET can be observed by comparing models with different adaptations as well. Fig 3.5 shows the dynamics of natural resource $S$ for models without adaptation and with various adaptations. The external shock reduces $S$ by 1,543 units at $t$ = 100 which is just above the $E E T$ for the model without adaptation. With the same shock at $t=100$, the system with $\mathrm{AT}_{\mathrm{H}}=4$ and $\mathrm{AT}_{\mathrm{M}}=2$ crosses the $E E T$, and $S$ does not stop until it becomes zero. The difference in adaptations affects the resilience in two ways. First because of the difference of adaptations, the state of the system (e.g., $S$ in Figure

\footnotetext{
${ }^{37}$ Since the EET cannot be derived analytically, it is derived by simulation.
} 
3.5) at $t=100$ varies. Second, because of the difference of adaptations, the responses to an external shock (e.g., how fast each price changes) are different.

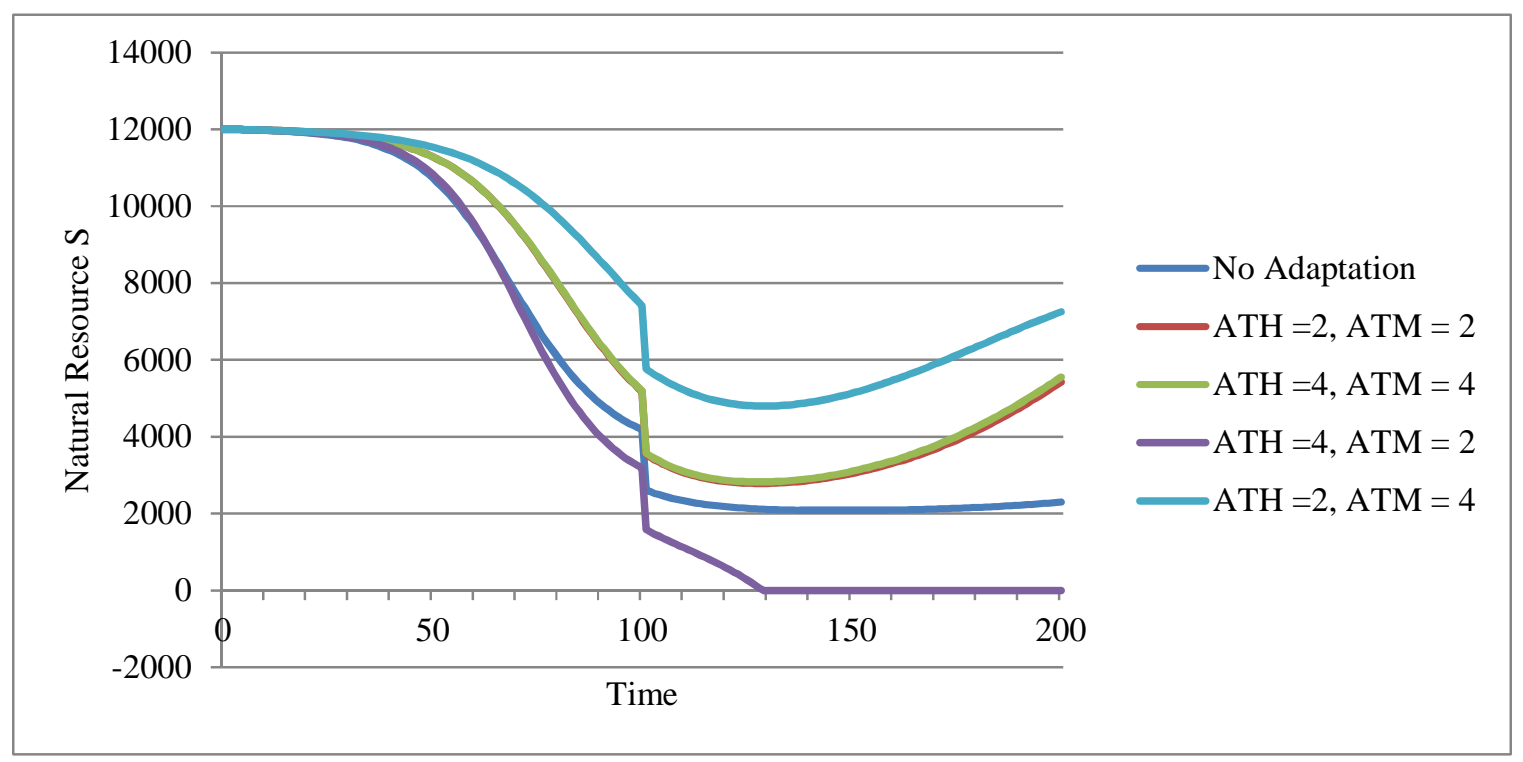

Figure 3.5 Change in Natural Resource $S$ after an external shock at $t=100$

Table 3.1 shows how much external shock at $t=100$ each system can tolerate. When an external shock larger than the tolerable maximum external shock is given at $t=100$ (i.e., $S$ crosses $E E T$ ), the system crosses the $E T$ later and $S$ goes extinct. 
Table 3.1. EET at $t=100$ for different models

\begin{tabular}{|l|r|r|r|r|}
\hline \multicolumn{1}{|c|}{ Model } & EET & $\begin{array}{l}\text { Tolerable } \\
\text { Maximum } \\
\text { External Shock }\end{array}$ & $\begin{array}{l}\text { S when the } \\
\text { shock Occurs }\end{array}$ & \multicolumn{2}{|c|}{ ET } \\
\hline No Adaptation & 2,639 & 1,543 & 4,182 & 2,000 \\
\hline $\mathrm{AT}_{\mathrm{H}}=\mathrm{AT}_{\mathrm{M}}=2$ & 3,051 & 2,112 & 5,163 & 2,000 \\
\hline $\mathrm{AT}_{\mathrm{H}}=\mathrm{AT}_{\mathrm{M}}=4$ & 3,036 & 2,157 & 5,193 & 2,000 \\
\hline $\mathrm{AT}_{\mathrm{H}}=4, \mathrm{AT}_{\mathrm{M}}=2$ & 2,884 & 290 & 3,174 & 2,000 \\
\hline $\mathrm{AT}_{\mathrm{H}}=2, \mathrm{AT}_{\mathrm{M}}=4$ & 3,252 & 4,146 & 7,398 & 2,000 \\
\hline
\end{tabular}

There are two things to worth highlighting. First, EET differs among the models. Second, interestingly, we can see wide differences in tolerable maximum external shock, ranging from 290 to 4,146 . This difference reflects the context of each model at $t=100$ : the size of population, the natural resource level, harvest rate, and regeneration of $S$. These results show that the computation of $E E T$ is difficult, if not impossible, in practice, as Carpenter et al. (2005) maintain.

\section{Discussion}

\subsection{Ecological Economic Threshold}

Simulation results show that even when an external shock which reduces the natural resource stock, $S$, is not large enough for the ecological economic system to pass $E T, S$ could continue declining until it goes extinct by crossing $E T$ due to interactions between ecological and economic systems. This indicates the presence of another threshold: EET. 
The presence of EET has not been a focus in standard textbooks for resource economics and ecological economics which uses the optimal management approach to renewable resources (Folke et al., 2002), while a critical depensation type sustainableyield curve (hereafter SY) is often adopted as a base (e.g., Conrad (2010); Daly and Farley (2010); Tietenberg and Lewis (2011)). ${ }^{38}$ Under the optimal management where perfect information is assumed, the harvest is always equal to the sustainable yield so that there is no possibility of either over-yield or under-yield. While I showed ET and EET by dynamic simulation, some implications about them could be explained by using the critical depensation type SY curve with a static catch-per-unit-effort (CPUE) curve in which the catching effort is fixed, as used by Daly and Farley (2010). ${ }^{39}$

In Figure 3.6, the straight line, $H$, is called a CPUE curve that shows a linear relationship between effort, $L_{H}$, natural resource, $S$, productivity coefficient, $\alpha$, and harvest, $H . S_{\max }$ is the carrying capacity. $S$ ' is a stable equilibrium point, and EET is an unstable equilibrium point. Daly and Farley (2010) dismiss EET, saying "[EET] is an

${ }^{38}$ Among these textbooks, Conrad (2010) derives conditions for overshoot to occur but does not analyze how economic systems respond to external shocks, which is the focus of this paper.

${ }^{39}$ In textbooks (Conrad, 2010; Daly and Farley, 2010; Goodstein, 2007; Tietenberg and Lewis, 2011), a curve for total revenues is derived by multiplying the sustainable yield curve by the price of the harvest to find the profit maximizing catching effort level. However, in my model, it is assumed that agents do not know the SY curve so that such total revenue curve is not adopted. 
unstable equilibrium of no practical interest in a dynamic world and hereafter ignored" (p.214). However, this should be the truly important threshold for the resilience of an ecological economic system in which ecological and economic systems affect each other. When an external shock reduces $S$ down to below EET but above $E T, H$ is greater than the regeneration of $S$, leading to a collapse. When the CPUE curve is steep enough not to cross the SY curve except at $S=0\left(H^{o}\right.$ in Fig.3.6), which is the only steady state, there is no EET and $S$ goes extinct anyway.

With a dynamic CPUE curve, as my model shows, $L_{H}$ is changing over time. This means that the slope of the CPUE curve is changing so that EET is context dependent and dynamic. For example, as indicated in Fig.3.3.b and d, $S$ may not go extinct even if the CPUE curve does not cross the SY curve temporarily. Because of the dynamic nature of the system, it is not easy, if not impossible, to find the EET analytically.

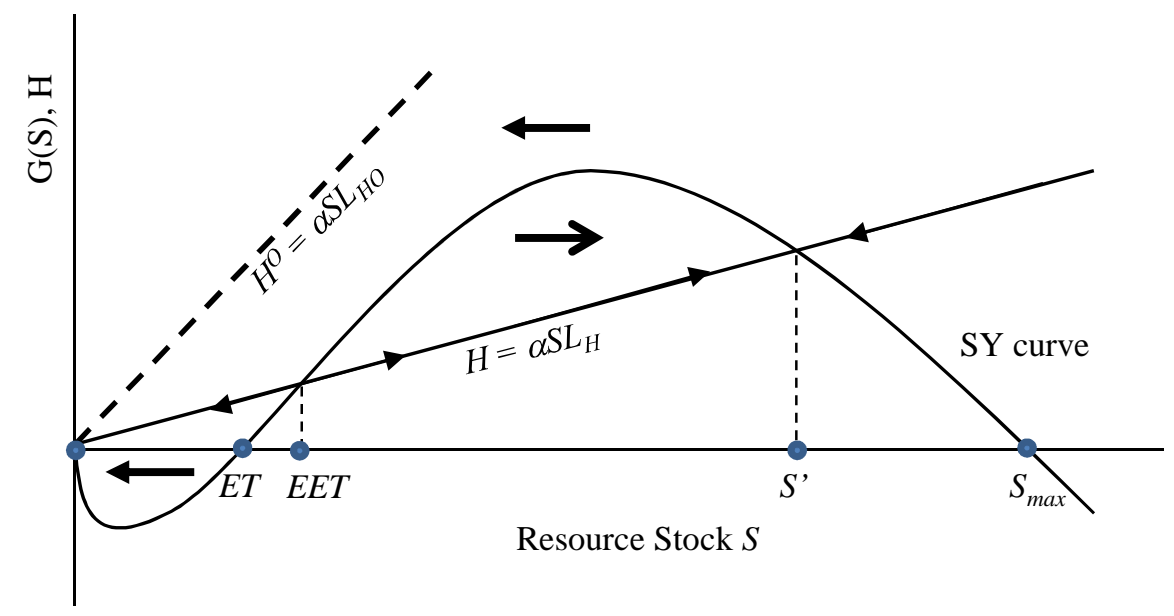

Figure 3.6. SY curve and CPUE curves 
Since population and labor may change relatively rapidly in developing economies, the dynamic version could be more appropriate for developing economies. In developed economies where population and labor dynamics are relatively stable, the static version could be more appropriate.

There would be two policy implications: EET could be a more accessible point than $E T$ for government to keep the system resilient in that it could be relatively easier to deal with; the additional complexity due to EET suggests the further importance of the Precautionary Principle.

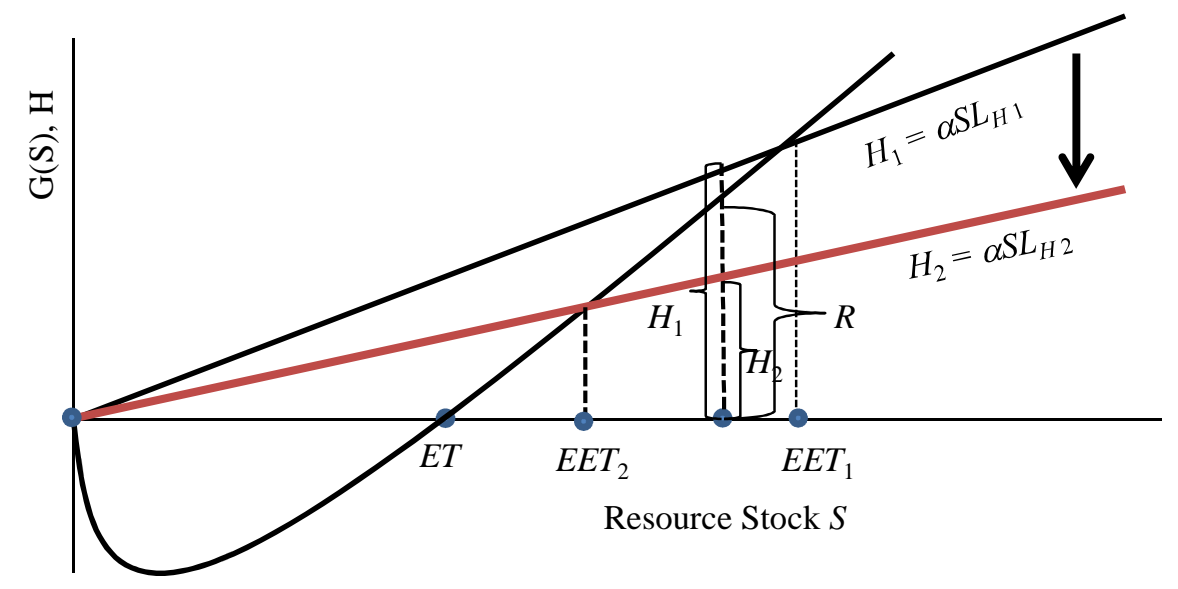

Figure 3.7. SY curve and CPUE curves with Government Intervention

In contrast to ET, EET could be a more accessible point for government to intervene to prevent the extinction of $S$. Even once an external shock makes $S$ below $E E T_{1}$ (i.e., S") as shown in Fig.3.7, an enlarged version of Fig.3.6, the system could avoid the extinction of $S$ by lowering the catching effort to $L_{H 2}$ by policies such as tax and 
quota. Achieving a lower $L_{H}$, the CPUE curve could be flatter enough that it intersects the SY curve ( $E E T$ is now $E E T_{2}$ ). Since the harvest $H_{2}$ is less than the regeneration $R$ so that $S$ will eventually move back to the stable equilibrium where $S>0$.

$L_{H}$ should not necessarily be reduced instantaneously to make a CPUE curve low enough to achieve $S>E E T$. As long as $S$ is above $E T$, we can avoid passing the $E T$ by satisfying the inequality (12) at some time before the $S$ passes the ET. This indicates that there are various transitional paths to keep the resilience of the system from drastic reduction to gradual reduction in $L_{H}$.

Because of the context dependency and dynamic nature of EET, our knowledge about an ecological economic system is further limited than when we deal with ET only. Hence, when a situation is uncertain, as the model indicates, and the environmental consequence is non-negligible, the Precautionary Principle should be supported. ${ }^{40,41}$ The principle maintains that instead of a "wait and see" attitude, proactive policy is necessary

${ }^{40}$ While there is no consensus definition of the Precautionary Principle, one often-cited description says 'When an activity raises threats of harm to human health or the environment, precautionary measures should be taken even if some cause and effect relationships are not fully established scientifically' (Common and Stagl, 2005, p.389).

${ }^{41}$ Although the results support the importance of the precautionary principle, it does not mean that the blind conformity to the precautionary principle should be supported, which may result in the situation where keeping everything intact is the best. 
and environmental quality goals should be more stringent than traditionally conceived (Kahn and O’Neil, 1999). ${ }^{42}$

\subsection{Adaptation}

The impacts of adaptation on the dynamics of an ecological economic system have not been well investigated. However, as simulation results show, how to model adaptation (i.e., the degree and difference in the speed of adjustment) may make a nonnegligible difference. There would be three policy implications: further understanding of the role of adaptation, information, and education.

While it is not easy to identify and predict how adaptation works in real world, it does not mean that we can ignore the impact of adaptation on maintaining the resilience of the system. The model developed here shows just some possible outcomes. Further modeling and analyses can contribute to get better understanding of the role of adaptation.

Governments could provide information and education to make an ecological economic system more resilient. Adaptation is justified for the situation in which people are limited in obtaining information. Better availability of information could help people

${ }^{42}$ In the same line with the Precautionary Principle, Safe Minimum Standards (SMS) which set the minimum levels of natural capital stocks so that the remaining stocks are above safe minimum levels (Markandya et al., 2002). While the SMS could be applied to ET, it could be difficult to apply to EET because EET could change more dynamically, not constant. 
make better decisions. Therefore, governments could help make systems more resilient by providing information. In my model, production decisions are based on price expectations that take market prices into account. Consumers simply use market prices to make decisions. Therefore, the scarcity of the natural resource is not reflected on their decision. The knowledge of the scarcity could induce consumers to consume less. In addition to further information, education could also contribute to resilience. With better education, agents could use more sophisticated learning mechanisms. Without proper education, however, people may not process provided information very well. ${ }^{43}$

\section{Conclusion}

This paper shows the context dependency and dynamic nature of EET. The presence of EET adds more uncertainty to the understanding of an ecological economic system, which supports the precautionary principle. Adaptation which reflects an important aspect of an actual ecological economic systems, will affect EET in a non-negligible way, a situation that could be improved by providing better information and education. A general equilibrium structure shows that market response to an external shock may be insufficient to maintain resiliency. However, compared with ET, EET is more accessible

${ }^{43}$ Recent theoretical and empirical studies on the confluence of resilience, learning, and education can be found in Krasny et al. (2011). 
in the sense that government could intervene to avoid restore the system even after crossing EET, and it is likely that various transitional paths may exist. Because of the importance of $E E T$, we should investigate further to gain a better understanding of $E E T$.

For further research, Nagase and Uehara (2011) highlight six areas through a comprehensive study of the BT model and its descendants: population dynamics, capital accumulation, substitutability, innovation, institutional designs, and modeling approach. While the present model is already complex, specific components, such as the population dynamics sector are not necessarily all that complex in isolation. Some factors, such as substitutability and institutional designs, are not incorporated into the present model, and to elicit better policy implications for developing economies, these factors may need to be incorporated. 


\title{
Chapter 4: System Dynamics Implementation of a Model of Population and Resource Dynamics with Adaptation
}

\begin{abstract}
We build and analyze a dynamic ecological economic model that incorporates endogenous innovation regarding input substitutability in order to elicit implications for the sustainability of developing economies. The use of the system dynamics method allows us to depart from conventional equilibrium thinking and to conduct an out-ofequilibrium (adaptation) analysis. Simulation results show that while improvements in input substitutability will expand an economy, this change alone may not improve sustainability measured by indicators such as utility-per-capita and natural resource stock. It could, however, be possible that improvement in input substitutability contributes to sustainable development in combination with other technological progress, which suggests the importance of focused investments. In addition, with the use of the system dynamics method, we also shed light on possible problems with exogenous consumer preference which is often assumed in standard economics, and provide analysis regarding the different system impacts of improvements in natural resource regeneration rates and carrying capacity.
\end{abstract}




\section{Introduction}

Real problems in complex systems do not respect academic boundaries.

Herman Daly and Joshua Farley (2010, xvii)

Sustainable development in developing economies faces a new economic reality in which natural resource constraints such as food, water and energy supplies, and climate change are largely defining the future outlook (UNESCAP, 2010, vii). Meanwhile, major economic growth models such as Solow growth model, neoclassical growth model, Ramsey-Cass-Koopmans, and the Overlapping Generations Model do not embrace natural resource constraints as a primary component of their models. ${ }^{44}$ Given the essential dynamic complexity of an ecological economic system (henceforth EES), we need a methodological approach that goes beyond the simplified, analytic approaches in conventional economics. We build and analyze a dynamic ecological economic model that incorporates endogenous innovation on input substitutability. Our simulation results indicate that over time improvement in input substitutability, ceteris paribus, may not make a significant contribution to sustainable development. We also demonstrate the usefulness of the system dynamics approach to ecological economics.

${ }^{44}$ Romer (2011) provides a comprehensive review of these standard economic growth models. 
Although EESs are "undeniably complex" (Limburg et al., 2002), standard economics has generally taken a strategy of simplification to be able to employ analytic approaches; however, simplification has drawbacks. First, simpler functions such as the Cobb-Douglas type function, while easy-to-handle analytically, limit the analysis of substitutability between man-made capital and natural resources that is essential for sustainable development under natural resource constraints. Second, natural resources are often treated as exogenous, resulting in missing feedbacks between ecology and economy that are critical in the study of the sustainability of an economy. Third, our focus on the state of equilibrium often results in neglecting the transitional dynamics. ${ }^{45}$ However, an approach that specifies behavioral rules and feedback loops and allows the system to be in a state of disequilibrium is critical for the study of EESs.

This paper integrates system dynamics (henceforth SD) into economic modeling and analyses to provide deeper insights into the dynamics of EESs. System dynamicists often dismiss economic theories because of their unrealistic assumptions (at least from the system dynamists' perspective). Meanwhile, SD models that are inconsistent with economic theories are not of interest to economists. We contribute to the two disciplines through 1) the development of an ecological economic model that is firmly based on

${ }^{45}$ There has been a development in equilibrium-seeking adaptive systems in the form of the learning (expectation) theory in macroeconomics (e.g., Evans and Honkapohja, 2009; Evans and Honkapohja, 2011; Bullard, 2006). 
economic theory, and 2) the construction and validation of the model using a SD method, as explained below.

Our ecological economic model is an extension of the so-called BT model (Brander and Taylor, 1998) that can depict a pattern of economic and population growth, resource degradation, and subsequent economic decline and is suitable for the study of sustainability and resilience of an economic system. ${ }^{46}$ Since its initial appearance, due to its simplicity and extendability the BT model has generated many descendants (Anderies, 2003; Basener and Ross, 2005; Basener et al., 2008; D'Alessandro, 2007; Dalton and Coats, 2000; Dalton et al., 2005; de la Croix and Dottori, 2008; Erickson and Gowdy, 2000; Good and Reuveny, 2006; Maxwell and Reuveny, 2000; Nagase and Mirza, 2006; Pezzey and Anderies, 2003; Prskawetz et al., 2003; Reuveny and Decker, 2000; Taylor, 2009). Our model is motivated by Nagase and Uehara's (2011) review of the existing models of this type and is an extension of the model developed by Uehara et al. (2010).

SD provides useful tools and approaches to analyze complex systems. In addition to technical characteristics of SD as a computer-aided approach to solve a system of

${ }^{46}$ The unified growth theory incorporates population dynamics endogenously into economic growth models. This theory is a variant of the endogenous growth theory focusing on the transition to a steadily growing economy (e.g., Strulik, 1997; Galor and Weil, 2000; Hansen and Prescott, 2002; Galor, 2005; Voigtlander and Voth, 2006; Strulik, and Weisdorf, 2008; Madsen et al. 2010). However, natural resources stocks and flows are fixed or ignored in their models. 
coupled, nonlinear, first-order differential equations, what characterizes SD is its emphasis on 1) feedback thinking, 2) loop dominance, 3) nonlinearity, and 4) taking an endogenous point of view. The endogenous point of view is the sine qua non of systems approaches (Richardson, 2011). SD also uses several unique techniques for mapping a model, including causal loop diagrams, system boundary diagrams, and stock and flow diagrams, in order to visualize a complex system. To validate a complex model, SD adopts various testing methods such as boundary adequacy test, structure assessment, and sensitivity analysis ( $c f$. Sterman, 2000).

There are four main findings from our simulation results. First, over time, improvement in input substitutability, ceteris paribus, may not make a significant contribution to sustainable development. While the production of goods will increase as input substitutability improves over time, utility-per-capita may barely change and the natural resource stock declines. Second, however, in combination with other technological progress, over-time improvement in input substitutability could increase utility-per-capita and save natural resource stock. Third, sensitivity analysis shows that consumers' preferences can affect the sustainability of the system drastically and hence deserve careful attention. Fourth, the regeneration rate and carrying capacity of a natural resource may have very different impacts on system behavior.

Our model is most applicable to developing economies where their sustainability critically depends on natural resources and population dynamics. Consequently, we intend our model to evolve further to provide case studies that can yield policy 
implications for such economies. A caveat is that current developing economies are going through experiences that are different from those of the developed economies due to, for example, the access to rapidly-evolving technologies and the increased scarcity of natural resources (UNESCAP, 2010). Therefore, we do not seek fitness of our model to any particular historical data to validate the model. Instead, we validate our model using the "reference mode" (described in the next section) chosen for the model, so that we assess the performance of our model based on how well it can depict the expected behavioral patterns of resource-constrained ecological-economic systems.

Section 2 presents the model and preliminary model testing, Section 3 provides the primary results from conducting a variety model experiments focused on parameter sensitivity. Section 4 provides a discussion of our results; and section 5 provides concluding remarks.

\section{Model}

\subsection{Reference mode}

To develop and validate a SD model, we typically need graphs and other descriptive data that represent a pattern of behavior of the system to be modeled. In SD, this is called a "reference mode." A reference mode identifies key concepts and variables for the model and sets the appropriate time horizon of the model during which the modeled system is expected to reveal, through the effects of complex feedback loops, how 
problems emerge and how they affect the dynamics of the system. Through these choices, the reference mode defines the pattern of behavior of the system. The identified behavioral pattern will become the point of reference, in the process of developing the model and for its validation (cf. Sterman, 2000).

One possible behavioral pattern for our reference mode is a collapse of an economy. There are many historical cases of collapse (Diamond, 2005). One of them is the boom and bust in Easter Island that faced a severe collapse after depleting natural resources as shown in Figure 4.1.

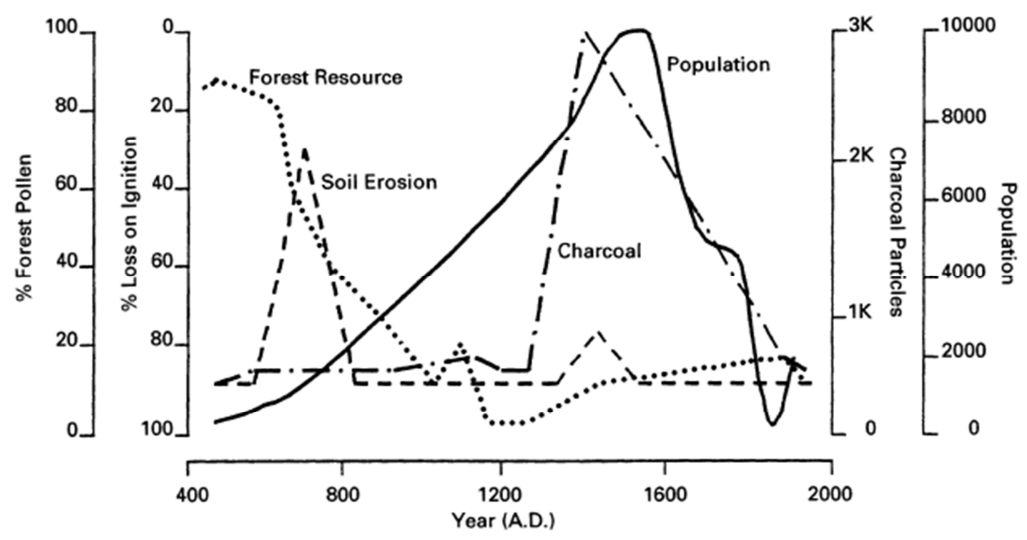

Figure 4.1. Easter Island dynamics from archaeological study by Bahn and Flenley (1992)

Another possible reference pattern is a dynamics in which population increases at the beginning and becomes stabilized later, without depleting natural resources. Japan presents such an example in its history. Figure 4.2 shows the population and cultivated land during the Edo era (1603-1868). During the Edo era, the Japanese economy was 
closed in that imports, exports, immigration, and emigration were all negligible. Therefore, in terms of natural resources Japan's growth during this period depended solely on its own. Population growth was $\mathrm{S}$-shaped and then stabilized until the Edo era ended, at which point the new, modern government opened the country. Compared with the peak of the size of cultivated land area in 1948, there seemed to be enough arable land uncultivated.

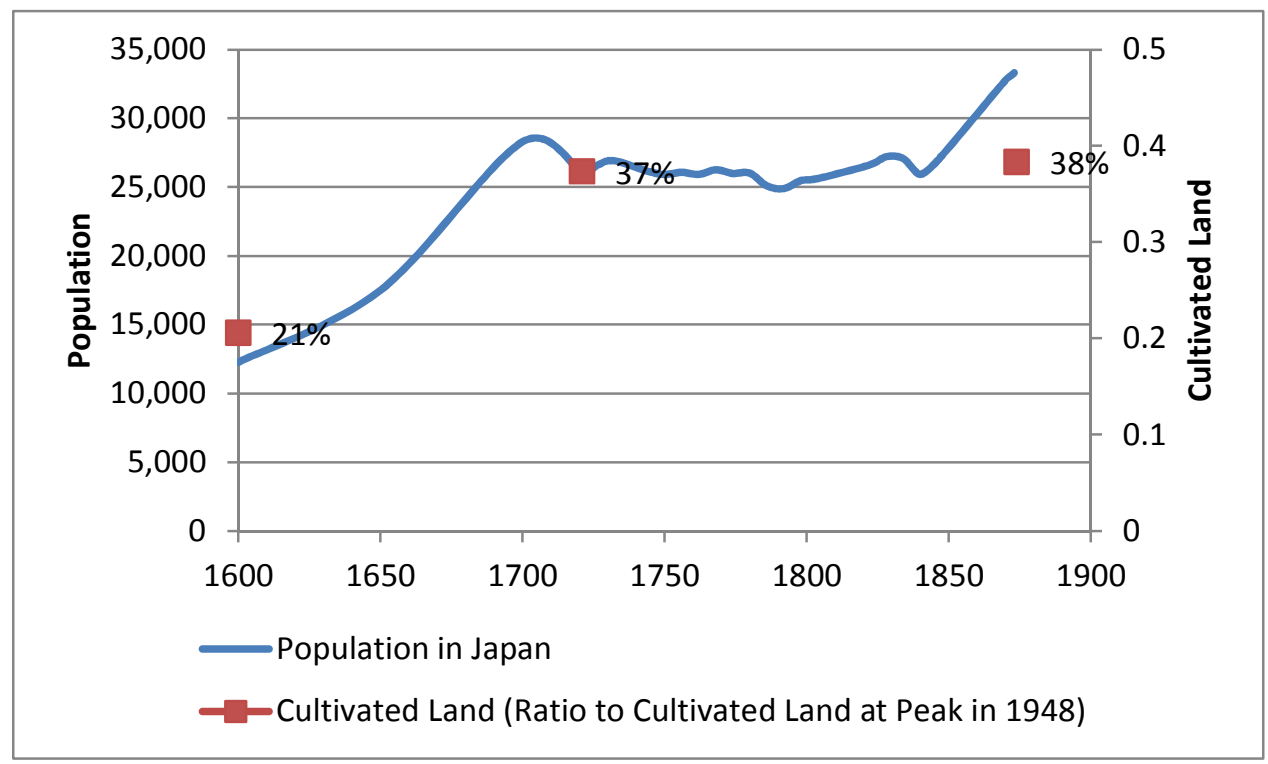

Figure 4.2. Population and Cultivated Land in Japan during Edo Era (1603-1868). Source: Wikipedia and Kito (1996)

In consideration of the fast-changing modern economy and environment (that favors a shorter time horizon) on the one side and the higher complexity of the modern economic system (that favors a longer time horizon) on the other side, we choose 300 
years as the time horizon for our reference mode. Sustainability being the primary theme of our research, we choose the behavioral pattern for our reference mode to be characterized by increasing population followed by the decline in the natural resource stock, leaving possibilities for both a collapse and stabilization of the system. For this purpose, the use of the BT model as the basis of our model development allows us to include the relevant variables and behavioral assumptions for the system.

\subsection{Model}

Our model can be classified as a static general equilibrium model whose dynamic transitional process from one time period to another is given by a set of first-order differential equations--except that, as revealed shortly, our SD approach does not require an analytic equilibrium solution for each time period.

The model depicts an economy consisting of two (harvest and manufacturing) sectors. Input availability in each time period is bounded by the existing sizes of population, renewable natural resource stock, and man-made capital. In contrast to standard approach in natural resource economics (e.g., Conrad, 2010), agents are rational but myopic; they maximize utility and profit yet only within each time period. It is a reasonable approach for the situation where the resource stock is held in common and agents are atomistic (Taylor, 2009). The renewable resource in our model is a commonproperty resource (CPR), and the lack of long-term perspectives among agents could 
result in severe resource depletion that can threaten the sustainability of the economy. The production and consumption activities in each period determine the growth rates of population, resource stock, and man-made capital.

One aspects of our model specification is particularly novel: we allow the model to address the issue of substitutability between natural resource and man-made capital endogenously. For this purpose we introduce a constant-elasticity-of-substitution (CES) production function for the manufacturing sector. Input substitutability in this sector evolves over time due to the endogenous technological change (ETC) driven by the relative input scarcity. Endogeneity of natural versus man-made input substitutability is a critical issue for sustainability, and to the best of our knowledge our model is the first attempt to integrate ETC and substitutability.

\subsubsection{Period-by-period behavior of agents}

Let us now describe the specifics of the model (time subscripts are suppressed for all variables). ${ }^{47}$ In each time period, agents make production and consumption decisions with the given sizes of population $(L)$, natural resource stock $(S)$, and man-made capital $(K)$. As a consumer, a representative agent maximizes utility subject to the budget constraint:

${ }^{47}$ Nagase and Uehara's (2011) circular flow diagram provides a useful visual representation for those who are not familiar with the BT-type models. 


$$
\max _{\{h, m\}} u(h, m)=h^{\beta} m^{1-\beta} \quad \text { s.t. } \quad p_{H} h+p_{m} m=(1-s)\left(w+\frac{r K}{L}\right) .
$$

$h$ and $m$ denote per-capita consumption levels of harvest good $(H)$ and manufactured good $(M)$, respectively. $s$ denotes the saving rate, $w$ and $r$ are prices of labor and manmade capital, respectively. ${ }^{48}$ This optimization problem yields the consumption demand functions for the two goods:

$$
\begin{aligned}
& H_{C}=L \cdot h=\frac{(1-s) \beta}{p_{H}}(w L+r K) \\
& M_{C}=L \cdot m=\frac{(1-s)(1-\beta)}{p_{M}}(w L+r K)
\end{aligned}
$$

where $h$ and $m$ denote per-capita consumption levels of $H$ and $M$, respectively.

Two sectors' constant-returns-to-scale aggregate production functions are defined as $H(L)=\alpha S L_{H}$ and $M\left(L_{M}, H_{M}, K\right)=v{L_{M}}^{1-\gamma}\left[\pi H_{M}{ }^{\rho}+(1-\pi) K^{\rho}\right]^{\gamma \rho}$, respectively, where $H_{M}$ denotes the amount of good $H$ consumed as an input, $L_{M}=L-L_{H}$, and $\gamma$ and $\lambda \in(0,1)$. $\rho<1$ so that the elasticity of substitution $\sigma=1 /(1-\rho)$ is positive. $\alpha$ and $\gamma$ are efficiency parameters.

The degree of substitutability between man-made capital and natural resources plays a critical role in determining the sustainability of EESs in which the economy faces

${ }^{48}$ For simplicity each agent has one unit of labor to be allocated across the two sectors, and the rental price of capital is evenly distributed back to all agents. 
natural resource constraints. Studies on substitutability have been almost exclusively conducted using CES production functions. ${ }^{49}$ With $\sigma<1$, inputs are complements so that the natural resource is essential for production, meaning that production becomes more difficult without the natural resource. ${ }^{50}$

In relation to sustainability, the key discussion of the substitutability is the tradeoff between natural resources and the accumulated man-made capital. Whereas mainstream economics has implicitly supported $\sigma=1$ through the ubiquitous employment of the C-D function, ecological economists assert $\sigma<1$ for various reasons (e.g., Cleveland et al., 1984; Cleveland and Ruth, 1997; Daly, 1991; Daly and Farley, 2010), although the empirical evidence remains inconclusive ( $c f$. Nagase and Uehara, 2011).

The first-order conditions for the two sectors' profit maximization are:

$$
\begin{gathered}
p_{H} \alpha S=w \\
p_{M} v(1-\gamma)\left(L-L_{H}\right)^{-\gamma}\left[\pi H_{M}{ }^{\rho}+(1-\pi) K^{\rho}\right]^{\frac{\gamma}{\rho}}=w
\end{gathered}
$$

${ }^{49}$ Stern (1994) proposes the translog production function because it can effectively model minimum input requirements, any elasticity of substitution, and uneconomic regions, for any number of inputs and outputs.

${ }^{50}$ For a comprehensive discussion about the relationship between substitutability and sustainability, see Hamilton (1995). 


$$
\begin{aligned}
& p_{M} v(1-\gamma)\left(L-L_{H}\right)^{1-\gamma} \gamma\left[\pi H_{M}{ }^{\rho}+(1-\pi) K^{\rho}\right]^{\frac{\gamma}{\rho}-1} \pi H_{M}^{\rho-1}=p_{H} \\
& p_{M} v(1-\gamma)\left(L-L_{H}\right)^{1-\gamma} \gamma\left[\pi H_{M}{ }^{\rho}+(1-\pi) K^{\rho}\right]^{\frac{\gamma}{\rho}-1}(1-\pi) K^{\rho-1}=r
\end{aligned}
$$

Using equations (1) and (2) and the production functions, the static market equilibrium conditions in the $\mathrm{H}$ - and $\mathrm{M}$-markets are given by

$$
\frac{(1-s) \beta}{p_{H}}(w L+r K)+H_{M}=\alpha S L_{H}
$$

and

$$
\frac{(1-s)(1-\beta)}{p_{M}}(w L+r K)=v\left(L-L_{H}\right)^{1-\gamma}\left[\pi H_{M}{ }^{\rho}+(1-\pi) K^{\rho}\right]^{\frac{\gamma}{\rho}} .
$$

Equations (3) through (8) yields the static equilibrium solution set $\left\{L_{H}^{*}, H_{M}^{*}, w^{*}, r^{*}\right.$, $p_{H}^{*}$, and $\left.p_{M}^{*}\right\}^{51}$ The harvest level $H$ in our model is determined endogenously as a result of an economic activity, in contrast to some other similar studies on the dynamics of population and natural resource (e.g., Shukla et al., 2011).

\subsubsection{Dynamic transition}

Given $\left\{L_{H^{*}}, H_{M}^{*}, w^{*}, r^{*}, p_{H}^{*}\right.$, and $\left.p_{M^{*}}\right\}$, the transitional dynamics for the three stock variables are given by the following equations.

${ }^{51} H_{C} *$ is obtained by substituting $p_{H}^{*}, w^{*}$ and $r^{*}$ into the production function for $M . H^{*}=H_{C}^{*}+H_{M}^{*}$. $M^{*}$ is obtained by substituting $L_{H}{ }^{*}$ and $H_{M} *$ into the production function for $M$. 


$$
\begin{gathered}
\frac{d L}{d t}=L\left[b\left(h^{*}, m^{*}\right)-d\left(h^{*}, m^{*}\right)\right] ; b=b_{0}\left(1-\frac{1}{e^{b_{1} h^{*}}}\right) \frac{1}{e^{b_{2} m^{*}}} \text { and } d=d_{0} \frac{1}{e^{h^{*}\left(d_{1}+d_{2} m^{*}\right)}} \\
\frac{d S}{d t}=G(S)-H^{*}=\eta S\left(1-\frac{S}{S_{\max }}\right)-H^{*} \\
\frac{d K}{d t}=\frac{s\left(w^{*} L+r^{*} K\right)}{p_{M}^{*}}-\delta K
\end{gathered}
$$

Equations (9) and (10) characterize our model as a Gordon-Schaefer Model, using a variation of the Lotka-Volterra predator-prey model (cf. Nagase and Uehara, 2011).

Equation (9) represents a Malthusian population dynamics in the sense that the higher per capita consumption of the resource good leads to higher population growth. $b$ and $d$ denotes the birth and death rates. We adopt Anderies' (2003) formulation that incorporates the impact of the manufactured good per capita $m$ as well as $h$ in order to reflect the demographic transition hypothesis. ${ }^{52}$ More specifically, real income and fertility are negatively correlated, and mortality is negatively correlated with improved

${ }^{52}$ The hypothesis consists of four basic stages: (I) Population has high birth and death rates that are nearly equal leading to slow population growth; (II) Death rate falls yet birth rate remains high, leading to rapid population growth; (III) Birth rate falls; (IV) Birth and death rates are both low and nearly equal, stabilizing the population at a higher level than at stage I. 
nutrition and infrastructure. The term $b_{0}\left(1-\frac{1}{e^{b_{1} h^{*}}}\right)$ depicts that as consumption of harvested good (nutrition) increases the birth rate increases, up to a maximum of $b_{0}$. The term $\frac{1}{e^{b_{2} m^{*}}}$ represents the downward pressure on birth rate as consumption of manufactured good increases. The death rate function depicts that improved nutrition reduces death rates via the term $h d_{l}$, while improved infrastructure reduces death rates via the term $h d_{2} m^{*}$.

Equation (10) represents the resource growth dynamics. $G(S)$ represents a logistic growth function of $S . \eta$ denotes the intrinsic growth rate, and $S_{\max }$ denote the carrying capacity.

Equation (11) represents a standard economic approach to model capital accumulation. Capital accumulation is a basic component in growth literature. In ecological-economic modeling, incorporating capital accumulation allows us to investigate the role of substitutability between man-made capital and natural resources for sustainability. The first term on the right hand side represents the amount of manufactured good used for capital formation. $s$ is an exogenously given (for simplicity) savings rate, and $\delta$ is the capital depreciation rate. Man-made capital accumulation depends indirectly on natural resource through the production of manufactured good. Therefore, in our model, natural resources are a so-called "growth-essential" reource (Groth, 2007). 
Finally, the transitional dynamics for the input substitutability is given by:

$$
\rho(t)=\frac{1}{1+e^{-x(t)}}-1 ; \frac{d x}{d t}=\zeta\left|\frac{p_{H}}{r}-1\right|, \zeta>0 .
$$

Variable $x$ is a measure of knowledge or experience that contributes to the innovation process. ${ }^{53}$ Equation (12) yields an S-shaped curve for innovation as knowledge/experience accumulates, as typically observed (Rogers, 1995). The equation also embodies the premise that economic agents respond to price changes that reflect relative resource scarcity (Löschel, 2002). For simplicity, we do not depict explicitly in our model how innovation takes place; meanwhile, one can interpret that we implicitly assume that innovation occurs as a side effect of capital accumulation (Allow, 1962; Romers, 1996; Castelnuovo et al., 2005). By incorporating scarcity-driven ETC, our model endogenizes the motivation for the depicted economy to better-utilize the relatively scarce input. Hence the production function for manufactured good, the capital accumulation rule, and the ETC rule together form a close relationship.

\subsection{System Dynamics}

${ }^{53}$ A very simple formula is adopted here. Since there is a rich literature on this subject, the impact different forms of innovation on sustainability should be one of important topics for further research. 
While the analyses of dynamic economic models tend to depend on terminal conditions of the system and focus on the steady state, an SD approach highlights the transitional paths, that is, how the dynamics of a system change over time. Thanks to the lack of requirement for analytic solutions, an SD approach facilitates the analysis of a complex EES without making undue simplifications.

An SD approach takes two steps. First, we construct an SD model of an EES whose specifications of the feedback loops are based on economic theory and scientific causal relations. Second, we let the model reveal the transitional paths of the variables, by way of an adaptation (out-of-equilibrium) mechanism. For our model, we employ a simple hill-climbing method, an iterative algorithm (Sterman, 1980 and 2000). For example, the manufacturing sector seeks to find the optimal combination of inputs $L_{M}$, $H_{M}$, and $K$ to maximize profit, i.e., to satisfy conditions (4), (5), and (6). In a standard equilibrium approach in economics, reduced-form analytic solutions represent the optimal values. In using a hill-climbing method, the system begins with an arbitrary set of solutions. The system then repeatedly adopts incremental changes to the solutions to find a better set of solutions. This process ends when no further improvement can be made to the solution set.

Two model descriptions can be helpful to gain a wholesome picture of our model: a causal loop diagram (CLD) and a description of the model boundary. Figure 4.3 shows CLDs for our extended model. The six boxes represent three stock variables (population, natural resource, and man-made capital) and three markets (harvested good, 
manufactured good, and labor). Thick arrows indicate critical interaction between manmade capital and natural resource, through the $M$-market. An arrow tells the direction of causality. For instance an increase in "population" $(L)$ results in a decrease in "food per capita" $(h)$ as the "-" sign indicates. An increase in "food" $(H)$ results in an increase in $h$ ("+" sign attached to the arrow). "R" means that the loop is a positive (reinforcing) feedback loop, while "B" means that the loop is a negative (balancing) feedback loop.

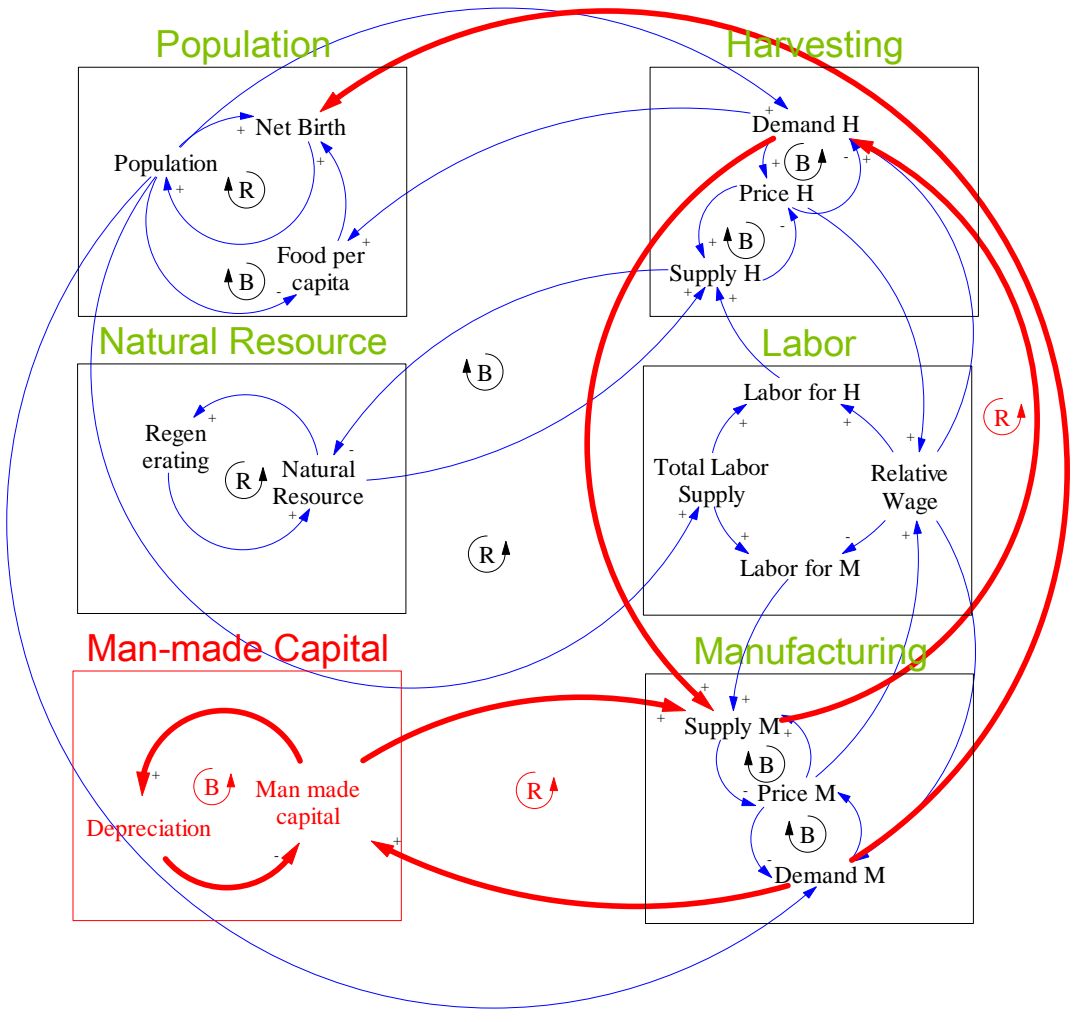

Figure 4.3. Causal Loop Diagrams for the Extended Model. Red texts and thick arrows indicate newly added items. 
Table 4.1 documents the boundary of our model and clarifies endogenous variables, exogenously-given parameters, and excluded variables. ${ }^{54}$ The choice to highlight specific excluded variables is somewhat subjective. They are chosen for their importance in view of EESs for developing economies. Nonrenewable resources are also important, as most studies on the economics of sustainability focus on nonrenewable resources (e.g., Hartwick, 1977). As energy inputs, societies tend to use less expensive nonrenewable resources first, such as oil, and then switch to more expensive renewable resources such as wind and solar when the marginal cost of the nonrenewable resource begins to exceed that of the renewable resources (Tietenberg, 2011). Negative externalities such as pollution may not be negligible. For example, a study by Asian Development Bank showed that the costs associated with climate change could be equivalent to a loss of $6.7 \%$ of their combined gross domestic product (GDP) by 2100 (ADB, 2009).

\footnotetext{
\begin{tabular}{|c|c|c|}
\hline Endogenous & Exogenous & Excluded \\
\hline
\end{tabular}

${ }^{54}$ Some of the exogenous parameters in our model could be modeled as endogenous. For example, the carrying capacity and the regeneration rate of natural resources could be endogenous via innovation. Adjustment times are often exogenously given in SD models, but these could be endogenous as well. For example, Kostyshyna (forthcoming) suggests an adaptive step-size algorithm to allow a time-varying learning speed (or a time-varying gain parameter) that change endogenously in response to changes in the environment.
} 


\begin{tabular}{|c|c|c|}
\hline 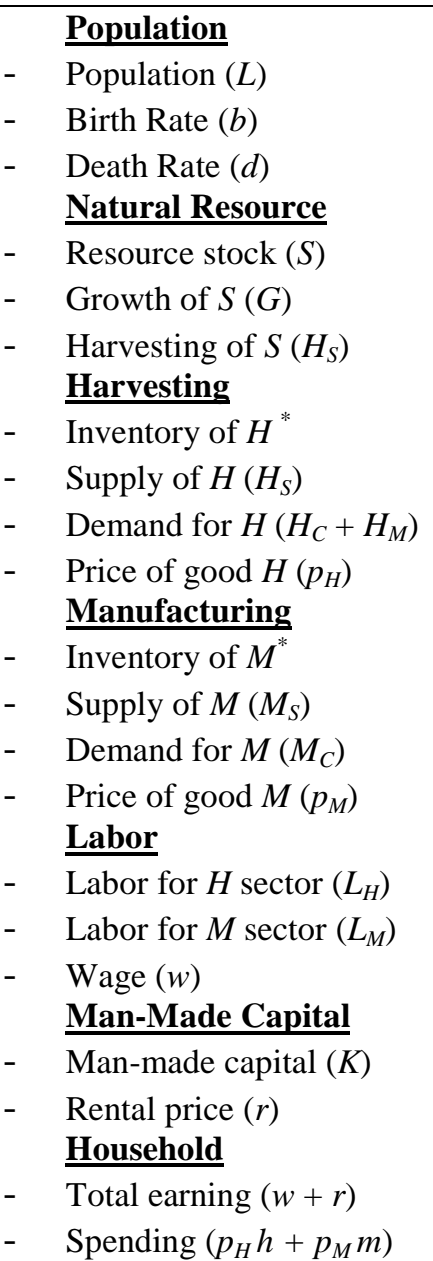 & $\begin{array}{ll} & \text { Population } \\
- & \text { Initial population }\left(L_{0}\right) \\
- & \text { Impact of } H \text { and } M \text { on } \\
\text { - } & \text { Mopulation }\left(b_{1}, b_{2}, d_{1}, d_{2}\right) \\
- & \text { Maximum fertility rate }\left(b_{0}\right) \\
& \text { Naturam mortality rate }\left(d_{0}\right) \\
- & \text { Initial natural Resource }\left(S_{0}\right) \\
- & \text { Regeneration rate of natural } \\
& \text { resource }(\eta) \\
- & \text { Carrying capacity }\left(S_{\text {max }}\right) \\
- & \text { Harvesting } \\
\text { Efficiency parameter }(\alpha) \\
\text { - }\end{array}$ & $\begin{array}{ll}- & \text { Non-renewable resources } \\
- & \text { Negative externalities of } \\
\text { production (pollution) } \\
-\quad & \text { International relationships } \\
& \text { (exports, imports, } \\
\text { immigration, emigration) } \\
-\quad & \text { Unemployment }\end{array}$ \\
\hline
\end{tabular}

Table 4.1. Model Boundary

* After production, $\mathrm{H}$ and $\mathrm{M}$ are stored as inventories before being sold.

International relationships may be most important factors excluded from our model. When international relationships exist, as is the case for most developing economies, they can use resources and new technologies from abroad and perhaps avoid collapse. Unemployment is also a crucial issue in developing economies, but following the standard treatment in growth literature, for simplicity, factors that prevent our SD model 
from reaching full employment are outside the scope of our model and are excluded. For the purpose of replication, the full model will be provided upon request. The numerical values adopted for our base model are available in appendix B. Exogenous variables for the baseline model are calibrated to generate a behavior such that the population and the natural resource are somewhat stabilized over time to be consistent with our chosen reference mode. Some values are adopted from Brander and Taylor (1998) or Anderies (2003). The stock and flow diagram for the full model is available in appendix C. 


\subsection{Model Testing}

In many cases, a full suite of model tests would be performed prior to actually applying the model to find answers to the questions posed at the outset of a modeling project. What is particularly unique about our SD model is that structural assessment was made based on economic theory, i.e., we assume that our model passes the structure assessment tests because the basic structure of the model follows standard economic theory. We tested to verify that the integration step-size was adequate. By conducting the integration error test to verify that the numerical integration parameters provide sufficiently accurate simulation results. ${ }^{55}$

The baseline model run is shown in Figure 4.4. Population grows rapidly, then declines and reaches a steady state value well above the initial value. The natural resource declines to nearly $60 \%$ of the carrying capacity. The model's behavior in Figure 4.4 is qualitatively similar consistent with our chosen reference mode.

${ }^{55}$ Euler integration is used for our simulation. 


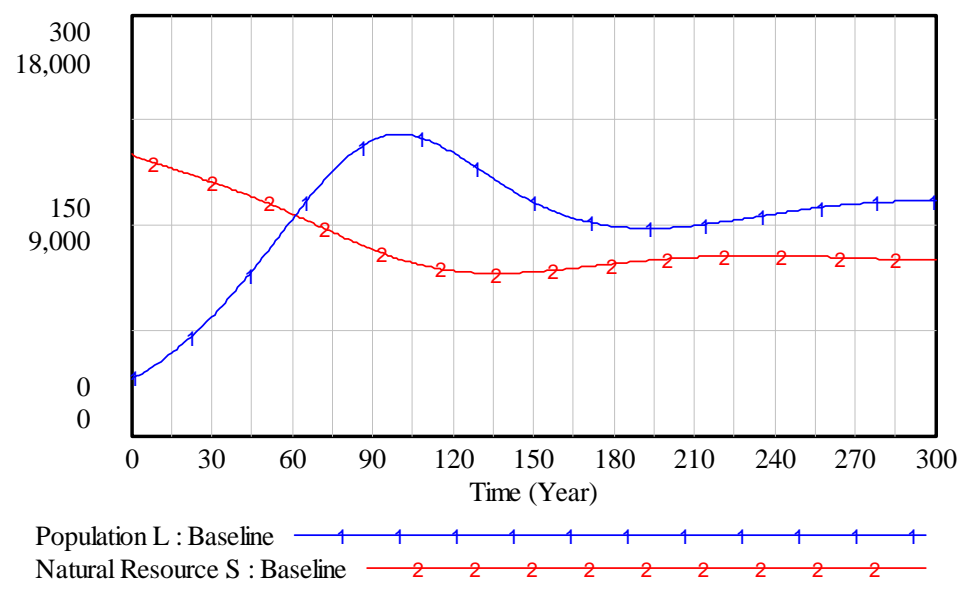

Figure 4.4. Extended Model Population and Resources

Another standard test is sensitivity analysis. A set of preliminary sensitivity analyses can also serve the role of model testing, by checking the model's responses to changes in certain variables. For example, a reduction in savings rate $s$ causes a decrease in the man-made capital accumulation over time and hence more intense use of the natural resource (i.e., decline in the natural resource stock). An increase in the regeneration rate $\eta$ stimulates its consumption and increases population. An increase in the positive effect of the consumption of the harvested good on fertility $\left(b_{1}\right)$ or a decrease in the negative effect of the manufactured good consumption on fertility $\left(b_{2}\right)$ results in a faster population growth and enhanced overshooting. These results are all consistent with the predicted responses of the model. 


\section{Results}

\subsection{Sensitivity Analyses}

For this paper we consider the sensitivity analyses to be a primary result in addition to serving as an important model validation tool. Sensitivity analysis can be used to investigate possible transitional paths for EESs. Given the complexity of such systems, it is almost impossible for an SD model to take account of a complete set of information on all possible future states. Nevertheless, policy makers can learn from SD modeling and analyses various transitional paths that highlight possible ecological/economic changes for society (Leach et al., 2010). ${ }^{56}$ Given past experiences, Folke et al. (2002) suggest "structured scenarios" as a tool to envision multiple alternative futures and the pathways for making policies.

In this study, before providing the findings about the impact of endogenous substitutability on sustainability, which is our main focus of this paper, we discuss two important topics: impacts of carrying capacity, $S_{\max }$ and the regeneration rate of a natural resource $\eta$ on the system, and the effect of consumer preference on the system outcome. The first section provides an interpretation about the mechanism which improvements in

${ }^{56}$ Leach et al. (2010) points out that dynamics and complexity have been ignored in conventional policy approaches for development and sustainability. They relate this tendency to prevailing equilibrium thinking as we describe in this study. 
$S_{\max }$ and $\eta$ have different impacts on the system. The second section sheds light on a possible problem of a well-accepted modeling approach in economics, that is, an exogenous consumer preference. The third section shows the impact of endogenous substitutability in terms of sustainability. The fourth section provides a preliminary result about the impact of endogenous substitutability in combination with other technological progresses.

\subsection{Impacts of $S_{\max }$ and $\eta$ on the System}

As Nagase and Uehara (2011) point out, the BT-type models with time-dependent exogenous technological changes in $S_{\max }$ and $\eta$ give interesting results, indicating the need for further research to explain the logic behind the differences. While higher resource regeneration rates $\eta$ can sustain larger population sizes, exponential growth of carrying capacity, $S_{\max }$, can lead to oscillations. Our SD model also gives similar results as shown in Figures 4.5 and 4.6..$^{57,58}$

${ }^{57}$ To make the difference explicit between with and without technological progress, only one growth rate was reported for each technological progress. But sensitivity analysis applying various growth rates was conducted and these tests show the similar patterns qualitatively.

${ }^{58}$ Since growth rates were chosen simply to illustrate the different behaviors, comparison of absolute sizes of $S$ and $L$ between the two different technological changes may have little meaning. 

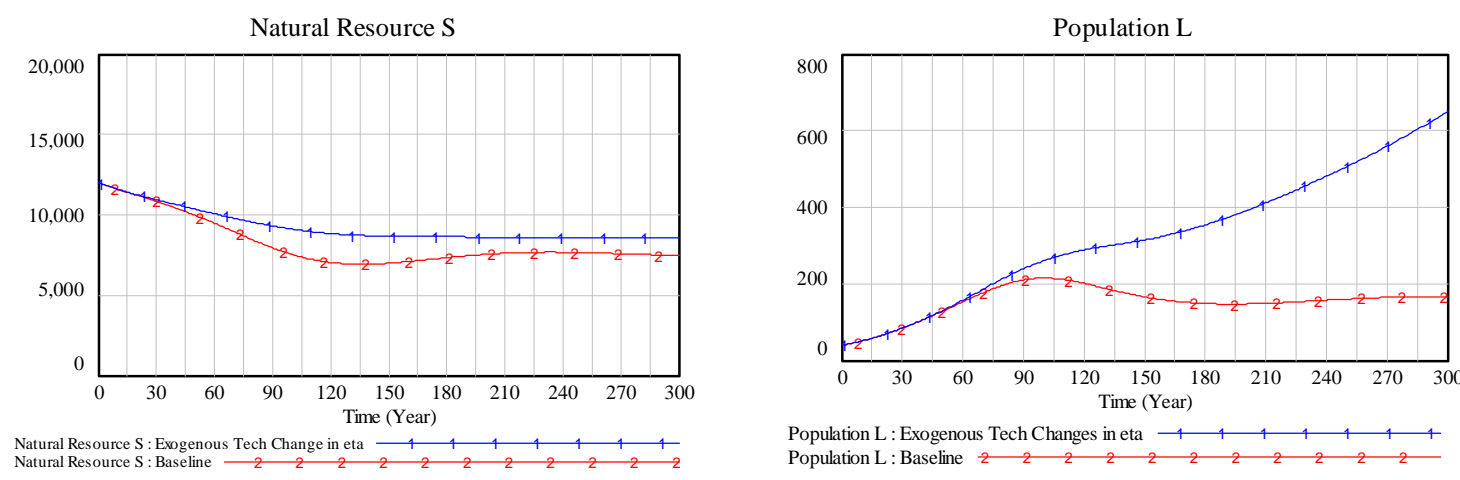

Figure 4.5. Impacts of Changes in $\eta$

$\eta$ with exogenous technological change $=0.04 e^{0.005 t}$ (increasing resource regeneration rate; fixed carrying capacity)
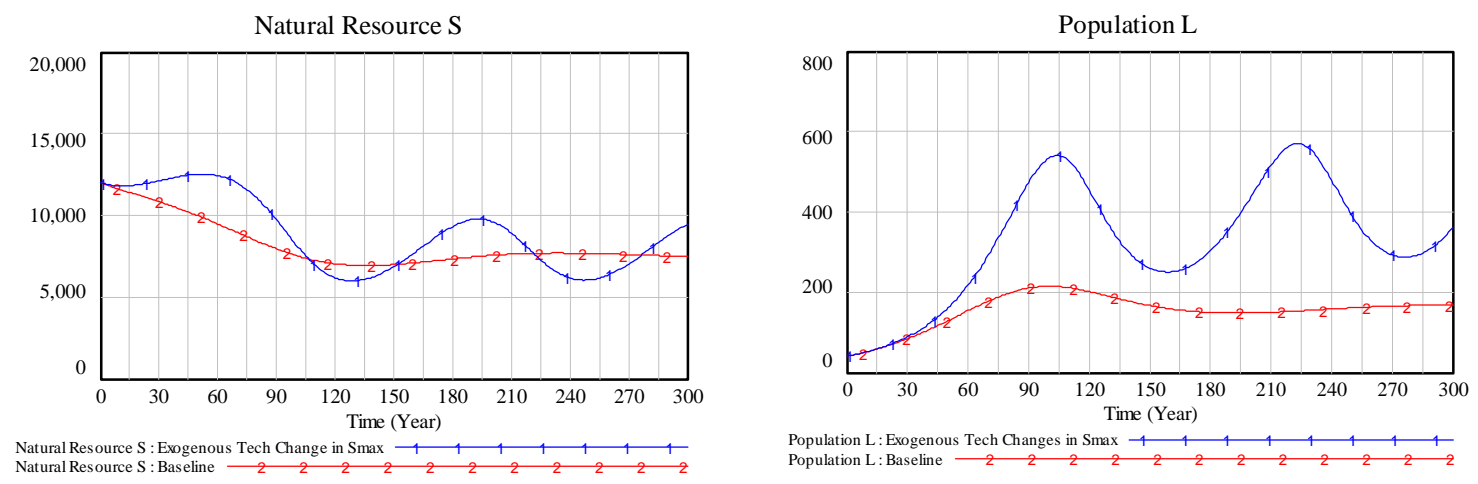

Figure 4.6. Impacts of Changes in $\mathrm{S}_{\max }$

$\mathrm{S}_{\max }$ with exogenous technological change $=12000 e^{0.01 \mathrm{t}}$ (increasing carrying capacity ; fixed resource regeneration rate)

This is somewhat counterintuitive because the growth function $G(S)$ is monotonically increasing with respect to $S_{\max }$ and $\eta$ (i.e., $\frac{\partial G(S)}{\partial S_{\max }}>0$ and $\frac{\partial G(S)}{\partial \eta}>0$ ). However, their difference becomes clear if we draw the growth curve. As shown Figure 4.7a and b, while increases in $\eta$ push up the growth curve for all values of $\mathrm{S}<S_{\max }, S_{\max }$ remains 
fixed. On the other hand, increases in $S_{\max }$ do not only push up the growth curve but also expand the curve to the right.

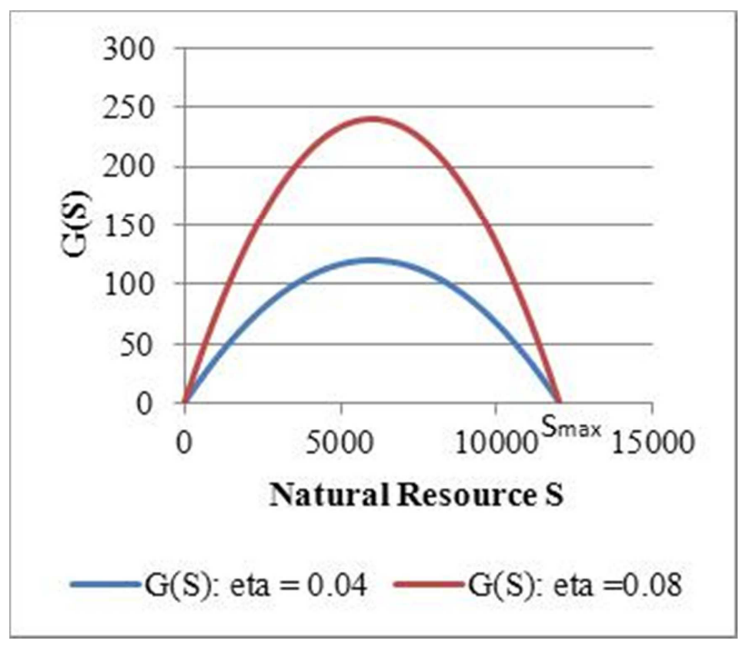

Figure 4.7a. Impact of $\eta$ on $\mathrm{G}(\mathrm{S})$

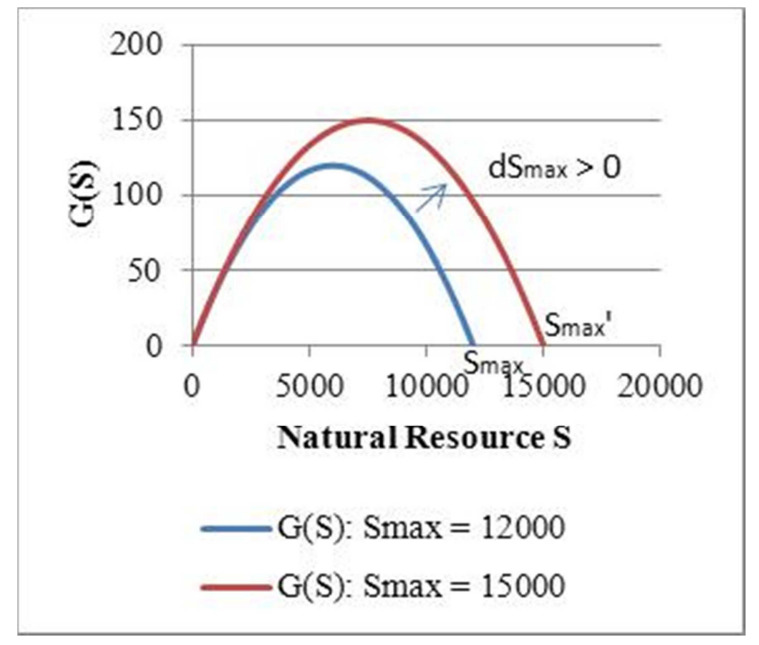

Figure 4.7b. Impact of $S_{\max }$ on $G(S)$

While dynamic behaviors in our model are results of complex relationships among positive and negative feedback loops, this difference in $S_{\max }$ is the key for the oscillation. The oscillation of a system with carrying capacity has been well investigated in system dynamics. Sterman (2000) points out the two conditions for overshoot and/or oscillation to occur: 1) the negative loops include some significant delays, and/or 2) carrying capacity is not fixed. Our model incorporates delays or adaptations, and the simulation with exogenous technological changes in $S_{\max }$, of course, changes carrying capacity. When carrying capacity changes, a system tends to seek for a new steady state consistent with the new carrying capacity. With significant delays in the negative loops (e.g., a 
downward pressure of population growth on available food intake in our model), the system tends to oscillate, as shown in Fig. 4.6. ${ }^{59}$

\subsection{Sensitivity to Consumer Preference}

In our model, following standard economics a preference for harvested good $\beta$ is exogenously given.

Although any value between 0 and 1 is consistent with economic theory, a low value for $\beta$ causes the system to go straight to population extinction. Figure 8 a shows the results of sensitivity of $L$ to various $\beta$, from 0.1 to 0.9 with an increment of 0.02 (i.e., $\beta=$ $\{0.10,0.12,0.14, \ldots, 0.90\})$. For $L$, higher values of $\beta$ (i.e., stronger preference towards good $H$ ) causes the system to generate larger population over time, with more volatile dynamics. Low values of $\beta$ can cause the system to generate immediate declines of the population, leading directly to extinction. In other words, there is a threshold value of $\beta$ below which population goes extinct. The threshold value of $\beta$ is context dependent (i.e., it depends on the other parameter values and the model structure). With our baseline

\footnotetext{
${ }^{59}$ The results are in line with the analytical explanation for the original BT model by Brander and Taylor (1998). They derive the condition for the convergence to a steady state with oscillations and the monotonic convergence to the steady state. Whereas the larger $\eta$ leads to the system converging monotonically, the large $S_{\max }$ leads to the system converging with oscillations.
} 
model, the threshold value of $\beta$ is 0.26 , below which $L$ goes extinct, and as a result the resource stock will return to its capacity $S_{\max }$ (Figure $4.8 \mathrm{~b}$ ) .

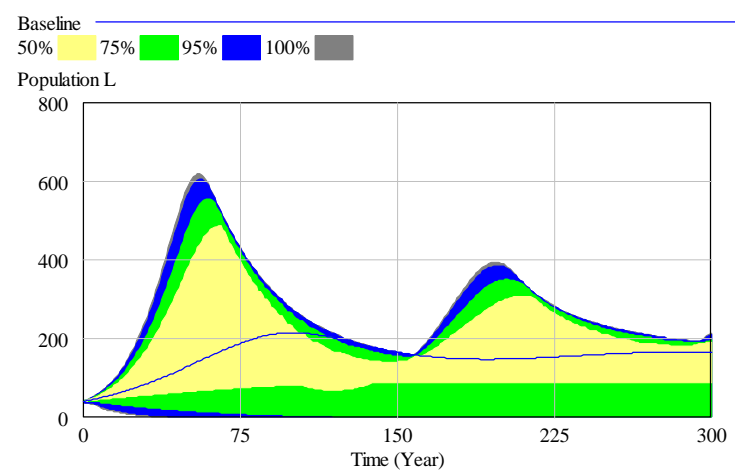

Figure 4.8a. Sensitivity of $L$ to various $\beta$

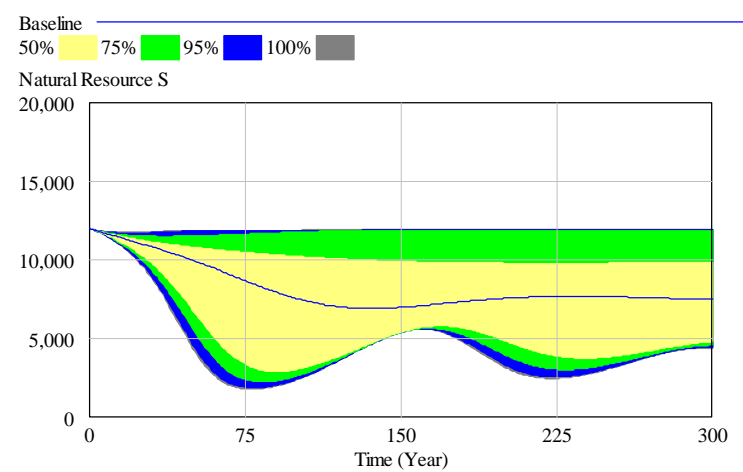

Figure 8 b. Sensitivity of $S$ to various $\beta$ The $50 \%$ region for value of $\beta(0.3$ to 0.7$)$ is shown in yellow. The above figures also show the $75 \%$ region (0.2 to 0.8 ), the $95 \%$ region ( 0.12 to 0.88 ), and the 100 (0.1 to 0.9 ).

Population going directly to extinction indicates that preferences are defined so that, given the surrounding socio-economic circumstances, agents in the system choose not to consume enough harvested good (the dynamic consumption path of $h$ shifts downward as $\beta$ declines). In reality, such a scenario is rarely observed and hence is not of interest to us.

We could avoid such a case by first finding the threshold value of $\beta$ for each numerical simulation. We could use a fixed $\beta$ which is above the threshold or use a specific utility function such as a Stone-Geary type utility function (e.g., Anderies, 2000).

A constant preference for goods is a standard approach in economics, and the effect of varying preferences on an EES has not been investigated. Stern (1997) points out that neoclassical economists are very reticent to discuss the origin of preferences and that 
preferences are normally assumed to be unchanging over time. Our sensitivity analysis, however, highlights the potential significance of studying the effect of varying consumer preferences. The importance of endogenous preferences for sustainability issues has been argued in ecological economics (Common and Stagl, 2005; Georgescu-Roegen, 1950; Stern, 1997), evolutionary economics (Gowdy, 2007), and institutional economics (Hahnel and Albert, 1990; Hahnel, 2001). Gowdy (2007) argues that neoclassical economics assumes that consumer choices are based not only on price signals but also on other incentives such as individual's personal history, their interaction with others, and the social context of the individual choice. The author calls the former the self-regarding preference and the latter the other-regarding preference. If these factors change over time, then preferences should reflect these changes. The author asserts further that modeling the other-regarding behavior would be more realistic for sustainability research. Common and Stagl (2005) argue that to change preference is a normative requirement from a sustainability perspective, including the idea that there could be an ethical basis for changing preferences. While there have been several discussions on endogenous preference, there is no standard way of modeling endogenous preference in economics literature. $^{60}$

${ }^{60}$ One example of modeling endogenous preference is proposed by Stern (1997). Using the symmetric characteristics of production and consumption, he proposes the factor augmentation model using an analogy to endogenously augmenting technology in production. 


\subsection{Impact of Endogenous Substitutability Factor, $\rho$}

As described in Section 2.2, the dynamic equation for substitutability factor $\rho$ generates an s-shaped curve for the value of $\rho$ over knowledge accumulation (KA) index $x$, varying from modest substitutability $(\rho=-1, \sigma=0.5)$ to high substitutability $(\rho \approx 0, \sigma$ $\approx 1$ ) which would be the maximum substitutability ecological economists would consider. The point at which $\rho$ begins to shift rapidly upwards depends on endogenous technological change (ETC) which is driven by relative resource scarcity. Endogenous here does not mean that the value is obtained from some optimization but means that it is determined in the system.

Figure 4.9 shows the results of an experiment to verify that $\rho$ is in fact being endogenously influenced by the evolving state of the system over time. The resource regeneration rate, $\eta$, a parameter that, as we showed in the previous section, strongly impacts $S, L$, and the production rates for the $H$ good and $M$ good, is first doubled and then halved. With a higher $\eta$, natural resource is more plentiful, $p_{H}$ remains relatively low for a long time, and there is less pressure to learn (Figure 4.9, left plot, trace 3). Consequently $\rho$ remained low longer (Figure 4.9, right plot, trace 3) before resource depletion eventually stimulates $p_{H}$, which increases KA index $x$ and $\rho$. 

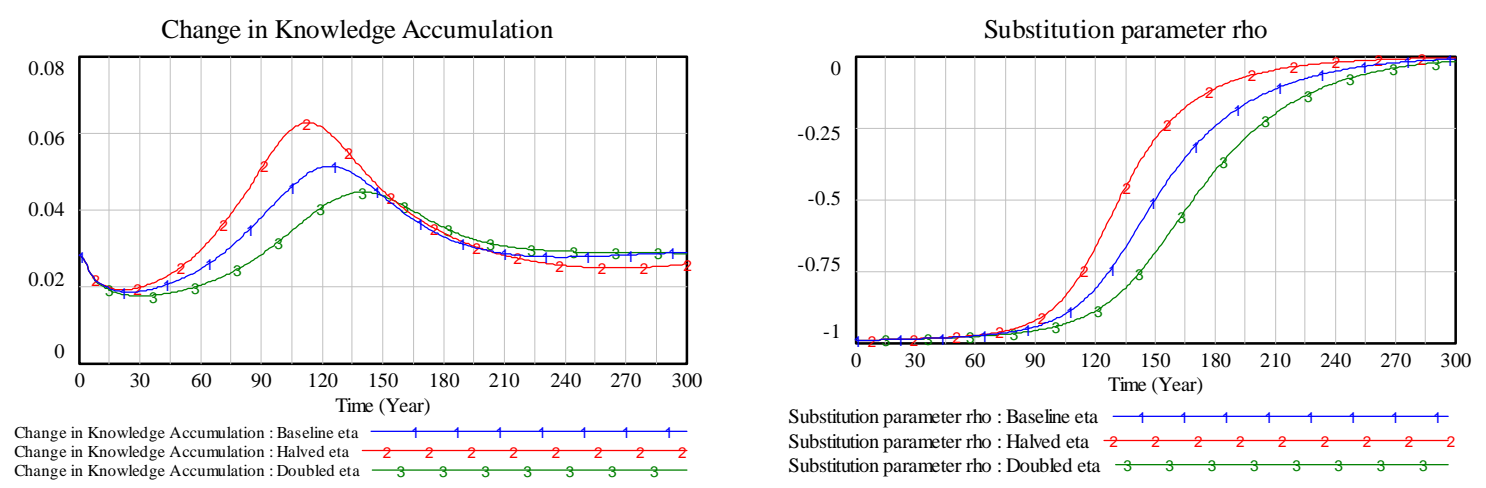

Figure 4.9. Test results to verify the logic that calculates $\rho$ endogenously. Change in Knowledge Accumulation over time is shown on the left, and rho is shown on the right. The traces in each sub-plot reflect three values for the resource regeneration rate: baseline (3) in the middle, doubled (1) lower and to the right, and halved (2), higher and to the left

Once the endogeneity of $\rho$ in our SD model is verified, we can compare the model results with a fixed $\rho$ and those with an endogenous $\rho$. Simulation outcomes of six key variables, utility-per-capita (henceforth, UPC), population $L$, natural resource stock $S, H$ production, $M$ production, and substitutability factor $\rho$ are shown in Figure 4.10, with $\rho=$ -1 , and endogenous $\rho$. A higher elasticity of substitution allows easier factor substitutions and a production could overcome decreasing returns to some degree. A recent survey on a CES function and growth theory by Klump et al. (2011) suggests that in general the elasticity of substitution can be an engine of growth. Our model also indicates that endogenous $\rho$ contributes to larger $L, H, M$, and more use of $S$ as shown in 
Figure $4.10 .^{61}$ However, the UPC, which is one of the indices of sustainability (Pezzey, 1989), shows a barely discernible difference. Barely changing UPC is somewhat counterintuitive since our population dynamics structure is not Malthusian but reflects the demographic transition. Hence it is important to study how the population dynamics structure affects the UPC by using sensitivity analyses to population parameters.

${ }^{61}$ The impact of endogenous $\mathrm{r}$ for the case of weak sustainability, $0<\rho<1(1<\sigma<\infty)$ is also tested and the simulation shows the similar results. 


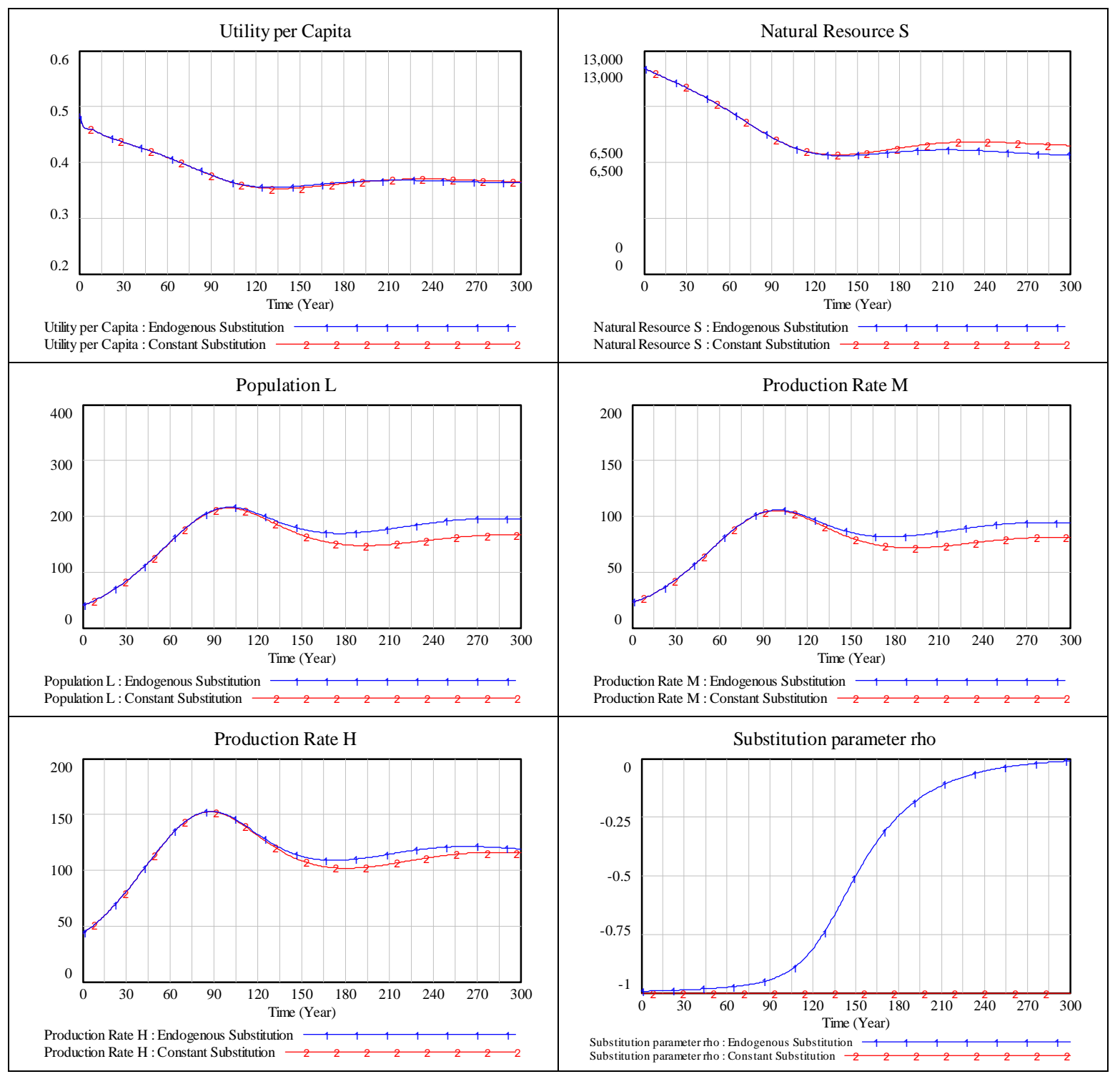

Figure 4.10. Impact of endogenous $\rho$ compared to fixed $\rho$ for six key model outcomes. Traces show $\rho=$ endogenous (1), and -1 (2). 
We provide sensitivity analyses to investigate whether the barely changing UPC between simulations with constant and endogenous $\rho$ is due to the choice of population parameters or if it indicates that the UPC is insensitive to the choice of the population parameters. Since utility is considered to be an ordinal number, we can only say whether it is increasing, decreasing, or not changing.

Among the six population parameters, following Anderies (2003), we provide analyses of the sensitivity of birth rate to manufactured good intake $b_{2}$, and the sensitivity of death rate to manufactured good intake $d_{2}^{62}$, which make our population model nonMalthusian. In our model, increases in $b_{2}$, ceteris paribus, lower population and increases in $d_{2}$, ceteris paribus, push up population as would be expected.

The range of parameters for sensitivity analysis should be reasonably wide to provide a robust result. We adopt the same ranges of parameters as Anderies (2003). However, since his model is similar (a two-sector renewable resource dependent economy with capital accumulation) but not identical to our model, the meanings of the

\footnotetext{
${ }^{62}$ Whereas Anderies (2003) fixes the other population parameters, we conduct preliminary sensitivity analyses for the other four population parameters by applying halved and doubled each parameter. Although thorough sensitivity analysis is recommended rather than just double and half parameters, our preliminary results indicate that difference in the UPC between simulations with constant and endogenous $\rho$ is barely discernible for all the cases.
} 
size of parameters are not necessarily the same. ${ }^{63}$ Following Anderies (2003), $b_{2}$ was tested from 0 to $2 ; d_{2}$ was tested from 0 to 3 ; and the combination of $b_{2}$ and $d_{2}$ was also tested.

Figure 4.11 shows the results. Results in the middle column show the UPC over time for simulations with constant $\rho$ and results in the right column show the UPC over time for simulations with endogenous $\rho$. Comparing figures in each row, difference in the UPC between simulations with constant and endogenous $\rho$ is barely discernable, which indicates that the barely discernible differences in UPC are not likely to be due to the parameter choice for population dynamics.

${ }^{63}$ While Anderies (2003) chooses population parameters analytically, we cannot choose them in the same way for our model because it cannot be solved analytically. This is a topic for further research, using theoretical and/or empirical approaches. 


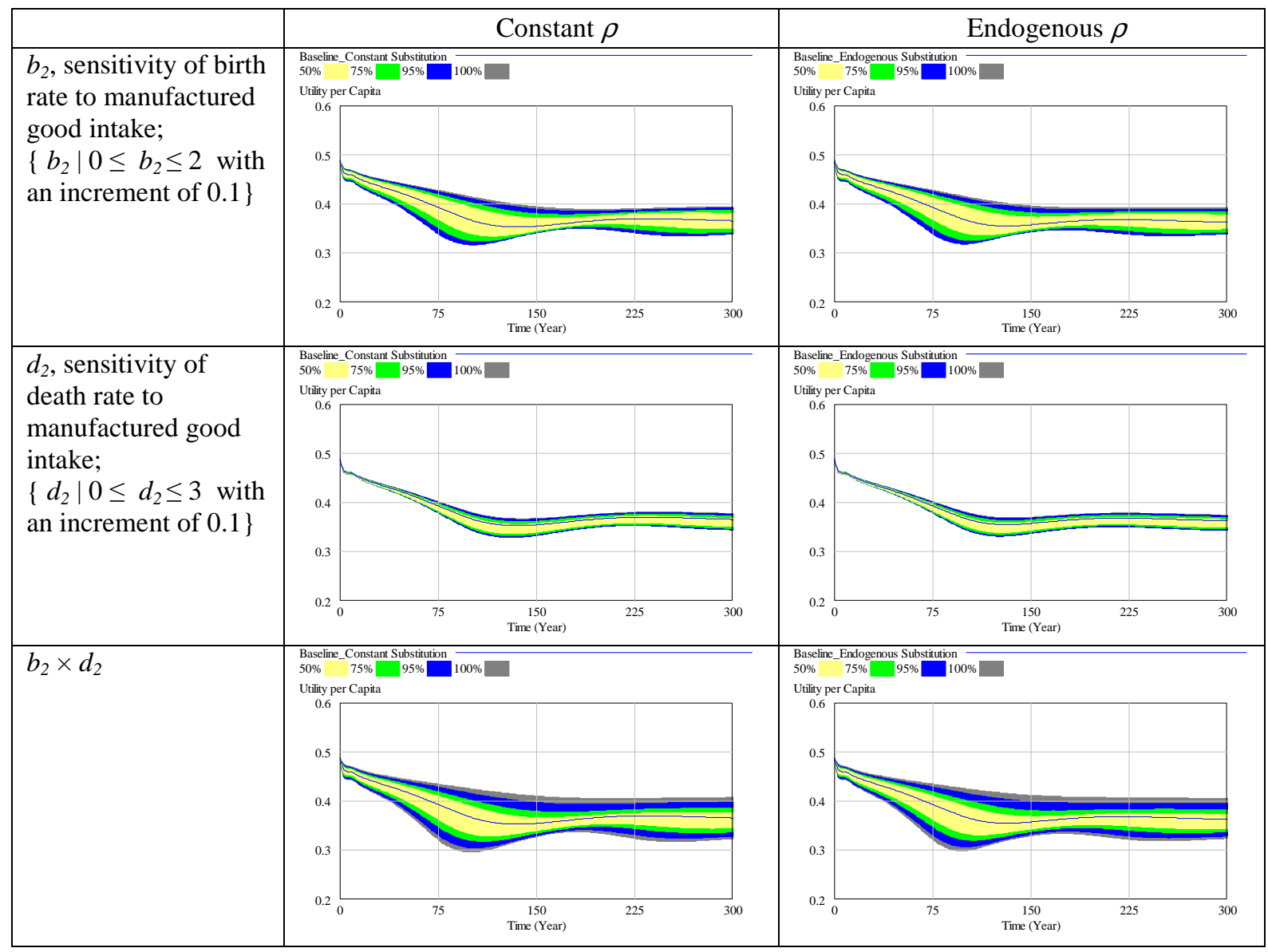

Figure 4.11. Sensitivity analyses to the choice of $b_{2}, d_{2}$, and $b_{2} \times d_{2}$ on UPC between simulations with constant and endogenous $\rho$

*Half of the simulations have generated a value within the $50 \%$ region. For example, the figures in the first row show the simulation results by changing $b_{2}$ ranging $0,0.1,0.2 ., \ldots, 2$. The $50 \%$ region is generated by the half the simulations using $b_{2}=0.6,0.7, \ldots, 1.5$. The $75 \%$ region is generated by the three quarters of the simulations using $\mathrm{b} 2=0.3,0.4, \ldots, 1.8$.

\subsection{Impact of Technological Progress on Utility-per-Capita}

As shown in the previous section, endogenously improving substitutability, $\rho$, ceteris paribus, may increase $M, H$, and $L$ with a further use of $S$, but barely affect UPC. But, 
could a combination of the endogenous $\rho$, combined with other aspects of technological progress impact UPC? Fully incorporating other types of technological progress based on recent literature on innovation is beyond our scope, so the purpose of the following experiments is merely to illustrate possible impacts. Therefore, we apply a simple exogenous technological progress without thorough sensitivity analysis.

Since our motivation is primarily to understand what influences UPC, $u$, we first consider how $u$ is calculated as a function of $H_{C}, M_{C}$, and $L$ :

$$
u(h, m)=u\left(\frac{H_{C}}{L}, \frac{M_{C}}{L}\right)=\left(\frac{H_{C}}{L}\right)^{\beta}\left(\frac{M_{C}}{L}\right)^{1-\beta}
$$

Since changes in $H_{C}, M_{C}$, and $L$ can be positive, zero, or negative, there are various combinations that could lead to $d u>0$.

We experiment with the two primary types of technological progress discussed in the growth literature focused on natural resource scarcity (e.g., Groth, 2007): 1) total factor productivity for $M$ (henceforth, TFP), and 2) resource-saving or $H_{M}$-augmenting technological progress. The following simple form of exogenous technological progress is used to simulate each type technological progress.

$$
E_{k}=E_{k, t=0} e^{\lambda_{k} t}=e^{\lambda_{k} t}
$$

where $k$ is either TFP or $H_{M}$-augmenting, and $E_{k, t=0}$ and $\lambda_{k}$ are, respectively, an initial productivity (assumed to be 1), and the growth rate of productivity for $k$. 
Figure 4.12.a and $\mathrm{b}$ shows selected results. There are three points worth highlighting. First, for both types of technological progress, UPC could increase when the technological progress is large enough, even with limited and constant substitutability, $\rho$ $<$ 0, which is in line with growth literature (Stiglitz, 1974; Groth, 2007). Second, UPC increases more when either type of exogenous technological progress is combined with endogenous substitutability $\rho$. Third, however, the "routes" by which the different types of technological progress combine with endogenous $\rho$ in order to contribute to a larger UPC are quite different. With TFP, compared to the case with constant $\rho$, endogenous $\rho$ raises UPC via a larger $H c, M c$, and $L$, and with smaller $S$. In other words, with endogenous $\rho$ and TFP, increases in $H c$ and $M c$ are sufficiently larger than the increases in $L$ which causes UPC to increase, compared to the case with constant $\rho$ and TFP. ${ }^{64}$ With $\mathrm{H}_{\mathrm{M}}$-augmenting technological progress, however, endogenous $\rho$ raises UPC via smaller $H c, M c$, and $L$, and with larger $S$ remaining. In other words, for the case with endogenous $\rho$ and $\mathrm{H}_{\mathrm{M}}$-augmenting technological progress, decreases in $H c$ and $M c$ are

\footnotetext{
${ }^{64}$ We can compare the dynamics only qualitatively since the rate of growth is chosen arbitrary for TFP and $\mathrm{H}_{\mathrm{M}}$-augmenting technology. The magnitude of the simulated differences between TFP and $\mathrm{H}_{\mathrm{M}^{-}}$ augmenting technology cannot be compared. For the magnitude of the differences to be meaningful, the rate and/or structure of growth should be chosen with a theoretical and empirical basis.
} 
sufficiently smaller than the decreases in $L$ which leads to higher UPC, compared to the case with constant $\rho$ and $\mathrm{H}_{\mathrm{M}}$-augmenting technological progress.

In sum, regarding technological progress and substitutability, while further experimentation is warranted given the complexity of the model and our quite limited experimentation, preliminary experimentation indicates that endogenous substitutability coupled with $H_{M}$-augmenting technological progress could be a desirable strategy from a sustainability perspective because it appears to be able to improve UPS with less consumption of $S .{ }^{65}$

${ }^{65}$ Further sensitivity was conducted and shows the similar result. However, a more thorough sensitivity analysis should be conducted to obtain a robust result. 


\section{Case 1: Total Factor Productivity: Constant $\rho$ vs. Endogenous $\rho$}

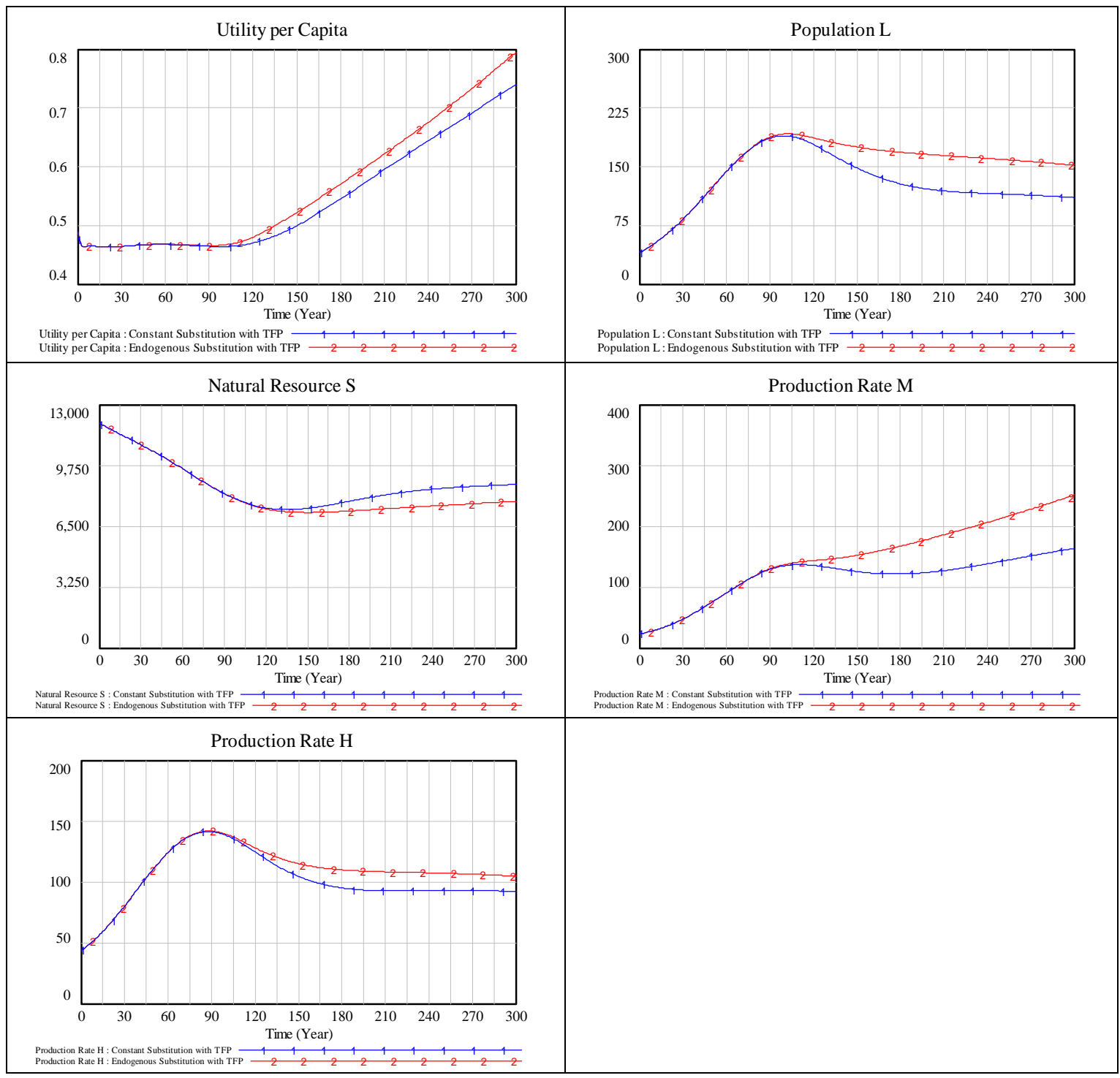

Figure 4.12.a. Impacts of Endogenous $\rho$ in combination with other technological progresses: Case 1 
Case 2: $\mathrm{H}_{\mathrm{M}}$ augmenting technology: Constant $\rho$ vs. Endogenous $\rho$

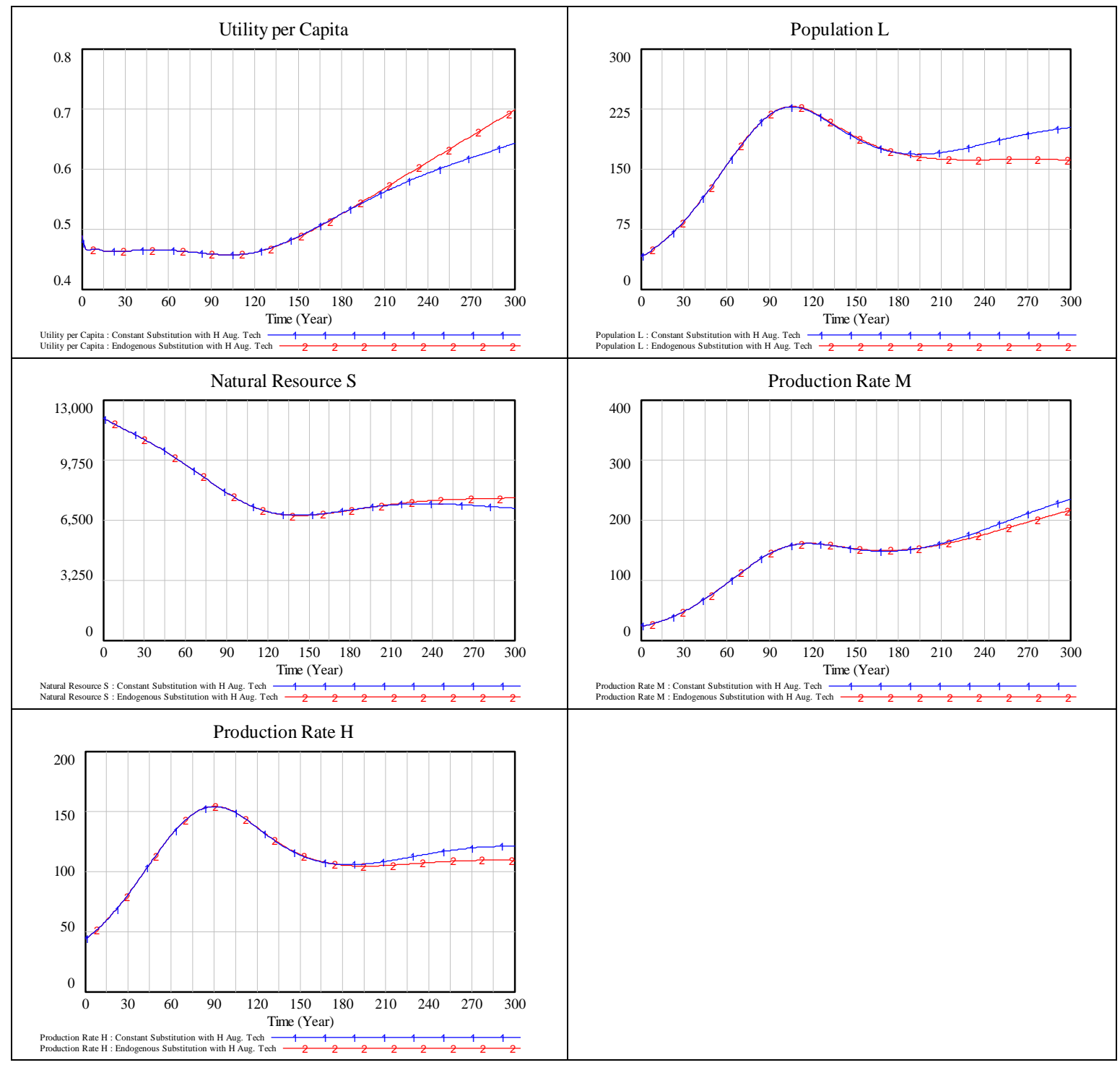

Figure 4.12.b. Impacts of Endogenous $\rho$ in combination with other technological progresses: Case 2 


\section{Discussion}

In addition to implications for sustainable development in developing economies, our simulation results provide two important contributions to the study of an EES. First, we show that while both the regeneration rate of a natural resource $\eta$ and carrying capacity $S_{\max }$ have a positive impact on the growth of the natural resource $G(S)$, their impacts on the system are quite different; the former sustains larger population $L$ with less oscillations and the latter creates oscillations. The difference indicates that we should focus on the better use of the existing natural resources rather than expanding the natural resource base if we want to avoid oscillations of $S$ and $L$. Second, the consumer preference parameter value must be carefully selected to keep the simulation outcomes within the scope of our analytical interest, i.e., to exclude the case of the population heading directly to extinction despite abundant $S$. The issue could be solved either using an exogenous consumer preference chosen with great care or endogenous consumer preference. In view of system dynamics, an endogenous treatment is highly recommended. Even if an exogenous treatment does not make the population go extinct, it still means that consumers do not change their preference in response to changes in their surrounding environment.

In terms of the implications for the sustainability of developing economics, we focus on the role of endogenous substitutability, which is the first such attempt, to the best of our knowledge. Endogenous substitutability, in comparison with a constant 
substitutability, could expand an economy (i.e., larger $H, M$, and $L$ ). However, its contribution to sustainability is questionable. Sustainability is a subjective concept (Derissen et al., 2011), and there are various definitions. In view of ecological economics, utility and natural capital may be appealing (e.g., Pezzey, 1989; Pezzey and Toman, 2005). Our results indicate that endogenous substitutability, ceteris paribus, reduces the natural resource stock $S$ and barely changes UPC. Larger use of $S$ is somewhat counterintuitive because higher substitutability gives us more flexibility in the choice of inputs between the harvest, $H_{M}$, and the man-made capital, $K$. Our model is however designed such that forming $K$ is based on $M$ which requires $H_{M}$ which is taken from $S$. Therefore even if we get more flexibility thanks to higher substitutability between $\mathrm{H}_{\mathrm{M}}$ and $K$, we still require $S$. In addition, our model assumes that agents are myopic and no institutional designs or property rights which promote the conservation of natural resource are incorporated. However, our preliminary simulation results indicate that endogenous substitutability could contribute to increases in UPC when it is associated with other technological progress. Further, there could exist several paths to increases in UPC. With total factor productivity, in raising UPC endogenous substitutability could expand an economy to a greater degree and uses more of $S$ on the one hand. With another approach, $\mathrm{H}_{\mathrm{M}^{-}}$-augmenting technology, endogenous substitutability could expand an economy to a lesser degree and save $S$, while raising UPC. Since the simulation was simple, a thorough sensitivity analysis was not conducted, further investigation is warranted. However, based on our results, we could at 
least corroborate the importance of focused investments to promote induced technological changes (ITC) for sustainable development as Jackson (2009) claims. ${ }^{66}$

\section{Conclusion}

We built and analyzed a dynamic ecological economic model that incorporates innovation regarding input substitutability. The use of the system dynamics method allows us to depart from conventional equilibrium thinking and conduct an out-ofequilibrium analysis. Our results indicate that an endogenous substitutability could, ceteris paribus, expand an economy but could do so in a less sustainable fashion (i.e., larger $H, M, L$ with more use of $S$ ). However, it could be possible for endogenous substitutability to contribute to sustainability in combination with some other technological progress, which promotes focused investments to promote facilitate types of technological progress (i.e., Induced technological changes). In addition to

\footnotetext{
${ }^{66}$ Jackson (2009) provides a detailed discussion about various types of investment. He argues two
} aspects of investment; the target for investment (e.g., energy efficiency and renewable supply) and the condition of investment (commercial rate of return, quasi commercial rate of return, and social rate of return). Given the fact that investments have not been made effectively, the author claims the importance of ITC which promotes the right mix of investments. The author also claims the importance of developing ecological macro-economic models which incorporate the investments properly to study a sustained economy. 
investigating the impact of an endogenous substitutability, we also provided insights into the different impacts of innovation regarding the regeneration rate of a natural resource and carrying capacity.

Our model was parameterized so as to create a specific behavior that is consistent with our chosen reference mode. However, there are different model structures and parameterizations which could create similar behavior. Therefore, further research using different model structures and parameterizations is highly recommended to improve understanding of the behavior of an EES. Our model adds one variation to the existing study of an EES. We do not claim that our model could serve as a panacea that could be applied to any EES (cf., Ostrom, 2007; Anderies et al., 2007).

As Nagase and Uehara (2011) suggest, one of the additional topics to be further investigated is property rights and institutional designs, whose importance is well supported both empirically and theoretically (e.g., Ostrom, 1990). Our model assumes open access. 


\section{Chapter 5: Synthesis and Conclusion}

My dissertation developed and analyzed ecological economic models to study the complex behavior of an EES in order to find conditions and measures that can sustain a developing economy over a long term in view of resilience and sustainability. As a partial fulfillment of the requirement for the degree of Ph.D. in Systems Science, I took a systems approach, using the system dynamics method and drawing from economics theory. Because of the essential complexity of an EES, taking the systems approach, I have shown results that could not have been investigated if I had taken only system dynamics or economics.

My dissertation is comprised of three interwoven articles: the first article provided a comprehensive analysis of the BT-type models to elicit directions of further research to get better understanding of an EES to realize a sustained economy; the second article built and analyzed an extended BT model with focuses on resilience and two types of threshold (i.e., ecological threshold and ecological economic threshold); the third article built and analyzed another extended BT model with a focus on the sustainability of an EES, especially investigating the role of an endogenous innovation regarding input substitutability.

The first article provides a comprehensive analysis of Brander and Taylor's (1998) model and its descendants from the following perspectives: population growth, substitutability, innovation, capital accumulation, property rights and institutional 
designs, and modeling approach. This review aims to contribute to a better understanding of population and resource dynamics models in general and facilitate further application of the model framework to relevant circumstances. Hence, this article provides a foundation for the modeling and analysis in the second and the third articles. The main claims are as follows. Although often treated as exogenous in optimal growth models, making population growth an endogenous function allows us to analyze broader effects of economic activities on population. The issues of substitutability, innovation and capital accumulation are intertwined; allowing a model to address the effect of an endogenous technological change on substitutability between natural and man-made capital facilitates our analyses of sustainability issues. To address internalizing inter-generational externalities in resource use, incorporating changes in property rights and institutional designs to this type of model is a useful exercise, but careful attention is needed for the consistency between such an arrangement and the mathematical representation of the depicted economy. Finally, although the common criticism regarding convenient mathematical assumptions applies to the existing BT-type models, the use of computer simulation can relax such assumptions, to better represent the intended relationships between the relevant variables.

The second article investigates ecological threshold and ecological economic threshold by developing an ecological economic model: an extension of the BT model. Hence the focus of this article is resilience of an EES rather than sustainability. The model reflects three important issues concerning an EES: system boundary, non- 
convexity, and adaptation. The main findings are: a) ecological and ecological economic threshold may not be identical, b) ecological economic threshold is highly context dependent and dynamic, which suggests the precautionary principle, c) market response to an external shock may be insufficient to maintain resiliency, d) it may be possible to restore an EES even after passing ecological economic threshold, e) various transitional paths could be possible to restore the system, and f) adaptation may affect resilience in a non-negligible way, which suggests the importance of better information and education. Because of the complexity of the model, the system dynamics approach is used to develop and analyze the model.

The third article implements some of the suggestions made by the first article except for property rights and institutional designs. An ecological economic model that incorporates endogenous innovation regarding input substitutability is built and analyzed in order to elicit implications for sustainability in developing economies. The use of the SD method allows us to depart from conventional equilibrium thinking and conduct an out-of-equilibrium (adaptation) analysis. Simulation results show that while improvement in input substitutability would expand an economy, the improvement, ceteris paribus, may not contribute to sustainable development. It could, however, be possible that improvement in input substitutability in combination with other technological progress could contribute to sustainable development, which suggests the importance of focused investments to stimulate particular types of technological progress. In addition, a possible problem related to exogenous consumer preference (which is often assumed in 
standard economics) is identified. Finally the system impact of improvements in natural resource regeneration rate and the carrying capacity are analyzed and reported.

In addition to findings about conditions and measures for a developing economy to sustain its economy in terms of resilience and sustainability, my dissertation is also an attempt to take a systems approach with economics as the foundation for the basic structure of an ecological economic model and SD as a method to build and analyze such complex ecological economic models. They complement each other and most of the findings in my dissertation could not have been found if I had taken only an economic approach or a SD approach. There are three contributions of the system dynamics method to the study of an EES: computer simulation, model description, and the SD way of thinking.

As the first article points out, a method which enables us to analyze models that cannot be solved analytically can help obtain further understanding of a complex system. For example, ecological economic threshold which changes dynamically needs a computer simulation to calculate its changes over time. The model in the third article cannot be solved analytically, but using the SD method we can easily analyze such complex models. This method does not require analytic solutions. A hill-climbing method allows us to analyze out-of-equilibrium behavior of the system. Sensitivity analysis helps check the robustness of findings, as shown for the impact of endogenous innovation regarding input substitutability. 
The SD method offers various techniques to portray various aspects of a complex model. Since the model involves many equations and interdependencies, it is hard to grasp the whole picture of the model by studying the equations themselves. Instead, causal loop diagrams, a model boundary table, and stock and flow diagrams, each of which sheds light on the different aspects of the model, were used to describe the model in the third article.

SD is not just a technical tool for computation but also offers a particular way of thinking. For example, the issue with consumer preference was found because the focus of SD on transitional paths, endogeneity, and sensitivity analysis. In the growth literature, the main focus is on the conditions for the steady state: with what conditions, could an economy sustain its growth indefinitely? Therefore, the steady state analysis argues for finding the optimal conditions that could attain, for example, the maximum consumption per capita forever rather than seeking to reveal possible transition paths we might be encountered depending on changes in the state of an EES. 


\section{References}

Asia Development Bank (ADB). (2009). The Economics of Climate Change in Southeast Asia: A Regional Review. Manila: ADB.

Anderies, John M. (2003). Economic development, demographics, and renewable resources: a dynamical systems approach. Environment and Development Economics, 8, 219-246.

Anderies, John M., Armando A. Rodriguez, Marco A. Janssen, and Oguzhan Cifdaloz. (2007). Panaceas, uncertainty, and the robust control framework in sustainability science. PNAS, 104(39), 15194-15199.

Arifovic, Jasmina., and Michael K. Maschek. (2006). Revisiting individual evolutionary learning in the Cobweb model - An illustration of the virtual spite-effect. Computational Economics, 28, 333-354.

Arrow, Kenneth., 1962. The economic implications of learning by doing. Review of Economic Studies 29, 155-173.

Arrow, Kenneth, Bert Bolin, Robert Costanza, Partha Dasgupta, Carl Folke, C. S. Holling, Bengt-Owe Jansson, Simon Levin, Karl-Goran Mäler, Charles Perrings, David Pimentel. (1995). Economic Growth, Carrying Capacity, and the Environment. Science, 268, 520-521.

Ayres, R., (1998). Eco-thermodynamics: economics and the second law. Ecological Economics, 26 (2), 189-209. 
Bahn, Paul G. and John Flenley. (1992). Easter Island, Earth Island. New York: Thames \& Hudson.

Barker, T., (2008). The economics of avoiding dangerous climate change. An editorial essay on the Stern Review. Climatic Change, 89 (3-4), 173-194.

Basener, B. and Ross, D. S. (2005). Booming and crashing populations and Easter Island. SIAM, Journal on Applied Mathematics, 65(2), 684-701.

Basener, W., Brooks B., Radin M., Wiandt, T., (2008). Dynamics of a discrete population model for extinction and sustainability in ancient civilizations. Nonlinear Dynamics, Psychology, and Life Science, 12 (1), 29-53.

Beltratti, A., (1997). Growth with natural and environmental resources. In: Carraro, C., Siniscalco, D. (Eds.), New Directions in the Economic Theory of the Environment. Cambridge University Press, Cambridge, UK, 7-42.

Brander, James A., and M. Scott Taylor (1998). The simple economics of Easter Island: a Ricardo-Malthus model of renewable resource use. American Economic Review, 88 (1), 119-138.

Barzel, Y., (2000). Property rights and the evolution of the state. Economics of Governance, 1 (1), 25-51.

Bullard, James B. (2006). The learnability criterion and monetary policy. Federal Reserve Bank of St. Louis Review, 203-217. 
Basener, W., Brooks, B., Radin, M., and Wiandt T. (2008). Dynamics of a discrete population model for extinction and sustainability in ancient civilizations. Nonlinear Dynamics, Psychology, and Life Sciences, 12(1), 29-53.

Bhattacharya, H., Lueck, D., (2009). The role of property rights in determining the environmental quality-income relationship. Ecological Economics, 68 (10), 25112524.

Birdyshaw, E. and Ellis, C., (2007). Privatizing an open-access resource and environmental degradation. Ecological Economics, 61 (2-3), 469-477.

Branch, William A. (2004). Restricted perceptions equilibria and learning in macroeconomics, Post Walrasian Macroeconomics: Beyond the Dynamic Stochastic General Equilibrium Model, ed. David Colander, Cambridge University Press

Bretschger, Lucas. (2005). Economics of technological change and the natural environment: How effective are innovations as a remedy for resource scarcity? Ecological Economics, 54, 148-163.

Bretschger, Lucas and Karen Pittel. (2008). From time zero to infinity: transitional and long-run dynamics in capital-resource economies. Environmental and Development Economics, 13, 673-689.

Caputo M., Lueck, D., (2003). Natural resource exploitation under common property rights. Natural Resource Modeling, 16 (1), 39-67. 
Carpenter, Stephen., Frances Weskley, and Monica G. Turner. (2005). Surrogates for resilience of social-ecological systems. Ecosystems, 8, 941-944.

Castelnuovo, Efrem, Marzio Galeotti, Gretel Gambarelli, and SergioVergalli (2005). Learning-by-doing vs. learning by researching in a model of climate change policy analysis. Ecological Economics 54: 261-276.

Cheviakov, A., Hartwick, J., (2009). Constant per capita consumption paths with exhaustible resources and decaying produced capital. Ecological Economics, 68 (12), 2969-2973.

Cleveland, Cutler J., Robert Costanza, Charles A.S. Hall, and Robert Kaufmann (1984). Energy and the US economy: a biophysical perspective. Science, 255, 890-897.

Cleveland, Cutler J. and Matthias Ruth (1997). When, where and by how much do biophysical limits constrain the economic process: a survey of Nicolas Georgescu-Roegen's contribution to ecological economics. Ecological Economics, 22, 203-223.

Conrad, Jon M. (2010). Resource Economics ( $2^{\text {nd }}$ Ed.). New York: Cambridge University Press.

Common, Michael., and Sigrid Stagl. (2005) Ecological Economics: An introduction. Cambridge: Cambridge University Press.

Costanza, Robert. (1987). Social traps and environmental policy. BioScience, 37, 407412. 
Costanza, Robert., Lisa Wainger, Carl Folke, and Karl-Goran Mäler. (1993). Modeling Complex Ecological Economic Systems. BioScience, 43(8), 545-555.

D’Alessandro, Simone. (2007). Non-linear dynamics of population and natural resources: the emergence of different patterns of development. Ecological Economics, 62, 473-471.

Dalton, Thomas R., and R. Morris Coats (2000). Could institutional reform have saved Easter Island? Journal of Evolutionary Economics, 10, 489-505.

Dalton, Thomas R., R. Morris Coats, and Badiollah R. Asrabadi (2005). Renewable resources, property-rights regimes and endogenous growth. Ecological Economics, 52, 31-41.

Daly, Herman E. (1991). Elements of an environmental macroeconomics. In Costanza, R. (Ed.). Ecological Economics (pp. 32-46). New York: Oxford University Press.

Daly Herman E. and Joshua Farley (2010). Ecological Economics: Principles and Applications (2nd Ed.). Washington: Island Press.

Dasgupta, Partha (2008). Nature in economics. Environmental Resource Economics, 39, $1-7$.

de la Croix., and Dottori, D. (2008). Easter Island: a tale of a population race. Journal of Economic Growth, 13, 27-55.

Dasgupta, P., Heal, G., (1974). The optimal depletion of exhaustible resources. Review of economic studies, symposium, 3-28. 
Dasgupta, Partha., and G.M. Heal. (1979). Economic theory and exhaustible resources. Cambridge: Cambridge University Press.

Dasgupta, Partha., and Karl_Goran Mäler. (2003). The economics of non-convex ecosystems: Introduction. Environmental and Resource Economics, 26, 499-525.

Day, Richard H. (1994). Complex Economic Dynamics, Volume I, An Introduction to Dynamical Systems and Market Mechanisms. Massachusetts: The MIT Press.

De la Croix, D., Dottori, D., (2008). Easter Island's collapse: a tale of a population race. Journal of Economic Growth, 13 (1), 27-55.

Demsetz, H., (2002). Toward a theory of property rights II: the competition between private and collective ownership. Journal of Legal Studies, 31 (2), S653-S672.

Derissen,Sandra, Martin F. Quaas, Stefan Baumgärtner. (2011). The relationship between resilience and sustainability of ecological-economic system. Ecological Economics, 70, 1121-1128.

de Vries, Bert (2010). Interacting with complex systems: models and games for a sustainable economy. Netherlands Environmental Assessment Agency. Retrieved 25 April, 2012 from http://www.pbl.nl/en/publications/2010

Diamond, J., (2004). Collapse: how societies choose to fail or succeed. Viking, New York.

Economides, G., Philippopoulos, A., (2007). Growth enhancing policy is the means to sustain the environment. Review of Economic Dynamics, 11 (1), 207-219. 
Edenhofer, O., Lessmann, K., Kemfert, C., Grubb, M., Köhler, J., (2006). Induced technological change: exploring its implications for the economics of atmospheric stabilization. Synthesis report from the innovation modeling comparison project. Energy Journal, Endogenous Technological Change and the Economics of Atmospheric Stabilization Special Issue, 207-222.

Elíasson, L., Turnovsky, S., (2004). Renewable resources in an endogenously growing economy: balanced growth and transitional dynamics. Journal of Environmental Economics and Management, 48 (3), 1018-1049.

Erickson, Jon D. and John M. Gowdy (2000). Resource use, institutions, and sustainability: a tale of two Pacific island cultures. Land Economics, 76, 345-354.

Evans, George W. and Seppo Honkapohja (2008). Learning in macroeconomics. The New Palgrave Dictionary of Economics, Second Edition.

Evans, George W. and Seppo Honkapohja (2009). Learning and macroeconomics. The Annual Review of Economics, 1, 421-449.

Evans, George W. and Seppo Honkapohja (2011). Learning as a rational foundation for macroeconomics and finance. Working Paper.

Folke, Carl, Steve Carpenter, Thomas Elmqvist, Lance Gunderson, C. S. Holling, and Brian Walker. (2002). Resilience and sustainable development: building adaptive capacity in a world of transformations. Ambio, 31(5), 437-440. 
Forini, Ilaria, Laura Gardini, and J. Barkley Rosser Jr. (2003). Adaptive and statistical expectations in a renewable resource market. Mathematics and Computers in Simulation, 63, 541-567.

Galor, Oded. (2005). From stagnation to growth: unified growth theory. In Philippe Aghion and Steven N. Durlauf (Ed.). Handbook of Economic Growth, Volume 1A (pp.171-293).

Galor, Oded and David Weil (2000). Population, technology, and growth: from Malthusian stagnation to demographic transition and beyond. The American Economic Review, 90(4), 806-828.

Gelso, B., Peterson, J., (2005). The influence of ethical attitudes on the demand for environmental recreation: incorporating lexicographic preferences. Ecological Economics, 53 (1), 35-45.

Georgescu-Roegen, N. (1950). The theory of choice and the constancy of economic laws. Quarterly Journal of Economics, 64, 125-138.

Gerlagh, R., van der Zwaan, B., (2002). Long-term substitutability between environmental and man-made goods. Journal of Environmental Economics and Management, 44 (2), 329-345.

Good, David H. and Rafael Reuveny (2006). The fate of Easter Island: the limits of resource management institutions. Ecological Economics, 58, 473-490.

Goodstein, Eban S. (2007). Economics and the Environment ( $5^{\text {th }}$ Ed.). Wiley. 
Gowdy, John (2007). Avoiding self-organized extinction: Toward a co-evolutionary economics of sustainability. International Journal of Sustainable Development \& World Ecology, 14, 27-36.

Gritsevskyi, A., Nakićenović, N., (2000). Modeling uncertainty of induced technological change. Energy Policy, 28 (13): 907-921.

Groth, Christian. (2007). A new-growth perspective on non-renewable resources. In L. Bretschger and S. Smulders (Eds.). Sustainable Resource Use and Economic Dynamics (pp.127-163). Springer.

Grubb, M., Köhler, J., Anderson, D., (2002). Induced technical change in energy and environmental modeling: analytic approaches and policy implications. Annual Review of Energy and Environment, 27 (1): 271-308.

Hahnel, Robin (2001). Endogenous preferences: The institutionalist connection. Dutt, In Amitava K. and Kenneth P. Jameson (Eds.). Crossing the Mainstream: Ethical and Methodological Issues in Economics (pp.315-331). Notre Dame: University of Notre Dame Press.

Hahnel, Robin and Michael Albert (1990). Quiet Revolution in Welfare Economics. Oxford: Princeton University Press.

Hamilton, Kirk. (1995). Sustainable development, the Hartwick rule and optimal growth. Environmental and Resource Economics, 5, 393-411.

Hanley, Nick (1998). Resilience in social and economic systems: a concept that fails the cost-benefit test? Environment and Economic Development, 3, 244-249. 
Hansen, Gary D. and Edward C. Prescott (2002). Malthus to Solow. American Economic Review, 92(4), 1205-1217.

Hartwick, John M. (1977). Intergenerational equity and investing rents from exhaustible resources. American Economic Review, 67(5), 972-974.

Holling, C.S. (1986). The resilience of terrestrial ecosystems: local surprise and global change. In: Clark, W.C., Munn, R.E. (Eds.). Sustainable Development of the Biosphere. Cambridge University Press, Cambridge.

Holling, C.S. (1999). Introduction to the special feature: Just complex enough for understanding; Just simple enough for communication. Conservation Ecology, 3(2):1. [online] Retrieved 25 April, 2012 from http://www.consecol.org/vol3/iss2/art1/

Holling, C.S. and Walker B.H. (2003). Resilience defined. In International Society of Ecological Economics (Ed.). Internet Encyclopedia of Ecological Economics.

Hommes, Cars H., and J. Barkley Rosser, Jr. (2001). Consistent expectations equilibria and complex dynamics in renewable resource markets. Macroeconomic Dynamics, 5, 180-203.

Hiroshi Kito (1996). The regional population of Japan before the Meiji period. Jochi Keizai Ronsyu. 41(1-2), 65-79 (in Japanese).

Jackson, Tim. (2009). Prosperity Without Growth. London: Earthscan.

Kahn, James R., and Robert V. O'Neill. (1999). Ecological interaction as a source of economic irreversibility. Southern Economic Journal, 66 (2), 391-402. 
Kaiser, B. and Roumasset, J., (2007). From rites to rights: the co-evolution of political, economic and social structures. University of Hawaii at Manoa, Department of Economics, $\quad$ Working 200703. http://www.economics.hawaii.edu/research/workingpapers/WP_07-3.pdf

Khatri, Y., Thirtle, C., Townsend, R., (1998). Testing the induced innovation hypothesis: an application to UK agriculture, 1953-90. Economics of Innovation and New Technology, 6 (1), 1-28.

Klump, Rainer., Peter McAdam and Alpo Willman. (2011). The normalized CES production function: Theory and Empirics. European Central Bank Working Paper Series, No.1294.

Köhler, J., Barker T., Pan, H., Agnolucci, P., Ekins, P., Foxon, T., Anderson, D., Winne, S., Dewick, P., Miozzo, M., Green, K., (2007). New lessons for technology policy and climate change: investment for innovation: a briefing for policy makers. Climatic Policy, 7, 156-161.

Kostyshyna, Olena. Application of an adaptive step-size algorithm in models of hyperinflation. Macroeconomic Dynamics (Forthcoming).

Krasny, Marianne E., Cecilia Lundholm and Ryan Plummer (Eds.). (2011). Resilience in Social-Ecological Systems: The Role of Learning and Education. London: Routledge. 
Lawn, P., (2003). How important is natural capital in terms of sustaining real output? Revisiting the natural capital/human-made capital substitutability debate. International Journal of Global Environmental Issues, 3 (4), 418-435.

Leach, Melissa, Ian Scoones and Andy Stirling. (2010). Dynamic Sustainabilities: Technology, Environment, Social Justice. London: Earthscan.

Leslie, P., (1948). Some Further Notes on the Use of Matrices in Population Mathematics. Biometrika, 35 (3-4), 213-245.

Levin, Simon A., Scott Barrett, Sara Aniyar, William Baumol, Christopher Bliss, Bert Bolin, Partha Dascupta, Paul Ehrlich, Carl Folke, Ing-Marie Gren, C.S. Holling, Annmari Jansson, Bengt-Owe Jansson, Karl-Goran Mäler, Dan Martin, Charles Perrings, and Eytan Sheshinski (1998). Resilience in natural and socioeconomic systems. Environment and Development Economics, 3, 222-235.

Libecap, G., (2009). The tragedy of the commons: property rights and markets as solutions to resource and environmental problems. Australian Journal of Agricultural and Resource Economics, 53 (1), 129-144.

Limburg, Karin E., Robert V. O'Neill, Robert Costanza, and Stephen Farber. (2002). Complex systems and valuation. Ecological Economics, 41, 409-420.

Löschel, Andreas (2002). Technological change in economic models of environmental policy: a0 survey. FEEM Working Paper No. 4.2002; ZEW Discussion Paper No. $01-62$. 
Madsen, Jakob B., James B. Ang, and Rajabrata Banerjee (2010). Four centuries of British economic growth: the roles of technology and population. Journal of Economic Growth, 15, 263-269.

Mäler, Karl-Goran. (2008). Sustainable development and resilience in ecosystems. Environmental Resource Economics, 39, 17-24.

Markandya, Anil., Patrice Harou, Lorenzo Giovanni Bellu and Vito Cistulli. (2002). Environmental Economics for Sustainable Growth: A Handbook for Practitioners. Edward Elgar: UK.

Markandya, A., Pedroso-Galinato, S. (2007). How substitutable is natural capital? Environmental and Resource Economics, 37 (1): 297-312.

Maxwell, John W. and Rafael Reuveny (2000). Resource scarcity and conflict in developing countries. Journal of Peace Research, 37(3), 301-322.

Merrill, T., (2002). Introduction: the Demsetz thesis and the evolution of property rights. Journal of Legal Studies, 31 (2), S331-338.

Muneepeerakul, Rachata and Murad R. Qubbaj. (2012). The effect of scaling and connection on the sustainability of socio-economic resource system, Ecological Economics, 77, 123-128.

Nagase, Yoko and Tasneem Mirza (2006). Substitutability of resource use in production and consumption. Conference Proceedings, 3rd World Congress of Environmental and Resource Economics. 
Nagase, Yoko and Uehara, Takuro (2011). Evolution of population-resource dynamics models. Ecological Economics, (72), 9-17.

Nerlove, Marc. (1958). Adaptive expectations and cobweb phenomena. The Quarterly Journal of Economics, 72(2), 227-240.

Neumayer, Eric (2000). Scarce or abundant? The economics of natural resource availability. Journal of Economic Surveys, 14(3), 307-335.

Nordhaus, W., Tobin, J., (1972). Is economic growth obsolete? In economic growth, the NBER Fiftieth Anniversary Colloquium, New York: Columbia University Press.

Ostrom, Elinor. (1990). Governing the Commons: the Evolution of Institutions for Collective Action. Cambridge, MA: Cambridge Univ. Press.

Ostrom, Elinor. (2002). The evolution of norms within institutions: comments on Paul R. Ehrlich and Anne H. Ehrlich's 'Population, development, and human nature'. Environmental and Development Economics, 7 (1), 177-182.

Ostrom, Elinor, Marco A. Janssen, and John M. Anderies. (2007). "Going beyond panaceas.” PNAS, 104(39), 15176-15178.

Pezzey, J.C.V. (1989). Economic Analysis of Sustainable Growth and Sustainable Development. Environment Department Working Paper No. 15. Published as Sustainable Development Concepts: An Economic Analysis, World Bank Environment Paper No. 2, 1992. Washington DC: World Bank. 
Pezzey, J., and Anderies, J. (2003). The effect of subsistence on collapse and institutional adaptation in population-resource societies. Journal of Development Economics, 72 (1), 299-320.

Pezzey, John C. V. and Michael A. Toman. (2005). Sustainability and its economic interpretations. In R.D. Simpson, M.A. Toman and R.U. Ayres (Eds.). Scarcity and Growth: Natural Resources and the Environment in the New Millennium (pp.121-141). Washington D.C.: RFF Press.

Pimm, S.L. (1984). The complexity and stability of ecosystems. Nature, 307, 321-326.

Pittel, Karen. (2002). Sustainability and Endogenous Growth. Massachusetts: Edward Elgar.

Popp, D., (2002). Induced innovation and energy prices. American Economic Review, 92 (1), 160-180.

Prskawetz, Alexia, Gragnani, Alessandra, and Gustav Feichitnger (2003). Reconsidering the dynamic interaction of renewable resources and population growth: a focus on long-run sustainability. Environmental Modeling and Assessment, 8, 35-45.

Reuveny, Rafael and Christopher S. Decker (2000). Easter Island: historical anecdote or warning for the future? Ecological Economics, 35, 271-287.

Richardson, George P. (2011). Reflections on the foundations of system dynamics. System Dynamics Review, 27(3), 219-243.

Rockstrom, J., Stephen, W., Noone, K., et al. (2009). A safe operating space for humanity. Nature, 461, 472-475. 
Rogers, Everett (1995). The Diffussion of Innovation, 4th ed., New York: Free Press.

Romer, David (2011). Advanced Macroeconomics. McGraw-Hill, New York.

Scrieciu, S., (2006). The inherent dangers of using computable general equilibrium models as a single integrated modelling framework for sustainability impact assessment: a critical note on Böhringer and Löschel (2006).” Ecological Economics, 60 (4), 678-684.

Solow Robert M. (1956). A contribution to the theory of economic growth. Quarterly Journal of Economics, 70, 65-94.

Solow, Robert M. (1974a). Intergenerational Equity and Exhaustible Resources. The Review of Economic Studies Symposium Issue, 41, 29-45.

Solow, Robert M. (1974b). The economics of resource or the resources of economics. American Economic Review Papers and Proceedings, 64(2), 1-14.

Solow, Robert M. (1999). Neoclassical growth theory, in Taylor, J., Woodford, M. (Eds.), Handbook of Macroeconomics 1 (1A), 637-667, New York: Elsevier.

Shukla, J. B., Kusum Lata and A.K. Misra (2011). Modeling the depletion of a renewable resource by population and industrialization: Effect of technology on its conservation. Natural Resource Modeling, 24(2), 242-267.

Stagl, Sigrid (2007). Theoretical foundations of learning processes for sustainable development. International Journal of Sustainable Development \& World Ecology, 14, 52-62. 
Stamford da Silva, A., (2008). Growth with exhaustible resource and endogenous extraction rate. Economic Modelling, 25 (6), 1165-1174.

Sterman, John (1980). The use of aggregate production functions in disequilibrium models of energy-economy interactions. MIT System Dynamics Group Memo D3234. Cambridge, MA 02142.

Sterman, John D. (2000). Business Dynamics: systems thinking and modeling for a complex world. Boston: McGraw-Hill Higher Education.

Stern, David I. (1997). Limits to substitution and irreversibility in production and consumption: A neoclassical interpretation of ecological economics. Ecological Economics, 21, 197-215.

Stiglitz, Joseph. (1974). Growth with exhaustible natural resources: Efficient and optimal growth paths. The Review of Economic Studies Symposium Issue, 41, 123-137.

Strulik, Holger (1997). Learning-by-doing, population pressure, and the theory of demographic transition. Journal of Population Economics, 10, 285-298.

Strulik, Holger and Jacob Weisdorf (2008). Population, food, and knowledge: a simple unified growth theory. Journal of Economic Growth, 13, 195-216.

Taylor, M. Scott (2009). Innis lecture: environmental crises: past, present, and future. Canadian Journal of Economics, 42(4), 1240-1275.

The Economist. (2009). The state of economics: the other-worldly philosophers. July 16, 2009. 
Thirtle, C., Townsend, R., van Zyl, J. (1998). Testing the induced innovation hypothesis: an error correction model of South African agriculture. Agricultural Economics, $19(1-2), 145-157$.

Tietenberg, Tom and Lynne Lewis (2011). Environmental \& Natural Resource Economics $\left(9^{\text {th }} E d\right)$. NJ: Prentice Hall.

Uehara, Takuro, Yoko Nagase, and Wayne Wakeland (2010). System dynamics implementation of an extended Brander and Taylor-like Easter Island model. Proceedings of the 28th International Conference of the System Dynamics Society, Seoul, Korea.

United Nations Economic and Social Commission for Asia and the Pacific (ESCAP) (2010). Green Growth, Resources and Resilience: Environmental Sustainability in Asia and the Pacific.

Turchin, P. (2003). Complex Population Dynamics: A Theoretical/Empirical Synthesis. New Jersey: Princeton University Press.

Volterra, V. (1931). Leçons sur la Théorie Mathématique de la lutte pour la Vie. Gauthier-Villars, Paris.

Voigtlander, Nico and Hans-Joachim Voth (2006). Why England? Demographic factors, structural change and physical capital accumulation during the Industrial Revolution. Journal of Economic Growth, 11, 319-361. 


\section{Appendix A: Stock and Flow Diagrams}

\section{The Stock and Flow Diagram for the model without Adaptation}

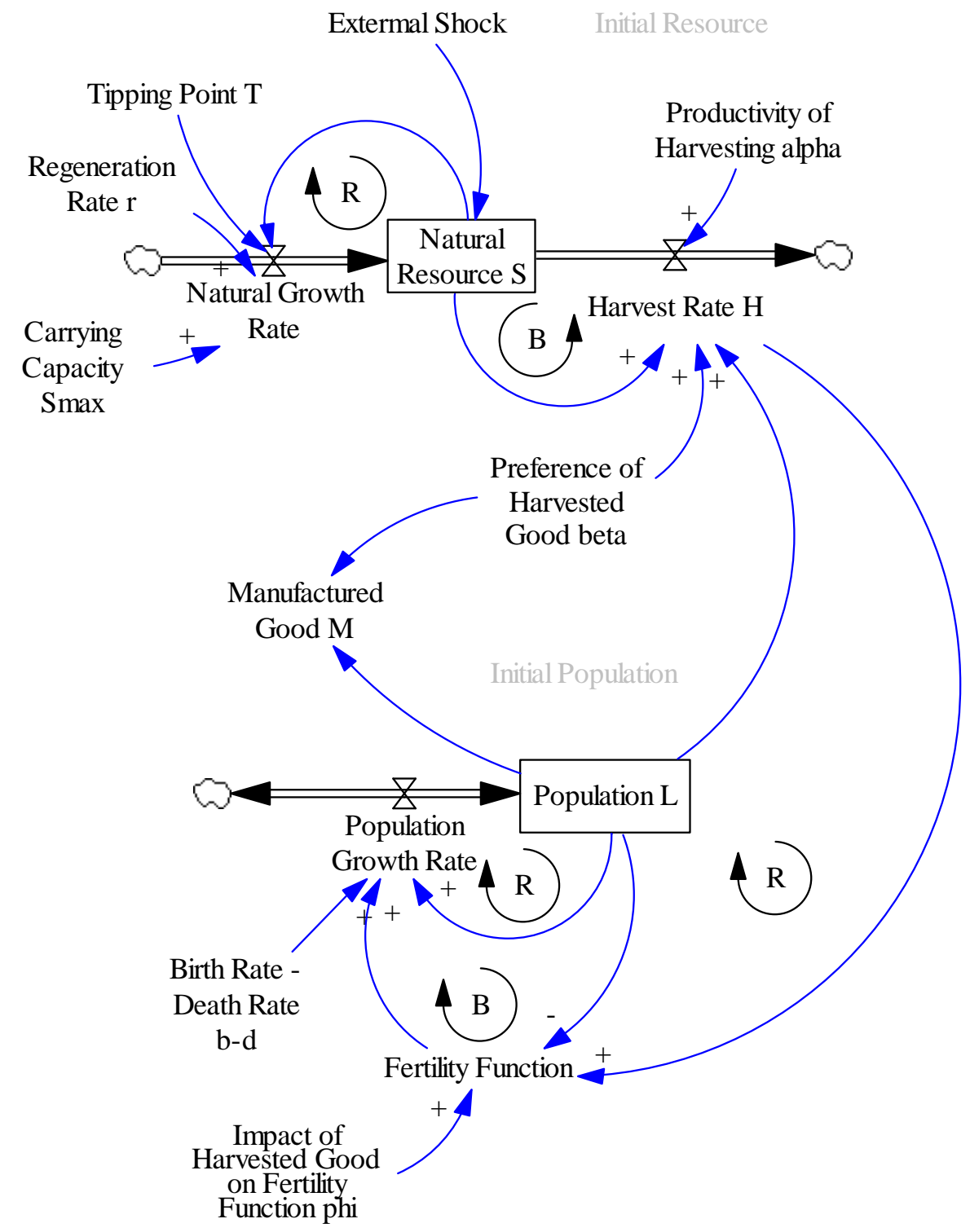




\section{The Stock and Flow Diagram with Adaptation}

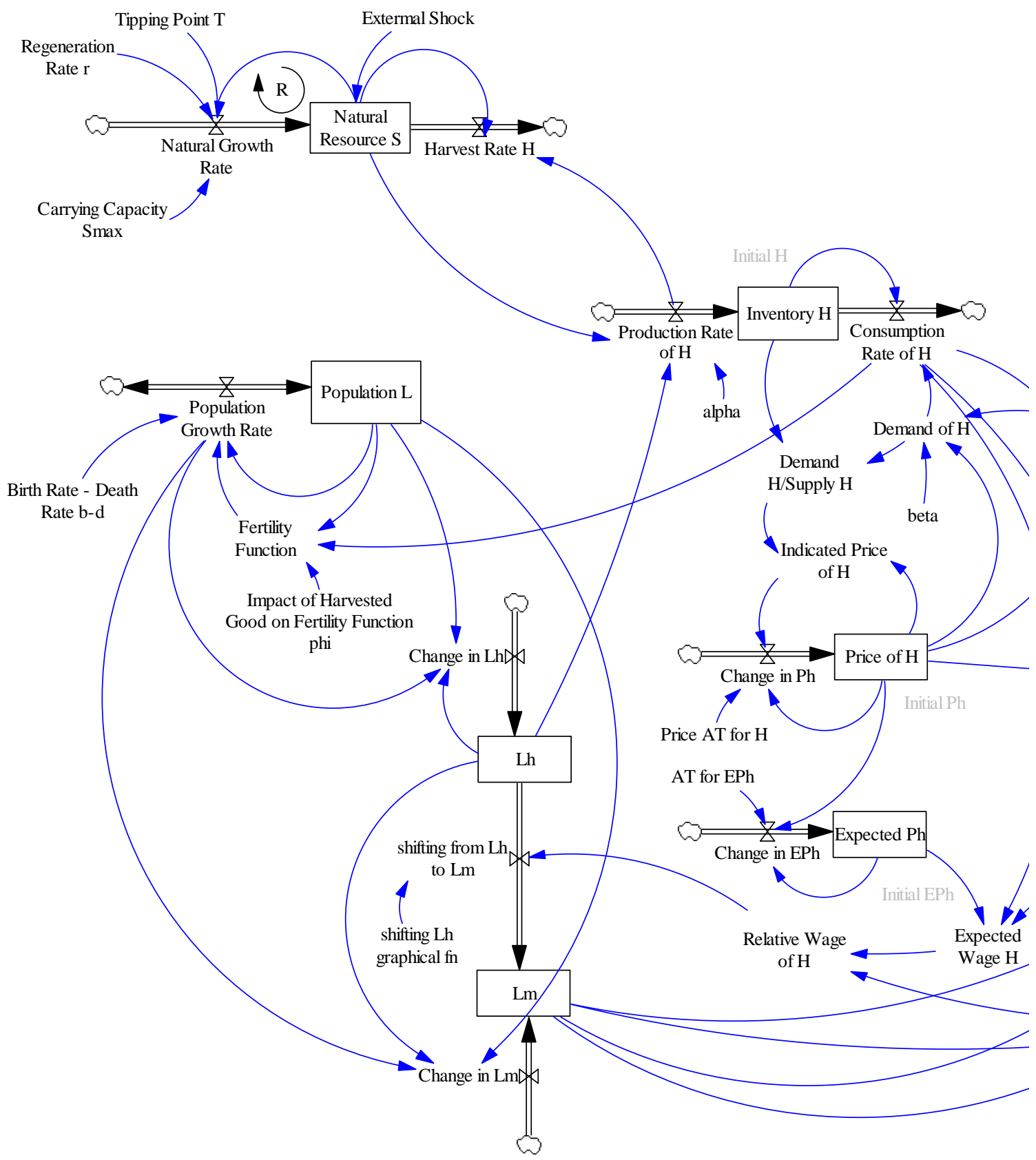




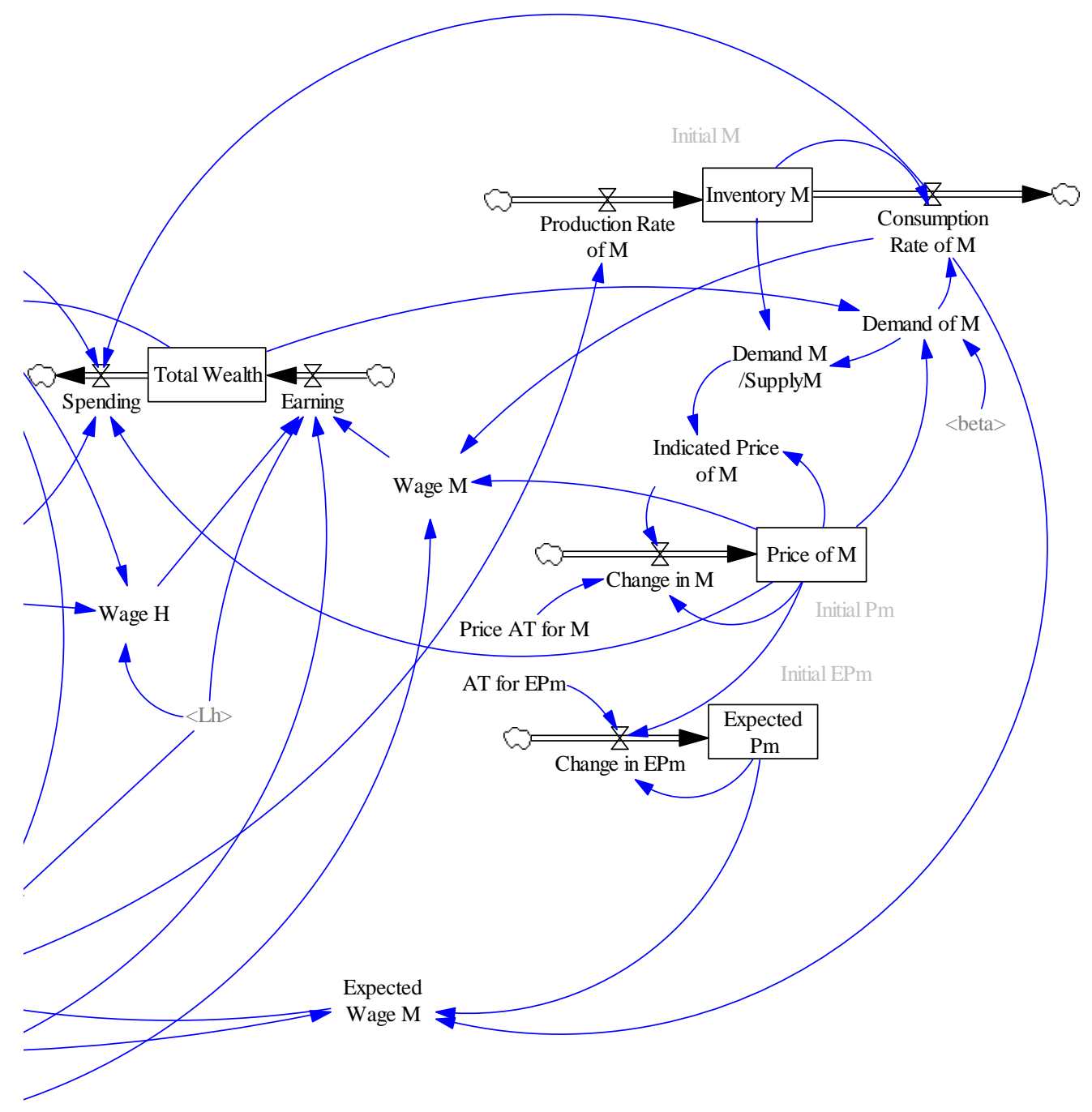




\section{Appendix B: Values of exogenous variables for the baseline model}

Exogenous variables for the baseline model are calibrated to generate a behavior such that the population and the natural resource are somewhat stabilized over time as observed in the Edo era in Japan (Figure 2). Some values are adopted from Brander and Taylor (1998) or Anderies (2003). Natural Resource $\mathrm{S}$ and Population $\mathrm{L}$ are considered to be an index rather than some actual unit. While population parameters are adopted from Anderies (2003), his model is not identical to our model so that the meanings of them are not necessarily the same. However, with these parameters, population growth with our baseline model ranges from $-0.68 \%$ to $2.56 \%$ which is not biologically unrealistic.

\begin{tabular}{|c|c|c|}
\hline Parameter & Value & Reference \\
\hline 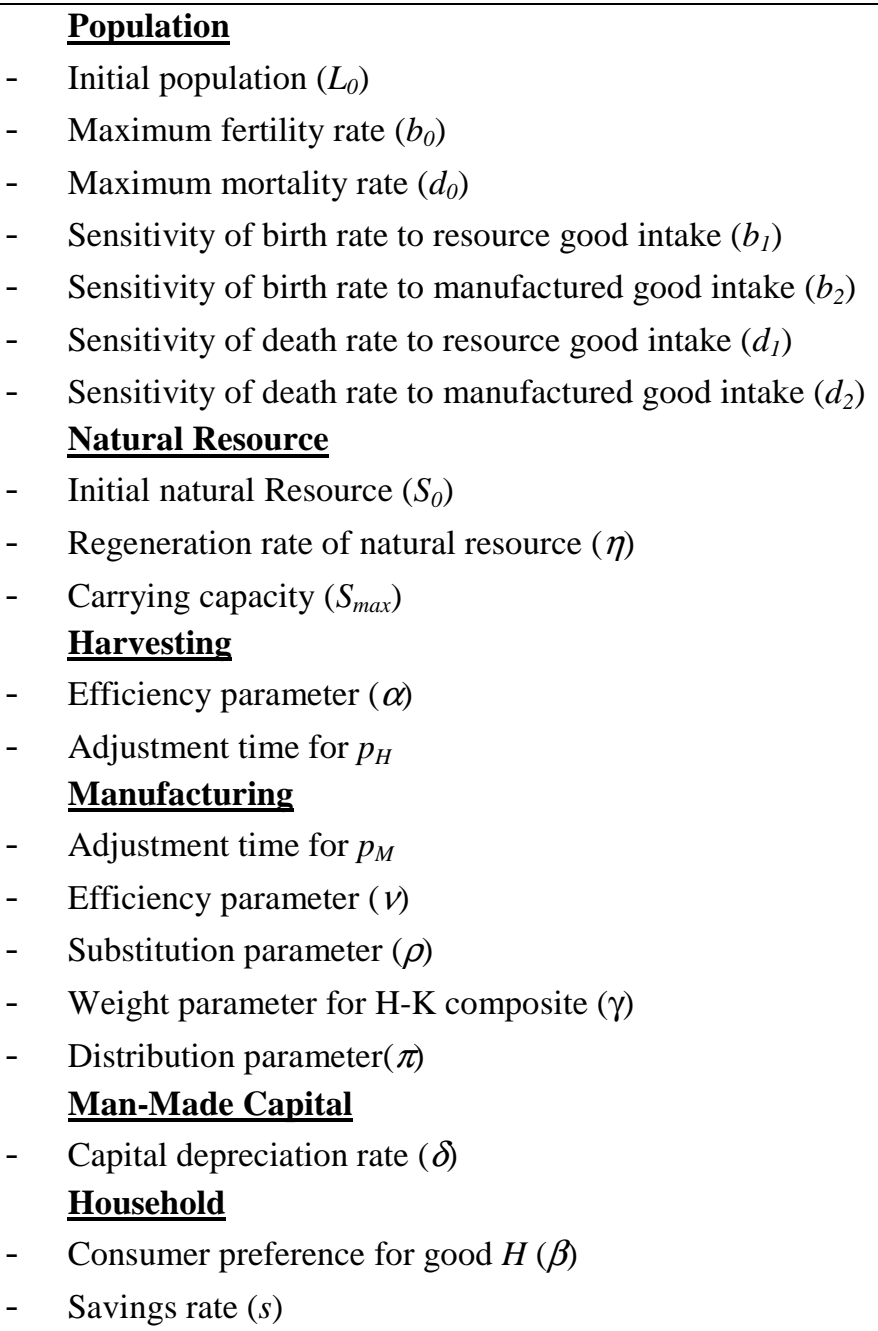 & $\begin{array}{c}12,000 \\
0.04 \\
12,000 \\
0.00015 \\
2\end{array}$ & $\begin{array}{l}\text { Brander and Taylor } \\
\text { Brander and Taylor } \\
\text { Brander and Taylor } \\
- \\
- \\
- \\
- \\
- \\
- \\
- \\
-\end{array}$ \\
\hline
\end{tabular}




\section{Appendix C: Stock and Flow Diagram}

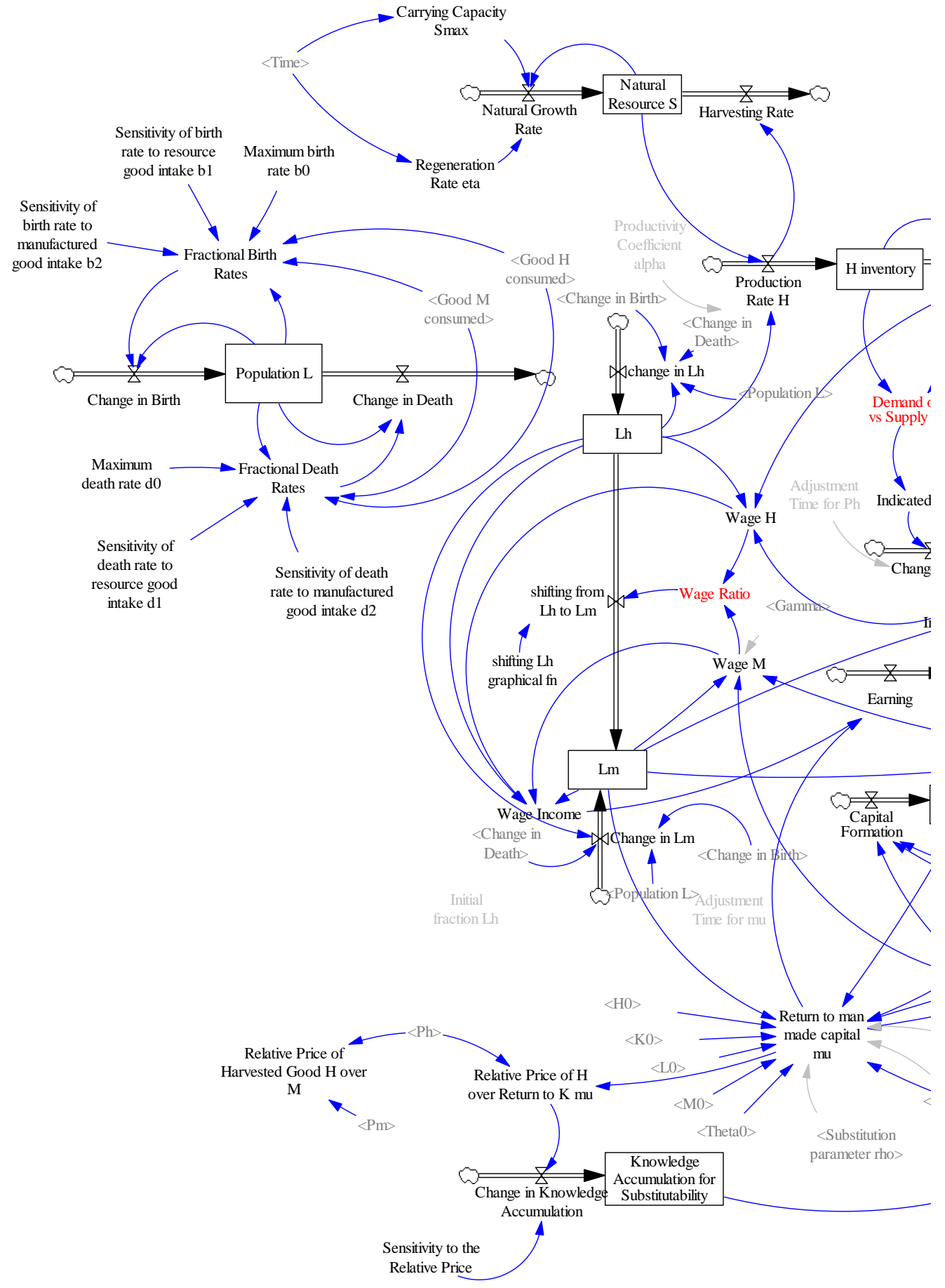




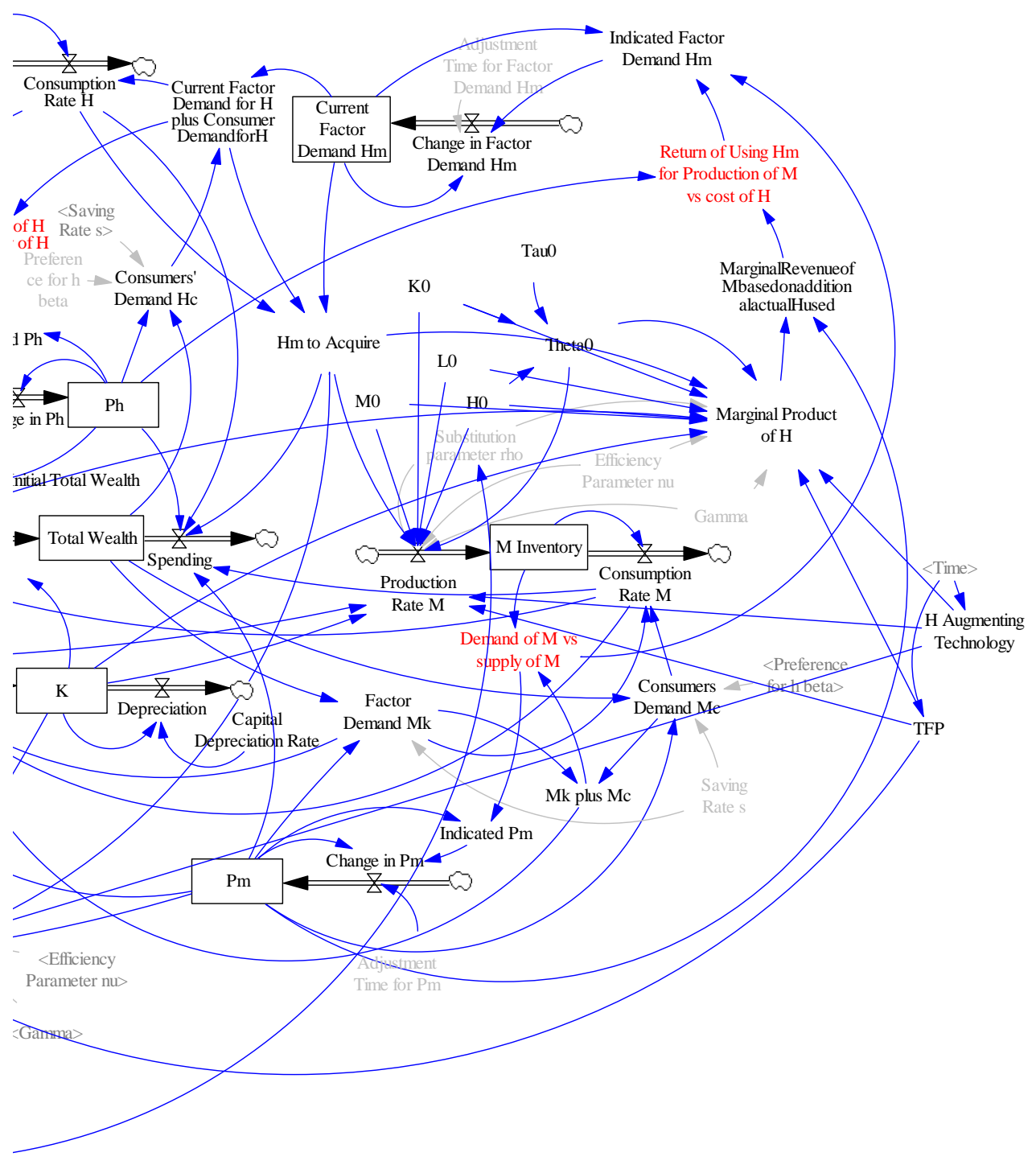

